\title{
Evaluation of the Performance of O-rings Made with Different Elastomeric Polymers in Simulated Geothermal Environments at $300^{\circ} \mathrm{C}$
}

\author{
Prepared for \\ The U.S. Department of Energy \\ Energy Efficiency and Renewable Energy \\ Geothermal Technologies Program \\ 1000 Independence Avenue SW \\ Washington, D.C. 20585 \\ Prepared by \\ Toshifumi Sugama and Tatiana Pyatina \\ Sustainable Energy Technologies Department \\ Brookhaven National Laboratory \\ Upton, NY 11973-5000
Erica Redline, James McElhanon, and Douglas Blankenship
Sandia National Laboratories
PO Box 5800
Albuquerque NM 87185

November 2014

Notice: This manuscript has been authored by an employee of Brookhaven Science Associates, LLC under Contract No. DE-AC02-98CH 10886 with the U.S. Department of Energy. The publisher by accepting the manuscript for publication acknowledges that the United States Government retains a non-exclusive, paid-up, irrevocable, world-wide license to publish or reproduce the published form of this manuscript, or allow others to do so, for the United States Government purposes.

Sandia National Laboratories is a multi-program laboratory managed and operated by Sandia Corporation, a wholly owned subsidiary of Lockheed Martin Corporation, for the U.S. Department of Energy's National Nuclear Security Administration under contract DE-AC04-94AL85000. 


\begin{abstract}
This paper aims to evaluate the survival of O-rings made with six different elastomeric polymers, EPDM, type I- and II-FKM, FEPM, FFKM, and FSR, in five different simulated geothermal environments at $300^{\circ} \mathrm{C}$. It further defines the relative strengths and weaknesses of the materials in each environment. The environments tested were: 1) non-aerated steam-cooling cycles, 2) aerated steam-cooling cycles, 3) water-based drilling fluid, 4) $\mathrm{CO}_{2}$-rich geo-brine fluid, and, 5) heat-cool water quenching cycles. Following exposure, the extent of oxidation, oxidationinduced degradation, thermal behaviors, micro-defects, permeation depths of ionic species present in environments throughout the O-ring, silicate-related scale-deposition, and changes in mechanical properties were assessed.
\end{abstract}

The reliability of the O-ring maintaining its integrity depended on the exposure environment. For instance, EPDM was oxidized to some degree in all environments, leading to the incorporation of oxidation derivatives into its molecular structure. The highest degree of oxidation was observed from a heat-water quenching environment which was designed to simulate thermal shock, causing the greatest decline in the integrity of the O-ring. Moderate oxidation, which occurred in all other environments, did not significantly change the integrity of O-rings, except for depositing silicate scales on their surfaces. Correspondingly, there was no creation of any microdefects in the O-rings during exposure, nor did ionic species permeate through the oxidized Orings.

The type I FKM O-ring suffered severe oxidation that was followed by its disintegration in steam-, drilling- and geo-brine fluid-environments; however, it withstood thermal shock. Oxidation was preferentially initiated at poly(vinylidene fluoride, VDF), rather than at poly(hexafluoropropylene) within the FKM copolymer structure. In contrast, type II FKM terpolmer, having a lower proportion of VDF than that of type I, exerted a better performance as an O-ring, but was still vulnerable to all the environments, with the exception of thermal shock. The densely oxidized subsurface-areas in the type II O-ring engendered the development of a rim-like structure, thereby creating undesirable micro-defects and allowing ionic species to permeate through the defective O-ring.

Like EPDM, the FEPM O-ring also underwent severe oxidation-induced degradation in the thermal shock environment. This degradation was more likely to begin with the oxidation of polypropylene as the hydrocarbon backbone chain in the copolymer structure, rather than that of the poly(tetrafluoroethylene) fluorocarbon backbone chain. The FEPM showed excellent compatibility with the other environments. Additionally, although the surfaces of O-ring were oxidized, they were inert to the deposition of silicate scale. The FFKM, assembled by fluorocarbon backbone chains and lacking hydrocarbon chains, displayed outstanding compatibility with all of the environments. However, one drawback for consideration was the deposition of silicate scales during the exposure in geo-brine fluid. 
Although FSR possessed the highest thermal decomposition temperature (i.e. enhanced heat stability) among these elastomeric polymers, it was extremely susceptible to hydrothermal oxidation; this susceptibility caused severe disintegration of the O-ring in all environments, indicating poor suitability to geothermal fields.

\section{Introduction}

Using elastomeric materials as non-metallic pump bearings in geothermal power-plants is very attractive because they offer several advantages to metallic bearings. First, they can be lubricated with water instead of oil, abating environmental issues. Second, they possess high resilience and stiffness, absorbing impact- or shock-loads without permanent deformation. In addition, these materials have low friction and excellent corrosion-resistance. Finally, their original dimensions are readily restored after localized deflections caused by passing mineral particles.

Considering these potential merits of elastomeric materials in extracting geothermal energy, two heat-resistant elastomeric polymers, fluorocarbon copolymer (type I FKM, Viton®) and acrylonitrile/butadiene copolymer, were chosen for use as elastomeric pump bearings and exposed for four months in a geothermal well operating at a temperature of $\sim 150^{\circ} \mathrm{C}$ [1]. The results revealed that the acrylonitrile/butadiene copolymer bearing underwent a high degree of swelling, embrittlement, and increase an in rigidity, demonstrating that this elastomer was severely degraded. In contrast, no significant changes in appearance were seen in the type I FKM-based bearing, making it a promising candidate for elastomeric bearings at this geothermal well temperature.

However, one inevitable question arose from that study: do the superficial layers of this FKM elastomeric material suffer hydrothermal oxidation and any other alterations in the chemical states at the molecular level? The results from the surface chemical analyses revealed that hydrothermal oxidation had occurred in the bearings, leading to the carboxylation of the poly(vinylidene fluoride, VDF) component in an FKM copolymer consisting of VDF and hexafluoropropylene (HFP). Such carboxylation not only caused the scission of VDF chains, but also the incorporation of the functional carboxylic acid groups into the fluorocarbon structure. This poly(fluorocarboxylic acid), which was identified by the ultimate oxidation product of FKM, was susceptible to reactions with metallic cations such as $\mathrm{Na}, \mathrm{Fe}, \mathrm{Mg}$, and $\mathrm{Ca}$, present in geo-fluid, thereby creating metal-bridged polyfluorocarboxylate complexes as oxidation derivatives. These derivatives, forming at the outermost surface sites of FKM, triggered the deposition of geothermal mineral-related scales like calcite and silicates on the elastomer surfaces. Thus, hydrothermal oxidation in the presence of geo-fluid chemicals was detrimental to the thermal stability, elasticity, and resiliency of FKM, and also promoted the scale deposition on its surface. Furthermore, this information was supported by the oxidation depth-profiling study of the cross-sectional area of an FKM bearing after a year-long exposure to a geothermal environment [2]. The results demonstrated that the subsurface layers, nearly $2000 \mu \mathrm{m}$ thick, 
underwent severe oxidation during the year-long exposure. Additionally, an $\sim 400 \mu \mathrm{m}$ deposition of massive mineral scales was observed on the bearing's surfaces by micro-probe, manifesting that the oxidation of fluorocarbon altered the physical and chemical properties of the surfaces. The altered surfaces not only created an undesirable affinity with the scales, but also caused their extended accumulation as a function of exposure time. More importantly, although the type I FKM possessed a good thermal stability at $150^{\circ} \mathrm{C}$, it was very sensitive and vulnerable to geofluid chemical environments.

On the other hand, there are many different-types of commercial fluorocarbon-based elastomeric materials that can withstand temperatures above $200^{\circ} \mathrm{C}$ [3-6]; among them are type II FKM terpolymers, consisting of VDF, HFP, and tetrafluoroethylene (TFE), the type III FKM tetrapolymer, comprising VDF, HFP, TFE, and perfluoromethylvinylether (PMVE), the FEPM copolymer consisting of TFE and propylene (P), the fluorosilicon copolymer (FSR) composed of polysiloxane (PS) and trifluoropropylpolysiloxane (TFPPS), and the perfluorocarbon copolymer (FFKM) including TFE and PMVE. Further, some geothermal wells have down-hole temperatures over $250^{\circ} \mathrm{C}$ in addition to harsh chemical environments containing highly concentrated corrosive $\mathrm{CO}_{2}(\mathrm{~g})^{-}$and $\mathrm{H}_{2} \mathrm{~S}_{(\mathrm{g})}$-induced acids. Drilling tool components, such as Orings, gaskets, seals, and packers, are exposed not only to chemistry containing these corrosive gasses, but also encounter water-based drilling fluids, including some organic compounds, in the down-hole well reservoir [7].

Based upon the information detailed above, our study focused on investigating and evaluating the stabilization and degradation of O-rings made with fluorocarbon-based elastomeric polymers, such as types I and II FKMs, FEPM, FFKM, and FSR polymers, after direct exposure (without any compression) to five different simulated geothermal environments at $300^{\circ} \mathrm{C}$ : 1) drilling fluid, 2) $\mathrm{CO}_{2}$-rich reservoir brine fluid, 3) aerated steam-cooling cycles, 4) non-aerated steamcooling cycles, and, 5) heating in air-water quenching thermal shock. For comparison, the ethylene propylene diene monomer (EPDM) polymer, consisting of a poly(ethylene-copropylene-co-5-ethylidene-2-norbornene) terpolymer structure, also was employed as nonfluorocarbon elastomeric O-ring. The factors to be investigated and evaluated included: the extent of oxidation, identification of oxidation derivatives, chemical structure-transformation at the molecular level, thermal stability and degradation, morphological alteration, micro-defects, permeation-depth profile of the ionic species through O-ring, and changes in mechanical properties. Obtaining information on these factors was accomplished using ATR-FTIR, TGA, micro-energy dispersive $\mathrm{X}$-ray, and modulus profile testing in conjunction with visual observations of the changes in the O-ring's appearance. 


\section{Experimental procedures}

\subsection{Materials}

Five different elastomeric polymer-based O-rings were supplied by Precision Associates, Inc. Among these were ploy(ethylene-co-propylene-co-5-ethylidene-2-norbornene, EPDM) terpolymer, poly[vinylidene fluoride (VDF)-co- hexafluoropropylene (HFP), type I FKM] copolymer, poly[vinylidene fluoride (VDF)-co- hexafluoropropylene (HFP)-cotetrafluoroethylene (TFE), type II FKM] terpolymer, poly[tetrafluoroethylene (TFE)-copropylene (P), FEKM] copolymer, and poly[tetrafluoroethylene (TFE)-coperfluoromethylvinylether (PMVE), FFKM] copolymer. The Stockwell Elastomirics, Inc. supplied the O-ring made with fluorosilicon (FSR) consisting of poly[siloxane (PS)-cotrifluoropropylpolysiloxane (TFPPS)] copolymer. Figure 1 shows the chemical structures.
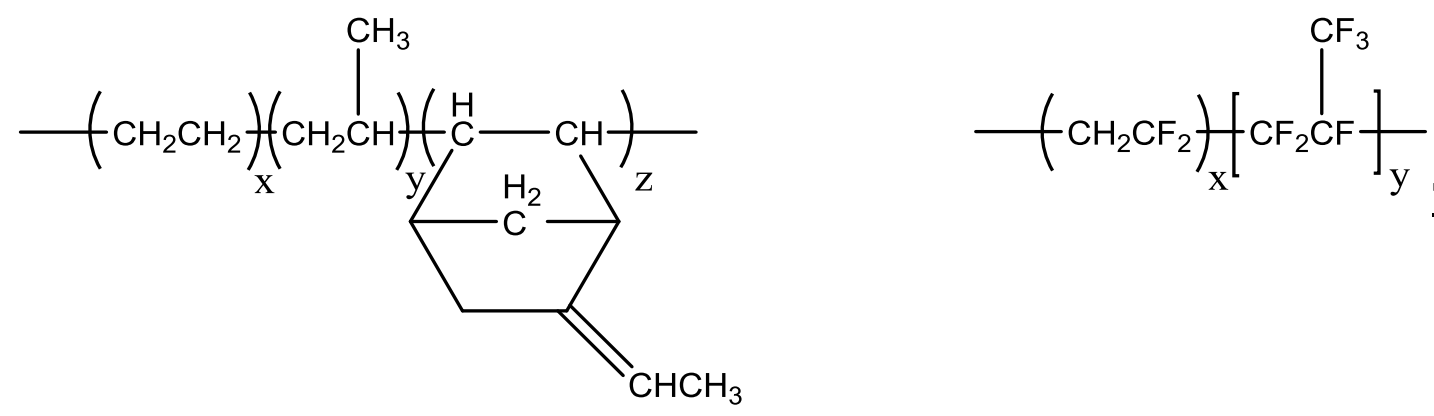

$\underline{\text { EPDM }}$

Type I FKM

$\underline{\text { FFKM }}$<smiles>[Y]C(C)(C)C(O[C@H](F)C(F)F)C(F)C(F)(F)C(C)(C)C</smiles>

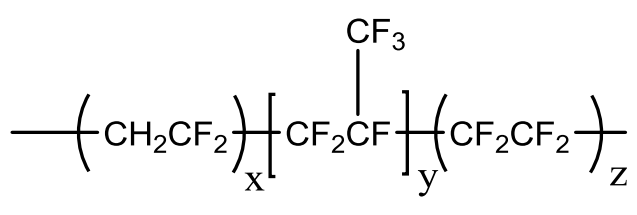

Type II FKM

$\underline{\text { FSR }}$
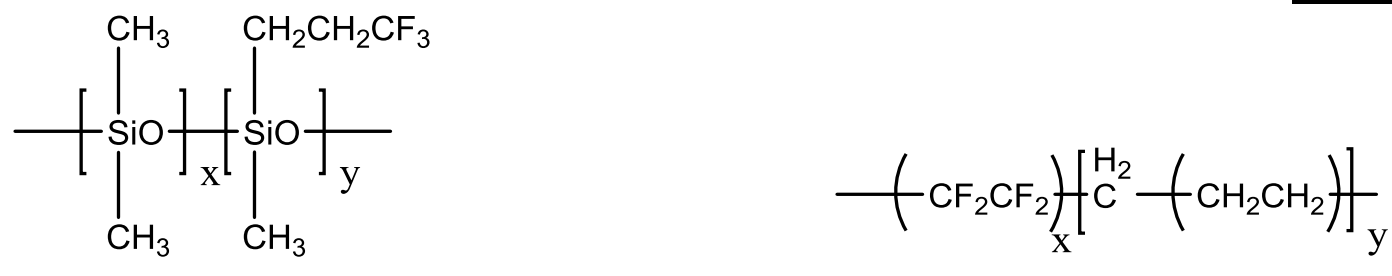

FEPM

Figure 1. Chemical structures of the various elastomeric polymers used in the O-rings.

\subsection{Measurements}

Five different exposure environments were employed in this work: The first environmental condition, denoted as No. 1 , was 5 -cycle $300^{\circ} \mathrm{C}-24 \mathrm{hr}$ non-aerated $\left(\mathrm{N}_{2}\right.$ (g) saturated) steam- $25^{\circ} \mathrm{C}$ cooling; the No. 2 condition was 5 -cycle $300^{\circ} \mathrm{C}-24 \mathrm{hr}$ aerated steam- $25^{\circ} \mathrm{C}$ cooling; the third, No. 
3, was exposure in water-based drilling fluid ( $\mathrm{pH} \mathrm{9-10)} \mathrm{at} 300^{\circ} \mathrm{C}$ for 7 days; fourth, No. 4, was exposure in $\mathrm{CO}_{2}$-rich geo-brine fluid ( $\mathrm{pH} 4-5$ ) at $300^{\circ} \mathrm{C}$ for 7 days; and, fifth (No. 5) was 5-cycle thermal shock (one cycle: $300^{\circ} \mathrm{C}$ air heating for $24 \mathrm{hrs}$ and then $25^{\circ} \mathrm{C}$ deionized (D.I.) water quenching). Details of the first testing procedure were as follows: First, $30 \%$ of the total volume of autoclave was filled with D.I. water; second, the O-rings were hung in the head space; third, the autoclave was sealed; fourth, $\mathrm{N}_{2}$ gas was injected in autoclave until all the air present in head space was replaced by $\mathrm{N}_{2}$; fifth, afterwards, the autoclave was heated to $300^{\circ} \mathrm{C}$, and remained there for 24 hours; and, finally, the autoclave was cooled off to room temperature at rate of $50^{\circ} \mathrm{C}$ /hour. This steam-cooling process was repeated 5 times. The same process, except for $\mathrm{N}_{2}$ saturation, was carried out in the conventional $300^{\circ} \mathrm{C}$ steam-cooling 5-cycle testing for the No. 2 condition in terms of the aerated steam. Exclusively, all of the O-rings after the No. 3 and 4 exposures were physically cleaned with a D.I. water-soaked napkin to remove any non-adhering contaminants from their surfaces, and then dried in an oven at $90^{\circ} \mathrm{C}$ for 24 hours before conducting the post-test analyses. The other O-rings exposed in Nos. 1, 2, and 5 environments also were dried at $90^{\circ} \mathrm{C}$ for 24 hours. The chemical composition of the drilling fluid employed in this study can be found in Table 1 and the chemical ingredients of water-based $\mathrm{CO}_{2}$-rich geobrine fluid in Table 2 .

Table 1. Composition of the drilling fluid mimic.

$\begin{array}{ll}\text { Major Component } & \text { Percent } \\ \text { Water } & 74-83 \\ \text { Barite } & 10-15 \\ \text { Bentonite } & 5-7 \\ \text { Caustic soda } & 0.3 \\ \text { Soda ash } & 1 \\ \text { Polyanionic cellulose } & 0.3-1.2 \\ \text { Xanthan gum } & 0.3-0.5 \\ \text { Starch } & 0.5-1\end{array}$


Table 2. Composition of the brine.

\begin{tabular}{ll} 
Major Components & Percent \\
\cline { 2 - 2 } Chlorine & 13.5 \\
Sodium & 6 \\
Calcium & 2 \\
Potassium & 1.5 \\
Magnesium & 0.9 \\
Minor Components & $\underline{\mathbf{P P M}}$ \\
Carbon dioxide & 15,000 \\
Iron (ferrous) & 1000 \\
Manganese & 930 \\
Lithium & 410 \\
Zinc & 370 \\
Boron & 330 \\
Silicon & 250 \\
Barium & 130 \\
Dihydrogen sulfide & 70
\end{tabular}

Attenuated Total Reflectance-Fourier Transform Infrared Spectroscopy (ATR-FTIR) was used to identify the oxidation derivatives that were incorporated into polymeric elastomer of O-rings exposed to these environments and to assess the oxidation-caused alteration in their chemical structures. To obtain information on thermal-, hydrothermal-, and chemical-stabilities and the extent of oxidation, Thermo Gravimetric Analysis (TGA) at the heating rate of $20^{\circ} \mathrm{C} / \mathrm{min}$ in a $\mathrm{N}_{2}$ flow was employed. The micro energy-dispersive X-ray spectrometer ( $\mu$ EDX) was used to explore whether these environments create micro-defects in O-rings, and to investigate the permeation depth of the ionic species in drilling and geo-brine fluids through O-rings.

To characterize changes in the mechanical integrity of the O-rings exposed to different environments, modulus profiles of each aged specimen were taken using a home-built instrument (Figure 2). The machine operates by scanning the surface with a parabolic tip at user-defined intervals (in this case, $0.2 \mathrm{~mm}$ ) and uses displacement from a known force applied to each point on a sample to calculate inverse tensile compliance, which is proportional to the tensile (elastic) modulus [8]. Sample preparation included cross-sectioning O-rings, embedding the materials in epoxy, and polishing with a polishing wheel to achieve a smooth surface (Figure 3). Note that the modulus of the embedding material was also tested and established as $3.5 \mathrm{MPa}$. 


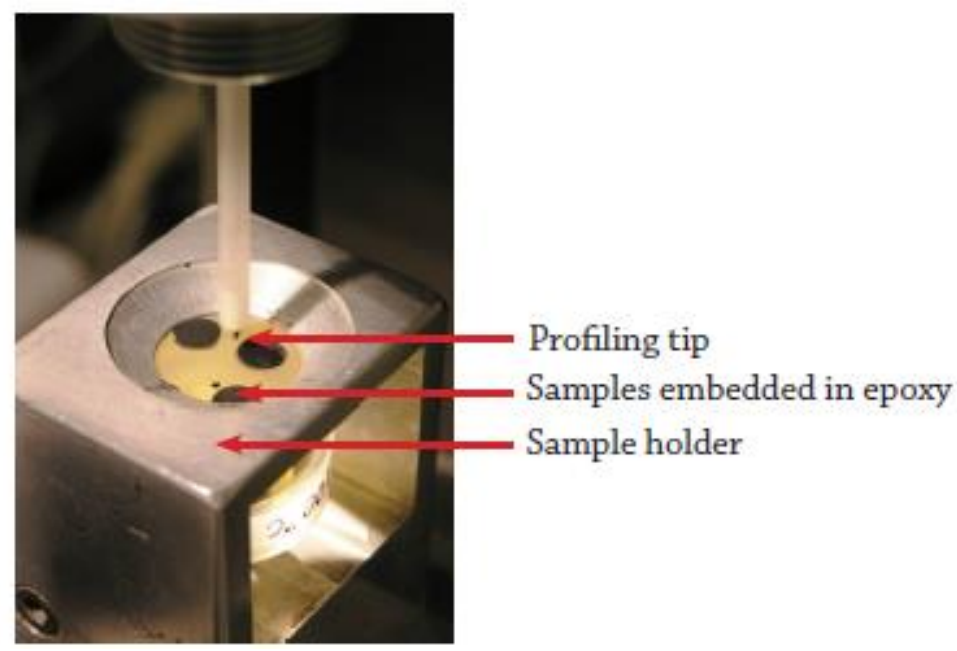

Figure 2. A close-up view of the modulus profiler set-up.
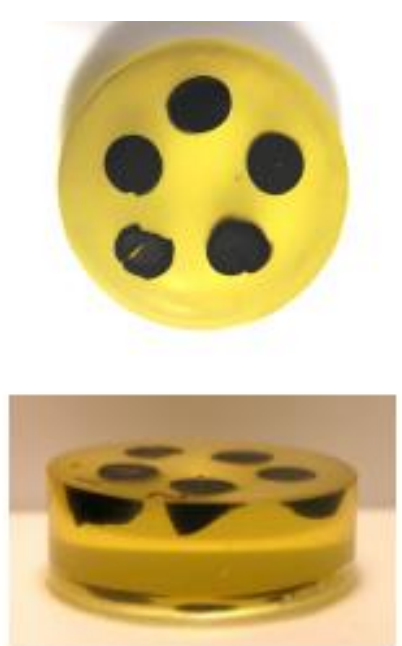

Figure 3. Top: top-down-, Bottom: side view of cross-sectioned O-rings embedded in epoxy.

\section{Results and discussion}

\subsection{ATR-FTIR analysis}

To gain information on the degradation and stabilization of various elastomeric polymer-based O-rings after exposure in five different harsh environments at $300^{\circ} \mathrm{C}$, our first approach was to investigate the oxidation-induced alterations of the different polymer molecular structures by ATR-FTIR. These data also were supported by visual observations of integrity of exposed Orings. 


\subsubsection{EPDM}

Figure 4 shows the ATR-FTIR absorption spectra in region of 4000 to $650 \mathrm{~cm}^{-1}$, and the outward appearances of O-rings for EPDM exposed to No. 1 and No. 2 environments (non-aerated, $\mathrm{N}_{2}$, steam-cooling cycle and aerated steam-cooling cycle, respectively). The spectrum for the control encompasses four representative absorption bands: those at 2919 and $2846 \mathrm{~cm}^{-1}$ are due to the $\mathrm{C}-\mathrm{H}$ asymmetric $\left(V_{\mathrm{as}} \mathrm{C}-\mathrm{H}\right)$, and symmetric $\left(V_{\mathrm{s} \mathrm{C}-\mathrm{H}}\right)$ stretching vibrations, respectively, and those at 1453 and $1367 \mathrm{~cm}^{-1}$ attributed to $-\mathrm{CH}_{2}$ - scissoring $\left(\delta_{\mathrm{CH} 2}\right)$ and $-\mathrm{CH}_{3}$ asymmetric bending $(\delta$ as $\left.\mathrm{CH}_{3}\right)$ vibrations $[9,10]$. When EPDM was exposed in the No. 1 environment, described as nonaerated $\left(\mathrm{N}_{2}\right.$ gas $)$ steam-cooling fatigue testing, no visible changes in appearance from the control was noticed and the appearance of new bands in the region of $1580-1530 \mathrm{~cm}^{-1}$, which were assigned to carboxylate, $\mathrm{COO}^{-}$, asymmetric $\left(V_{\text {as }} \mathrm{COO}^{-}\right)$stretching vibration [11-13] were detected. Similar features were evident in the spectrum obtained from the sample exposed in the No. 2 environment, while the appearance of the O-ring remained unchanged. Thus, EPDM O-rings appeared to undergo some oxidation during both the non-aerated- and aerated-steam-cooling cycle fatigue tests.

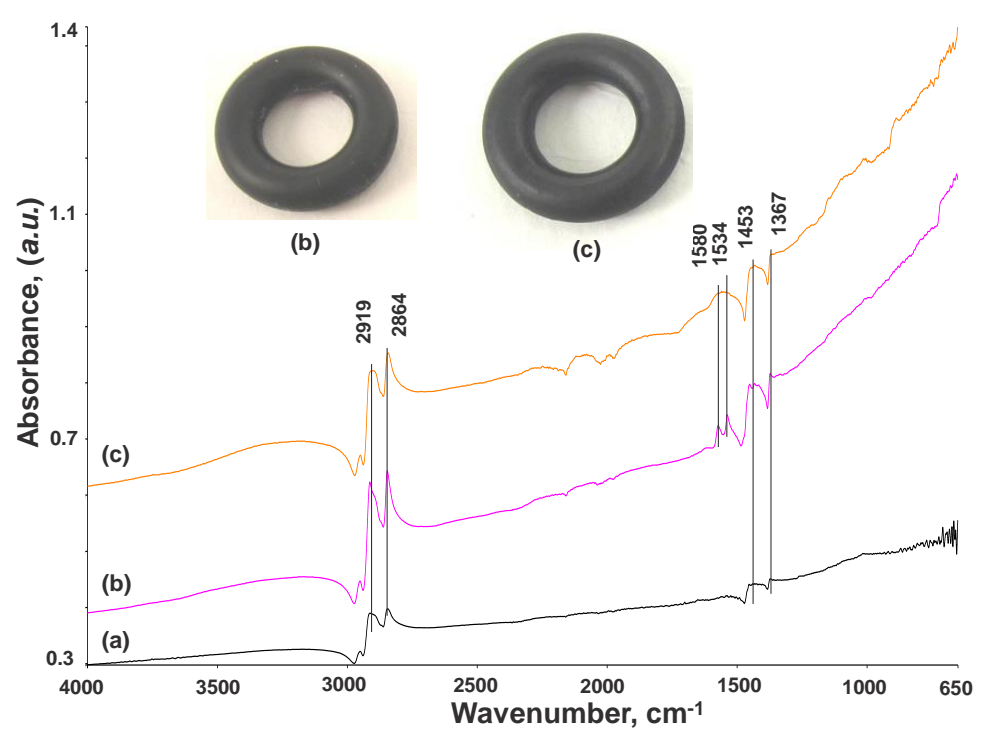

Figure 4. ATR-FTIR absorption spectra and appearance of EPDM O-rings before (a) control, and after: (b) No. 1 non-aerated $\left(\mathrm{N}_{2}\right)$, and (c) No. 2 aerated steam-cooling cycles.

Figure 5 depicts the spectra and the outward appearance of EPDM O-rings after exposure in No. 3 (drilling fluid), 4 (geo-brine fluid), and 5 (thermal shock) environments. As is evident in the photos, the O-rings exposed to conditions No. 3 and No. 4 displayed excellent integrity; in contrast, they disintegrated during the No. 5 environment, i.e., thermal shock cycle testing. In particular, it was very difficult to recognize the presence of C-H-related bands at 2919 and 2846 
$\mathrm{cm}^{-1}$, demonstrating that the EPDM was degraded by the oxidation-caused rupture of its backbone hydrocarbon chains. In contrast, the $\mathrm{C}-\mathrm{H}$ bands at 2919 and $2846 \mathrm{~cm}^{-1}$ still were observed in the samples exposed in No. 3 drilling fluid and No. 4 geo-brine fluid, despite the presence of oxidation-induced $\mathrm{COO}^{-}$band at $1536 \mathrm{~cm}^{-1}$ and the appearance of $\mathrm{C}=\mathrm{C}$ stretching $\left(V_{\mathrm{C}=\mathrm{C}}\right)$ vibration at $1634 \mathrm{~cm}^{-1}$ [14]. Additionally, the prominent band at $1014 \mathrm{~cm}^{-1}$ perhaps was due to the precipitation of a silicate (bentonite or other)-related scale layer $[15,16]$ present in drilling fluid and geo-brine fluid on the surfaces of the O-rings during the exposure. These scales seemed to adhere well to the O-ring surfaces. Nevertheless, EPDM was susceptible to oxidation reactions, particularly in the thermal-shock environment.

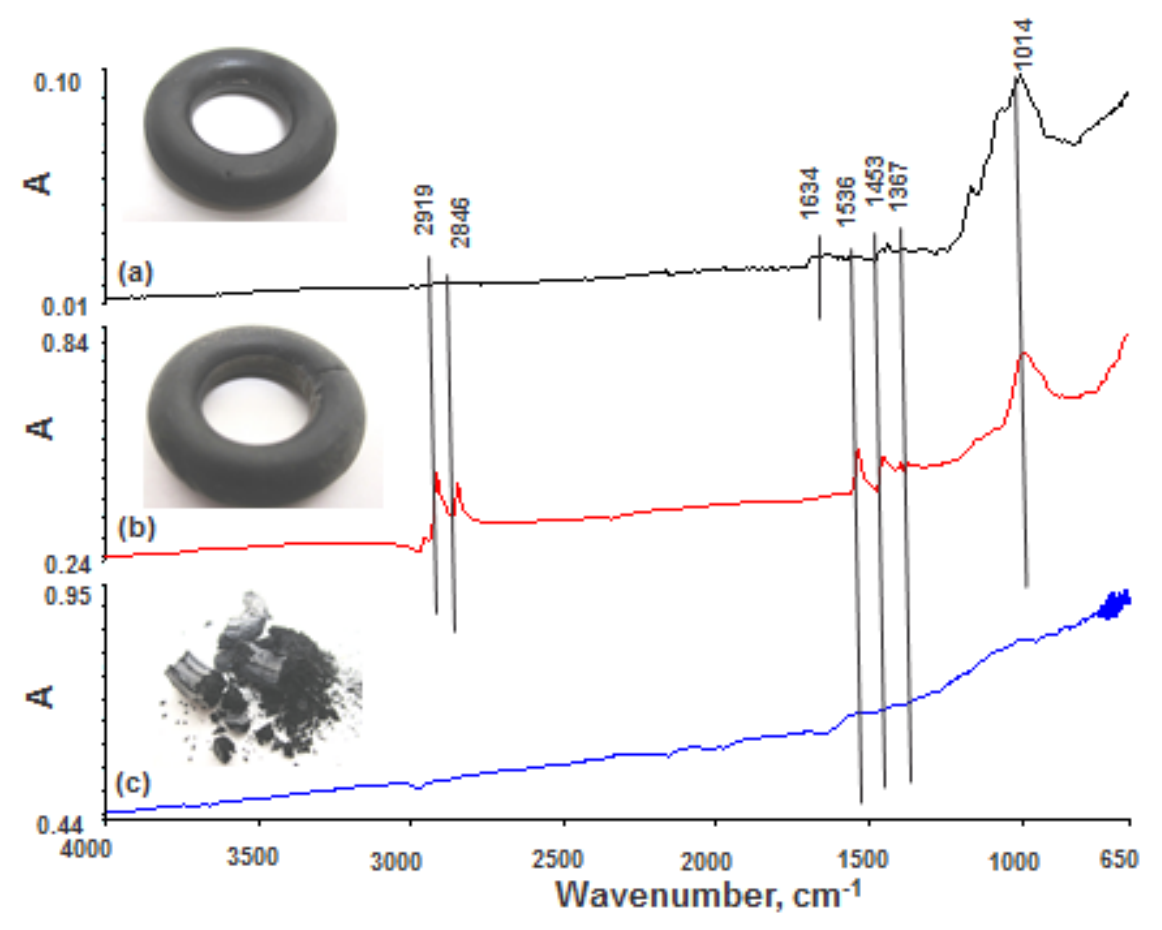

Figure 5. ATR-FTIR absorption spectra and appearance for EPDM O-rings after exposure in (a) No. 3 drilling fluid; (b) No. 4 geo-brine fluid; and, (c) No. 5 thermal shock cycle testing.

According to reference [14], Figure 6 illustrates hypothetic mechanisms of oxidation degradation involving oxygen incorporation, chain scissions, and following the deposition of free radical derivatives for each polymeric sections in the ploy(ethylene-co-propylene-co-5-ethylidene-2norbornene) EPDM terpolymer structure. 

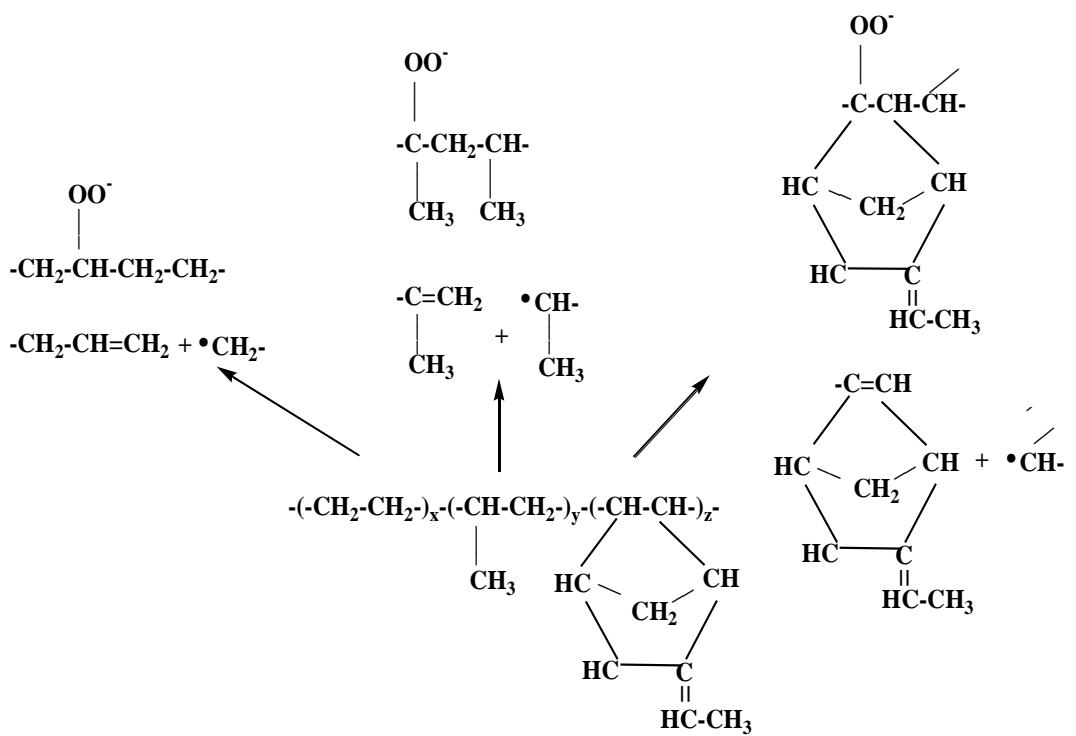

Figure 6. Hypothetical oxidative degradation mechanisms of EPDM terpolymer.

\subsubsection{Type I FKM}

Figure 7 illustrates the ATR-FTIR absorption spectra and the outward appearance of type I FKM O-rings after exposure in No. 1 non-aerated- and No. 2 aerated-steam-cooling cycles. For the control, all absorption bands, except for three at 3392, 3189, and $1645 \mathrm{~cm}^{-1}$ ascribed to water, were related directly to three different fluorocarbon groups [1,17-19], $\mathrm{CF}\left(V_{\mathrm{CF}}\right)$ at $1391 \mathrm{~cm}^{-1}, \mathrm{CF}_{2}$ asymmetric $\left(V_{\mathrm{as}} \mathrm{CF}_{2}\right)$ at 1211 , and $\mathrm{CF}_{2}$ symmetric $\left(V_{\mathrm{S}} \mathrm{CF} 2\right)$ at $1134 \mathrm{~cm}^{-1}$, and $\mathrm{CF}_{3}$ at $877 \mathrm{~cm}^{-1}$, within the FKM copolymer structure as the poly(VDF-co-HFP); the absorption bands at 2920 and $2852 \mathrm{~cm}^{-1}$ were the $\mathrm{C}-\mathrm{H}\left(V_{\text {as C-H }}\right)$, and $\left(V_{\mathrm{s} \text { C-H }}\right)$ stretching modes in VDF. After exposure to No. 1 and 2 environments, the appearance of both O-rings remained intact. Under the No. 1 environment, there were two major changes in spectral features: first, the peak intensity of C-H bands had declined considerably, and second was the emergence of two new bands at 1716 and $1608 \mathrm{~cm}^{-1}$. Possible contributors to these new bands were the $\mathrm{C}=\mathrm{O}\left(V_{\mathrm{C}=\mathrm{O}}\right)$ [17] stretching at 1716 $\mathrm{cm}^{-1}$, and $\mathrm{C}=\mathrm{C}\left(V_{\mathrm{C}=\mathrm{C}}\right)$ at $1608 \mathrm{~cm}^{-1}$ representing the oxidation of VDF. Vanishing of the $\mathrm{C}-\mathrm{H}$ peak was detected from the sample exposed in the No. 2 aerated steam environment, emphasizing that the extent of the oxidation of type I FKM in aerated steam was much higher than in non-aerated steam. On the other hand, there were no remarkable changes in the peak intensity of all fluorocarbon-related bands compared with that of the control. 


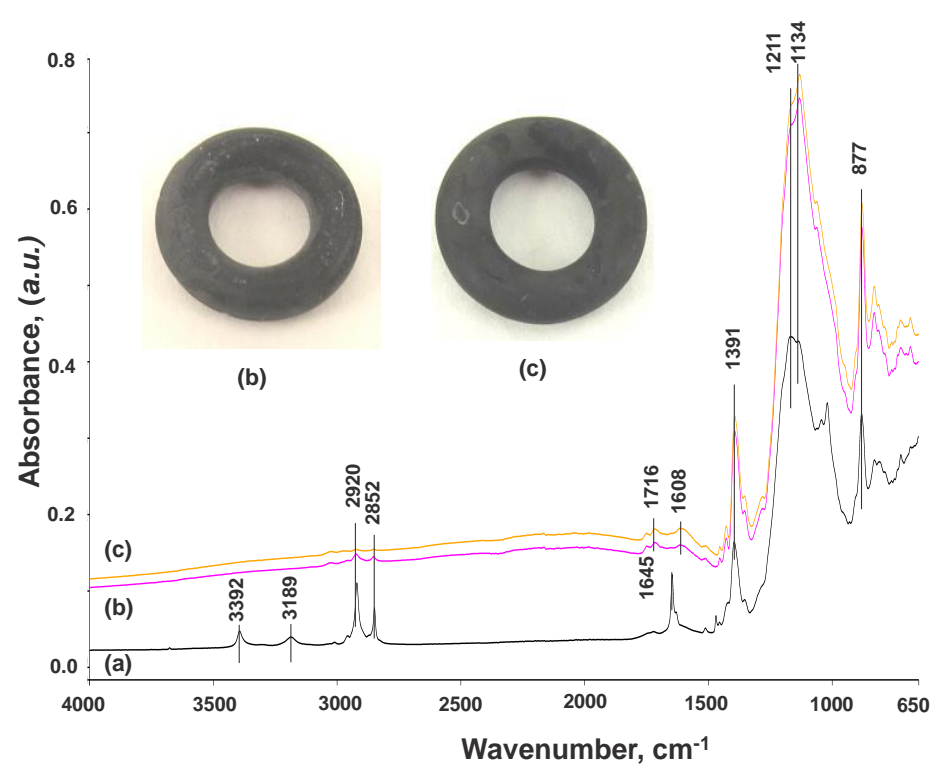

Figure 7. ATR-FTIR absorption spectra and appearance for Type I FKM O-rings before (a) control, and after (b) No. 1 non-aerated, and (c) No. 2 aerated steam-cooling cycles.

Figure 8 shows the ATR-FTIR absorption spectra and the changes in appearance for type I FKM O-rings exposed to No. 3 (drilling fluid), 4 (geo-brine fluid), and 5 (thermal shock) environments. Unlike the steam environments, the first two environments degraded this material, as seen in photographs; namely, visual observation revealed the failure of the O-ring, disclosing the creation of multiple cracks, partial tears, breakage, surface spalling, and severe deposition of scales.

The ATR-FTIR survey on oxidation derivatives formed in these degraded O-rings exhibited the following: in the drilling fluid, three derivatives, $\mathrm{C}=\mathrm{O}\left(V_{\mathrm{C}=\mathrm{O}}\right)$ at $1716 \mathrm{~cm}^{-1}, \mathrm{C}=\mathrm{C}\left(V_{\mathrm{C}=\mathrm{C}}\right)$ at 1608 $\mathrm{cm}^{-1}[20,21]$, and $\mathrm{COO}^{-}$, asymmetric $\left(V_{\text {as }} \mathrm{COO}^{-}\right)$, at $1536 \mathrm{~cm}^{-1}$, were incorporated into type I FKM structure, and also, the C-H-related band intensities at 2920 and $2852 \mathrm{~cm}^{-1}$ were too weak to be measured; and, in geo-brine fluid, the same three derivatives, $\mathrm{C}=\mathrm{O}, \mathrm{C}=\mathrm{C}$, and $\mathrm{COO}^{-}$, as those from the drilling fluid, formed within FKM along with weak $\mathrm{C}-\mathrm{H}$-related bands. In contrast, the appearance of the No. 5-exposed O-ring was far better, strongly suggesting that the impact of this environment on the degradation of the type I FKM copolymer was less than that caused by No. 3 and 4. However, three oxidation derivatives, $\mathrm{C}=\mathrm{C}, \mathrm{COO}^{-}$, and $\mathrm{COOH}\left(V_{\mathrm{COOH}}\right)$ at $1752 \mathrm{~cm}^{-1}$ [1] coexisting with decayed $\mathrm{C}-\mathrm{H}$ bands, were incorporated into this copolymer. 


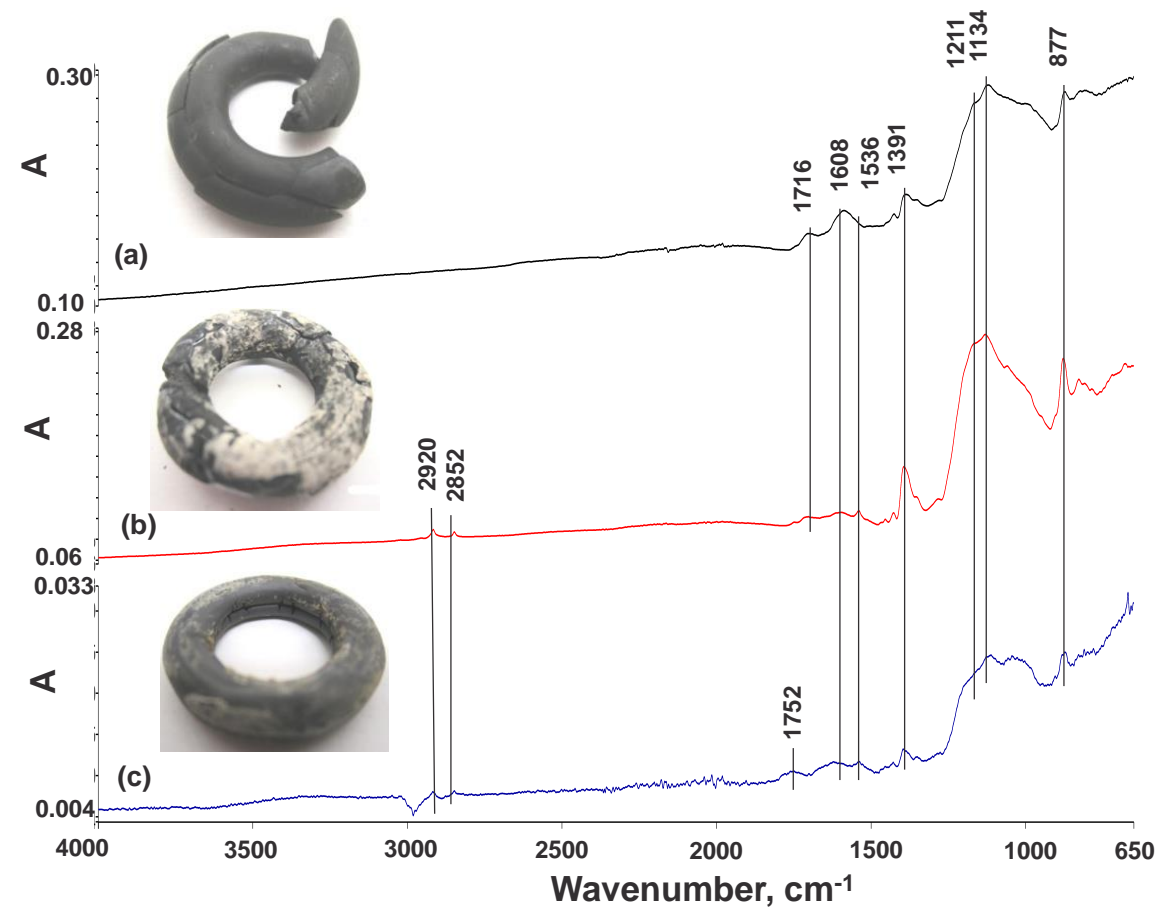

Figure 8. ATR-FTIR absorption spectra and outward appearance of Type I FKM O-rings after exposure in (a) No. 3 drilling fluid, (b) No. 4 geo-brine fluid, and, (c) No. 5 thermal shock cycle tests.

Figure 9 shows the $V_{\text {as C-H }} /, V_{\mathrm{CF}} /$ and $V_{\mathrm{CF} 3} / V_{\text {as CF2 }}$ absorbance- height ratios for the fluorocarbonand hydrocarbon-groups in type I FKM before and after exposure in different environments. The control had $V_{\text {as C-H }} /, V_{\mathrm{CF}} /$ and $V_{\mathrm{CF} 3} / V_{\text {as CF2 }}$ ratios, respectively, of $0.342,0.474$, and 0.531 . These ratios decreased correspondingly by $93.0,36.0$, and $28.1 \%$ to $0.024,0.300$, and 0.382 , after exposure in the No. 1 environment. A further decrease in the $\mathrm{V}_{\text {as C-H }} /$ and $V_{\mathrm{CF}} / V_{\text {as CF2 }}$ ratios was found in the No. 2 environment, while the $V_{\mathrm{CF} 3} / V_{\mathrm{as}} \mathrm{CF} 2$ ratio increased, verifying that the aerated steam aggressively promoted the oxidation-caused degradation of type I FKM, in particular, for $-\mathrm{CH}_{2}$ - and $\mathrm{CF}$ groups, compared with those in non-aerated steam. Similar degradation of the $-\mathrm{CH}_{2}$ - and $\mathrm{CF}$ groups was confirmed in samples exposed in the drilling fluid and those exposed to thermal shock. The reactivity of geo-brine fluid with type I FKM was lower than in all other environments. 


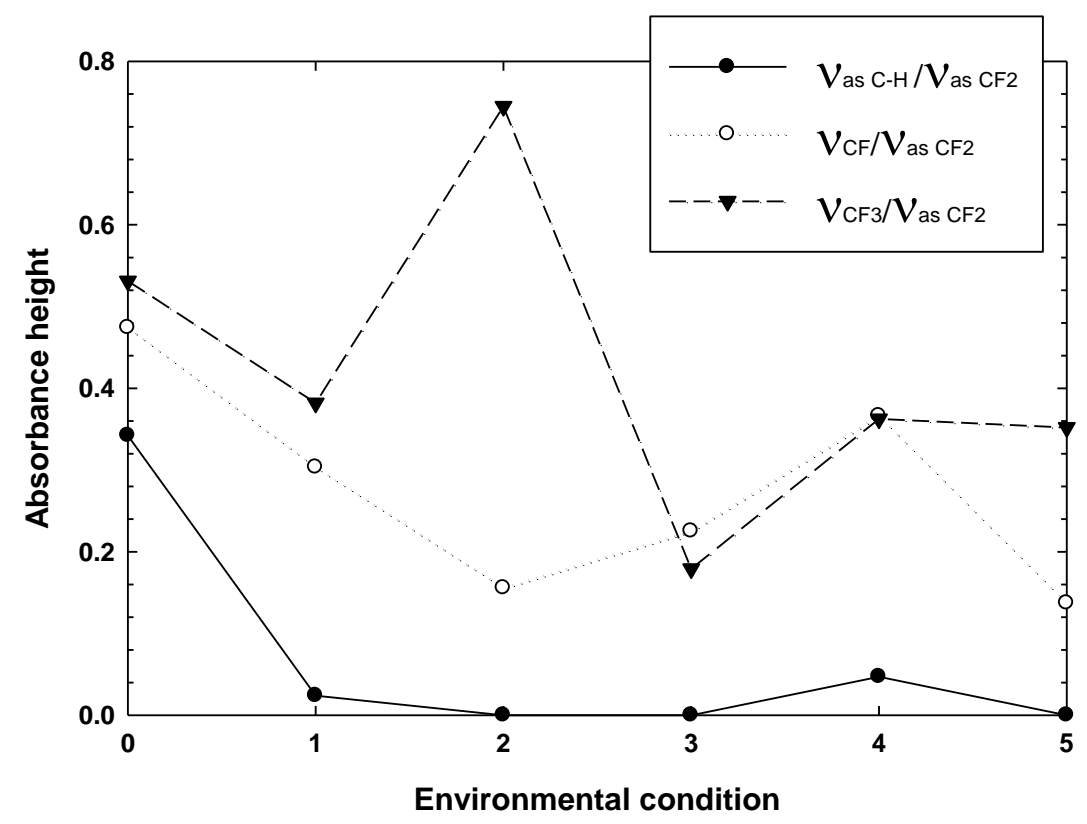

Figure 9. The $V_{\text {as C-H }} /, V_{\mathrm{CF}} /$, and $V_{\mathrm{CF} 3} / V_{\text {as CF2 }}$ absorbance-height ratios for Type I FKM after exposure in different environments; (0) control, (1) 5-cycle non-aerated- and (2) aerated steamcooling, (3) drilling fluid, (4) geo-brine fluid, and (5) 5-cycle thermal shock.

This data, in conjunction with our previous study [2] and articles by other investigators [18, 20, $22,23]$, suggests that the poly-VDF in type I FKM was oxidized preferentially over poly-HFP, leading to its oxidation-caused degradation mechanism (Figure 10). Like EPDM, type I FKM also was oxidized to different degrees in all the environments. However, undermining the integrity of O-ring seems to depend primarily on the environments, as the material was affected by the chemical ingredients present in the drilling fluid and the geo-brine fluid, but unaffected by the D.I. water used in the aerated- and non-aerated-steam, and also by thermal shock. Thus, the oxidation due to the combination of hydrothermal and chemical effects was detrimental to the integrity of O-rings.

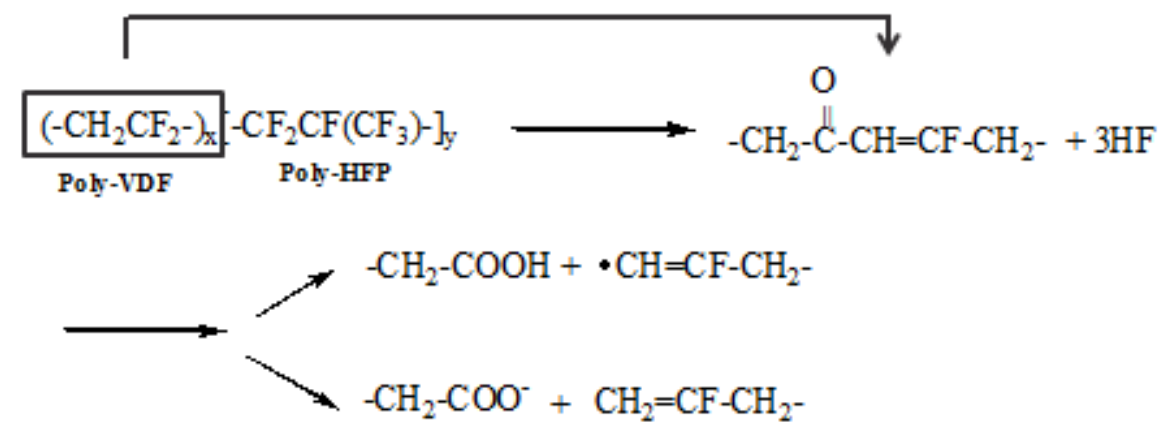

Figure 10. Degradation mechanisms of type I FKM copolymer. 


\subsubsection{Type II FKM}

Figure 11 shows the ATR-FTIR spectra and the appearance of type II FKM O-rings after exposure in the No. 1 and No. 2 environments. Since the type II FKM terpolymer, poly(VDF)$c o$-(HFP)-co-(TFE), incorporates the additional poly-TFE fluorocarbon into the type I FKM structure, the spectral features of the control closely resembled that of the type I control. Thus, the spectrum encompassed four fluorocarbon-related bands, $\mathrm{CF}\left(V_{\mathrm{CF}}\right)$ at $1391 \mathrm{~cm}^{-1}, \mathrm{CF}_{2}$ asymmetric $\left(V_{\mathrm{as} \mathrm{CF} 2}\right)$ at $1114 \mathrm{~cm}^{-1}$, and $\mathrm{CF}_{2}$ symmetric $\left(V_{\mathrm{sCF} 2}\right)$ at $1030 \mathrm{~cm}^{-1}$, and $\mathrm{CF}_{3}$ at $878 \mathrm{~cm}^{-}$ 1, and two hydrocarbon-related bands, C-H $\left(V_{\text {as C-H }}\right)$, and $\left(V_{\text {s C-H }}\right)$ at 2920 and $2852 \mathrm{~cm}^{-1}$. Of particular note in the spectral features was the very weak intensity of the $V_{\text {as C-H }}$ and $V_{\mathrm{s} \text { C-H }}$ bands, compared with that of type I; in fact, the value of $V_{\text {as C-H }} / V_{\text {as CF2 }}$ absorbance height ratio in type II was nearly ten-fold lower than that of type I ( 0.0349 versus 0.342$)$. Type II appeared to have a lower proportion of poly-VDF to other poly-fluorocarbons. Although, there were no significant changes in appearance, type II also suffered from oxidation after exposure in No. 1 and 2 environments. Like type $\mathrm{I}$, the oxidation derivatives were identified as containing $\mathrm{C}=\mathrm{O}\left(V_{\mathrm{C}=\mathrm{O}}\right)$ at $1719 \mathrm{~cm}^{-1}$, and $\mathrm{C}=\mathrm{C}\left(V_{\mathrm{C}=\mathrm{C}}\right)$ at $1602 \mathrm{~cm}^{-1}$. Furthermore, the $\mathrm{C}-\mathrm{H}$ bands vanished after exposure in No. 2 aerated steam-cooling.

Figure 12 compares the spectral features and the appearance of type II FKM O-rings exposed in the No. 3, 4, and 5 environments. As is evident, the integrity of the No. 3-exposed O-ring was undermined, resulting in multiple cracks and partial tearing and spalling. Compared with this, Orings exposed in No. 4 and 5 environments displayed better integrity, with no cracking or tearing, underscoring that the type II not only possessed a good resistance to thermal shock, but also withstood the attack of a combined hydrothermal- and brine environment. As expected, all Oring samples were oxidized, and the oxidation derivatives containing $\mathrm{C}=\mathrm{O}, \mathrm{C}=\mathrm{C}, \mathrm{COOH}$, and $\mathrm{COO}^{-}$groups, were incorporated into type II FKM. No C-H $\left(V_{\text {as } \mathrm{C}-\mathrm{H}}\right)-$ and $\left(V_{\mathrm{sC}-\mathrm{H}}\right)$-related bands were detected in the samples exposed in the No. 3 and No. 5 environments. 


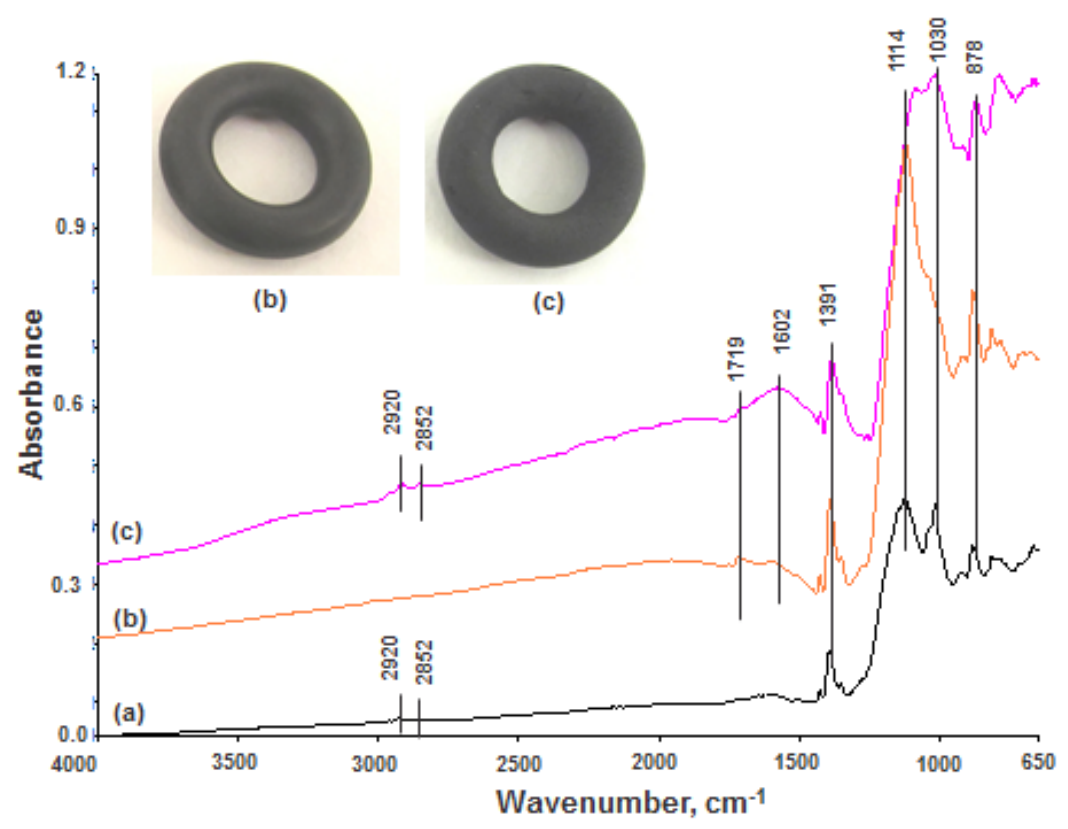

Figure 11. ATR-FTIR absorption spectra and appearance for type II FKM O-rings before (a) control, and after (b) No. 2 aerated steam- and (c) No. 1 non-aerated-cooling cycles.

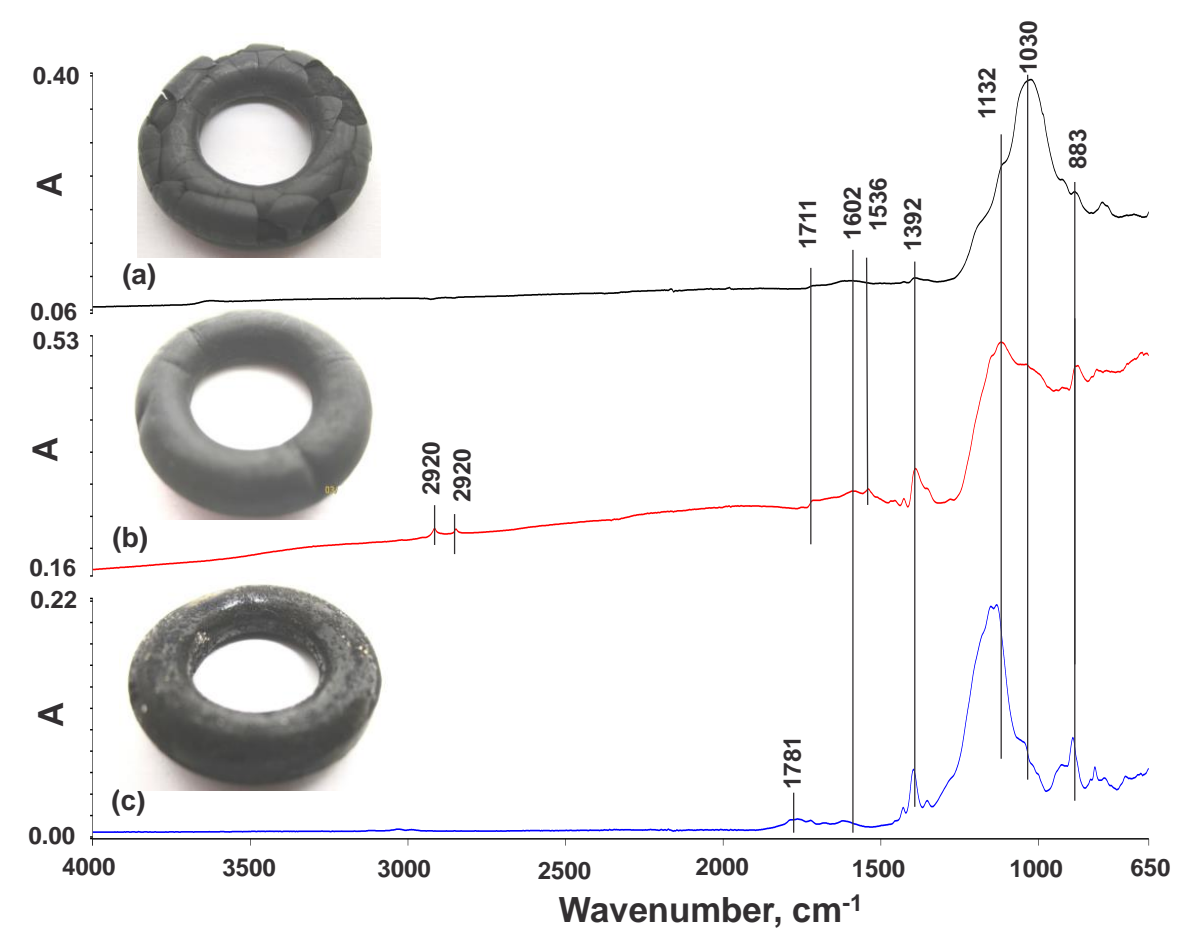

Figure 12. ATR-FTIR spectra and appearance of type II O-rings after exposure in (a) No. 3 drilling fluid, (b) No. 4 geo-brine fluid, and, (c) No. 5 thermal-shock cycle tests. 
Figure 13 shows the $V_{\text {as C-H }} /, V_{\mathrm{CF}} /$ and $V_{\mathrm{CF} 3} / V_{\text {as CF2 }}$ absorbance height ratios for the fluorocarbonand hydrocarbon-groups in type II FKM before and after exposures in various environments. These data provide information on the extent of O-ring's degradation for each environment; namely, the magnitude of the impact on the O-ring integrity can be estimated by the reduction of these ratios, compared with those of control. As expected, the highest reductions were recorded from the No. 3 (drilling fluid)-exposed O-ring, with the second highest reductions observeds in No. 2 (aerated steam-cooling) and 5 (thermal shock) environments. By contrast, the lowest impact was observed from both No. 1 (non-aerated steam-cooling) and 4 (geo-brine fluid). This result was similar to that of type I, thus similar oxidation mechanisms to that of type I can be proposed, namely, the preferential oxidation of poly- VDP in type II, rather than poly-HFP and poly-TEF. However, since type II contained a lower proportion of poly-VDF, it had a better stability in these environments than did type I.

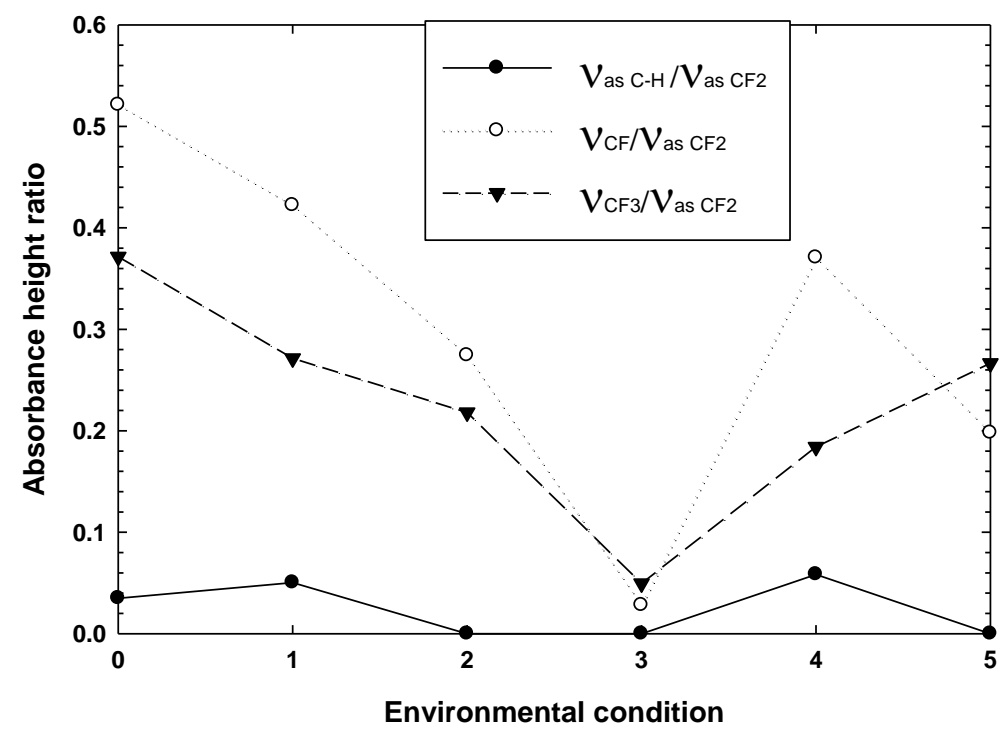

Figure 13. The $V_{\mathrm{as} \mathrm{C}-\mathrm{H}} /, V_{\mathrm{CF}} /$, and $V_{\mathrm{CF} 3} / V_{\mathrm{as}}$ CF2 absorbance-height ratios for type II FKM after exposure in different environments; (0) control, (1) 5-cycle non-aerated- and, (2) aerated- steamcooling, (3) drilling fluid, (4) geo-brine fluid, and (5) 5-cycle thermal shock.

\subsubsection{FEPM}

Figure 14 gives the ATR-FTIR spectra and the appearance for FEPM O-rings after exposure in No. 1 and No. 2 conditions. Since FEPM is the copolymer consisting of poly(TFE-co-P), the spectrum of the control revealed the $\mathrm{C}-\mathrm{H}$ asymmetric $\left(V_{\text {as C-H }}\right)$, and symmetric $\left(V_{\mathrm{s} \text { C-H }}\right)$ absorption bands at 2920 and $2852 \mathrm{~cm}^{-1}$, respectively, the $\mathrm{CH}_{2}$ scissoring $\left(\delta_{\mathrm{CH}_{2}}\right)$ in region of $1465-1442 \mathrm{~cm}^{-}$ ${ }^{1}$, the $\mathrm{C}-\mathrm{H}$ bending vibration $\left(\delta_{\mathrm{CH}}\right)$ at $1388 \mathrm{~cm}^{-1}, \mathrm{CF}\left(V_{\mathrm{CF}}\right)$ at $1326 \mathrm{~cm}^{-1}$, and $\mathrm{CF}_{2}\left(V_{\text {as } \mathrm{CF} 2}\right)$ at 1168 and $\mathrm{CF}_{2}\left(V_{\mathrm{S} \mathrm{CF} 2}\right)$ in region of $1089-1014 \mathrm{~cm}^{-1}$. The band at $1688 \mathrm{~cm}^{-1}$ may be due to water. There was no significant change in spectral features of the O-ring exposed in the No. 1 environment, 


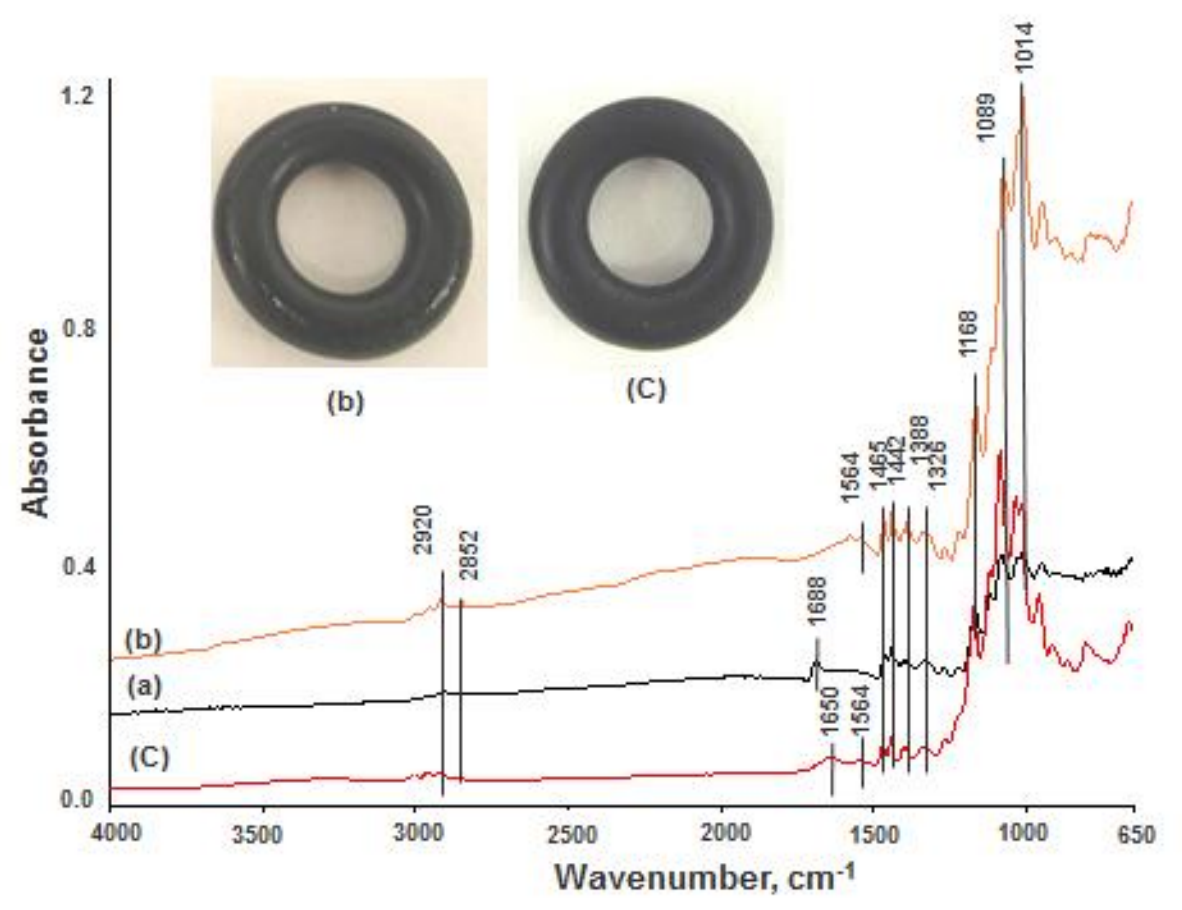

Figure 14. ATR-FTIR absorption spectra and appearance for FEPM O-rings before (a) control, and after (b) No. 1 non-aerated- and (c) No. 2 aerated steam-cooling cycles.

except for the incorporation of one new band at $1564 \mathrm{~cm}^{-1}$ attributed to the $\mathrm{COO}^{-}$, asymmetric $\left(V_{\text {as }} \mathrm{COO}^{-}\right)$, into the original spectrum. After exposure in No. 2 environment, another additional band was generated at $1650 \mathrm{~cm}^{-1}$ attributed to $\mathrm{C}=\mathrm{C}\left(V_{\mathrm{C}=\mathrm{C}}\right)$. Hence, this O-ring underwent some oxidation in both the No. 1 and No. 2 environments. In environments 3, 4, and 5 (Figure 15), like EPDM, the No. 5 thermal-shock environment considerably undermined the integrity of O-ring, leading to its local tearing and partial spalling. Correspondingly, the spectrum revealed the disappearance of all $\mathrm{C}-\mathrm{H}$ - and $\mathrm{CH}_{2}$-related bands, considerable reduction of the intensities of the $\mathrm{CF}$ - and $\mathrm{CF}_{2}$-associated bands, and appearance of oxidation-induced derivatives such as $\mathrm{C}=\mathrm{O}$ $\left(V_{\mathrm{C}=\mathrm{O}}\right)$ at $1690 \mathrm{~cm}^{-1}$, and $\mathrm{COO}^{-}\left(V_{\text {as }} \mathrm{COO}^{-}\right)$at $1538 \mathrm{~cm}^{-1}$. Of primary importance in understanding degradation in the No. 5 environment is the disappearance of the $\mathrm{C}-\mathrm{H}$ and $\mathrm{CH}_{2}$ groups, which indicates the Poly-P within FEPM was severely degraded in the No. 5 environment. However, in No. 3 and 4 environments, although oxidation derivatives like the $\mathrm{C}=\mathrm{O}$ and $\mathrm{COO}^{-}$groups were formed, the spectra indicated strong absorption bands of all TFE- and P-associated groups, indicating a relatively good integrity of the O-ring after exposure to drilling fluid and geo-brine fluid. Further, there was no silicate-related band, suggesting that although the surface of O-ring was oxidized, it seems to be inert to the deposition of silicate scales. 
To gain data on the extent of oxidation, we compared the height ratios of $V_{\text {as C-H }} /$ and $V_{\mathrm{CF}} / V_{\text {as CF2 }}$ between the control and various different environment-exposed O-rings (Figure 16). The results showed that the $V_{\mathrm{CF}} / V_{\mathrm{as}} \mathrm{CF} 2$ values of all environments, except No. 5, were almost the same as that of the control, demonstrating that FEPM had a great stability in hydrothermal and harsh chemical environments; however, one drawback was its vulnerability to the hot dry air heatingwater quenching environment.

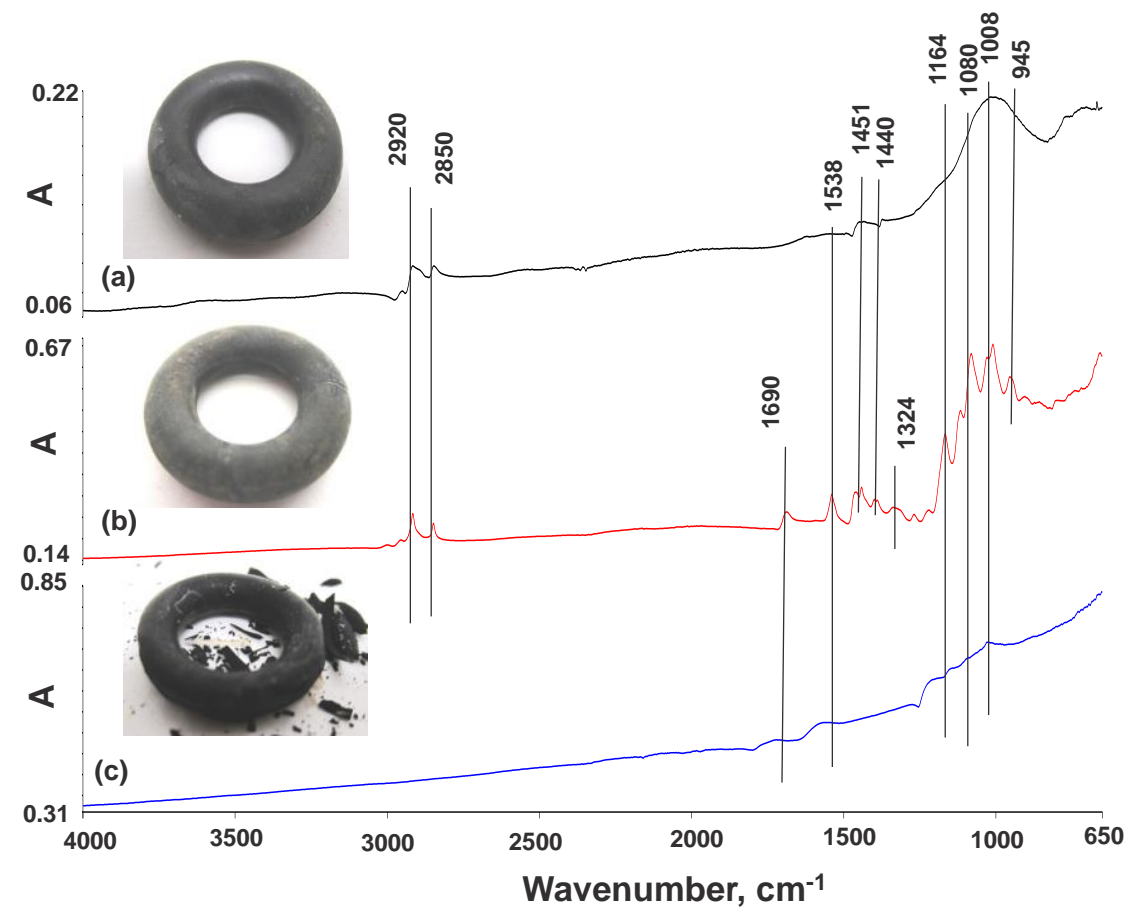

Figure 15. ATR-FTIR absorption spectra and oappearance for FEPM O-rings after exposure in (a) No. 3 drilling fluid, (b) No. 4 geo-brine fluid, and, (c) after No. 5 thermal shock cycle testing. 


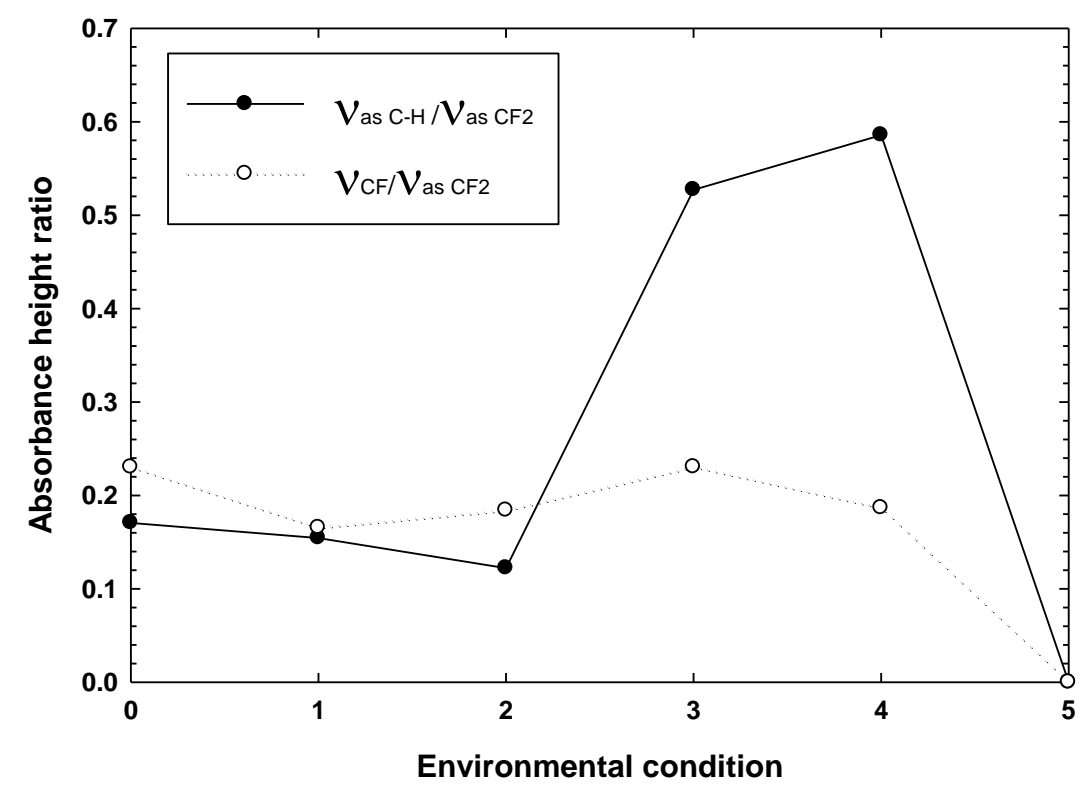

Figure 16. The ratio of $V_{\text {as C-H }} /$ and $V_{\mathrm{CF}} / V_{\text {as CF2 }}$ absorbance height for FEPM after exposure in different environments; (0) control, (1) 5-cycle non-aerated- and (2) aerated-steam-cooling, (3) drilling fluid, (4) geo-brine fluid, and (5) 5-cycle thermal shock testing.

Based upon two pieces of evidence for the O-ring after the thermal shock: 1) the elimination of all $\mathrm{C}-\mathrm{H}$ - and $\mathrm{CH}_{2}$-related bands in FEPM, and, 2) the presence of the $\mathrm{CF}$ and $\mathrm{CF}_{2}$ bands, we concluded that the oxidation-induced degradation of FEPM may be initiated at Poly-P (Figure 17) $[24-26]$.

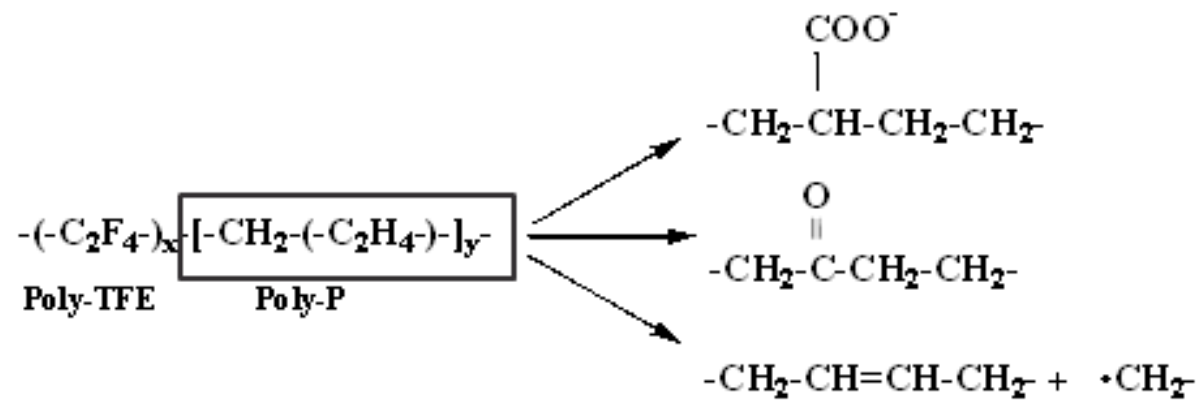

Figure 17. Oxidation degradation mechanism of FEPM copolymer. 


\subsubsection{FFKM}

Figure 18 shows the ATR-FTIR spectra and the appearance for FFKM O-rings after exposure in No. 1 and No. 2 environments. The spectrum of the control FFKM, poly(TFE-co-PMVE) copolymer structure contained five representative bands at 1287, 1177, 1140, 1095, and 879 $\mathrm{cm}^{-1}$. The contributors to these bands were as follows; $\mathrm{CF}\left(V_{\mathrm{CF}}\right)$ at $1287 \mathrm{~cm}^{-1}$, and $\mathrm{CF}_{2}\left(\mathrm{~V}_{\mathrm{as}} \mathrm{CF} 2\right)$ at 1177 , and $\mathrm{CF}_{2}\left(V_{\mathrm{s} \mathrm{CF} 2}\right)$ at $1095 \mathrm{~cm}^{-1}, \mathrm{CF}_{3}\left(V_{\mathrm{CF} 3}\right)$ at $879 \mathrm{~cm}^{-1}$, and C-O-C asymmetric $\left(V_{\text {as C-O-C }}\right)$ and symmetric stretching $\left(V_{\mathrm{s} \text { C-O-C }}\right)$, at 1140 and $1005 \mathrm{~cm}^{-1}$, respectively, as shoulder bands. As is seen in the photographs (Figure 18), the O-rings did not show any visual changes after exposure to aerated- and non-aerated-steam-cooling cycle environments. Correspondingly, the spectral features were similar to those of the control, and unlike for any other O-rings, it was very difficult to identify the presence of oxidation derivatives. Thus, the FFKM O-rings possessed outstanding stability in both aerated- or non-aerated-steam-cooling cycle environments. Similar results were obtained from the O-rings exposed in the No. 3, 4, and 5 environments (Figure 19); namely, their spectra had $\mathrm{CF}\left(V_{\mathrm{CF}}\right)$ at $1287 \mathrm{~cm}^{-1}$, and $\mathrm{CF}_{2}\left(V_{\text {as } \mathrm{CF} 2}\right)$ at 1180 and $\mathrm{CF}_{2}\left(V_{\mathrm{s} \mathrm{CF} 2}\right)$ in the region of 1111 to $1075 \mathrm{~cm}^{-1}, \mathrm{CF}_{3}\left(V_{\mathrm{CF} 3}\right)$ at $885 \mathrm{~cm}^{-1}$, and C-O-C asymmetric $(V$ as C-O-C $)$ at $1140 \mathrm{~cm}^{-1}$.

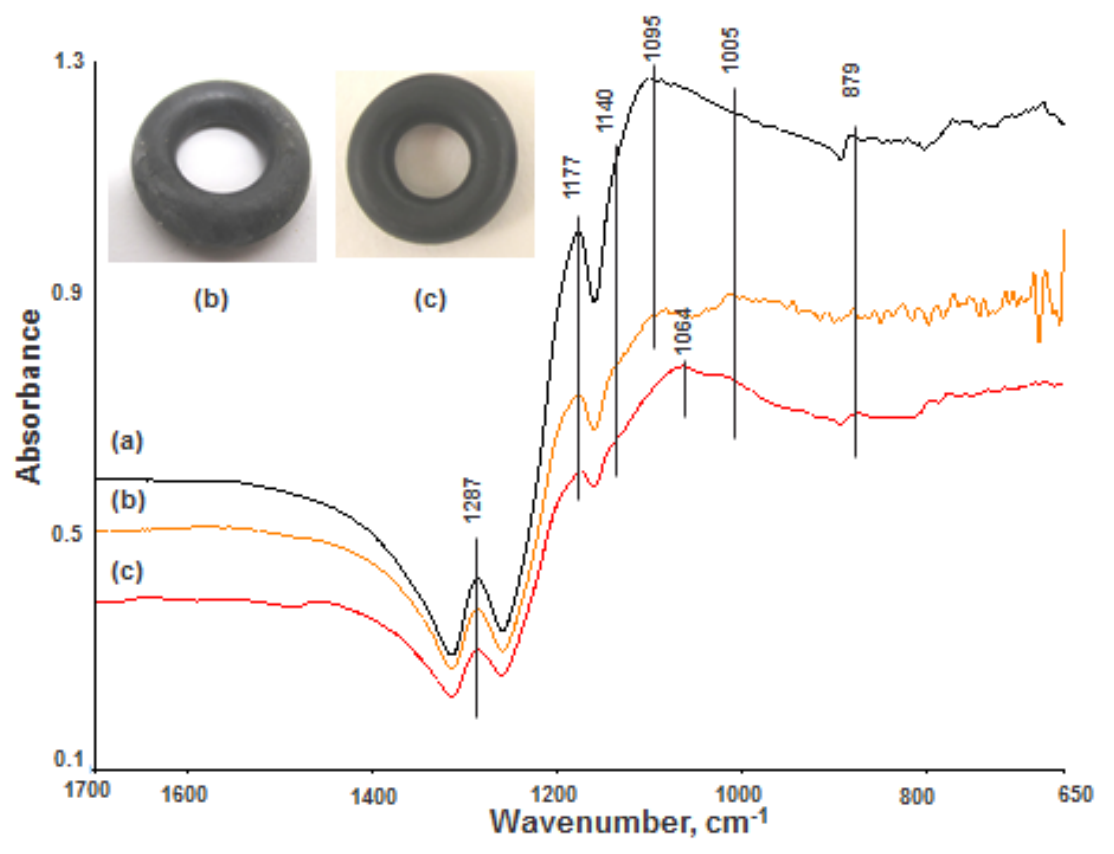

Figure 18. ATR-FTIR absorption spectra and appearance for FFKM O-rings before (a) control and after exposure in (b) No. 2 aerated and (c) No. 1 non-aerated steam-cooling cycles. 


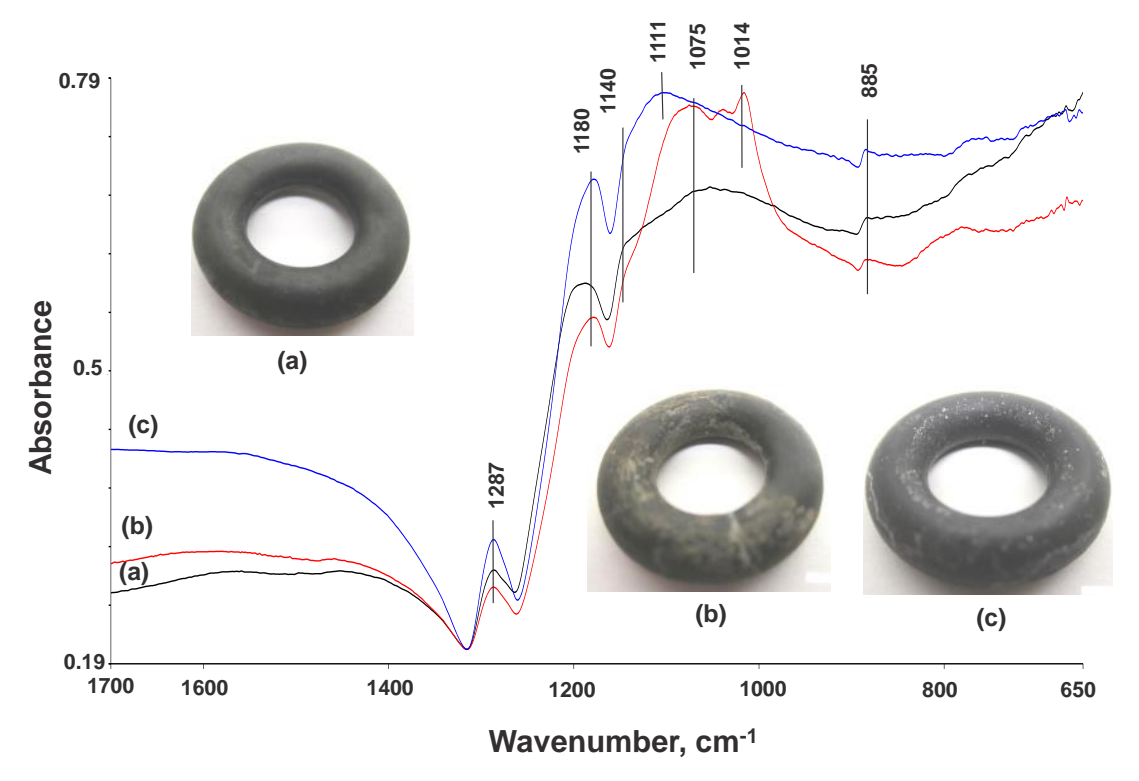

Figure 19. ATR-FTIR absorption spectra and appearance for FFKM O-rings after exposure in (a) No. 3, (b) No. 4, and, (c) No. 5 environments.

However, one consideration centered on the O-ring exposed to No. 4 geo-brine fluid. We observed the deposition of some scales on it, and the presence of the pronounced band at 1014 $\mathrm{cm}^{-1}$ assigned to the silicate scale. Nonetheless, this $\mathrm{O}$ - ring displayed the best performance in these five different harsh environments, compared with all other O-rings made with EPDM, Type I and II FKM, and FEPM. Such anti-oxidation behavior of FFKM also can be recognized from the fact that there were no significant changes in the ratios of $V_{\mathrm{CF}} /$ and $V_{\mathrm{CF} 3} / V_{\mathrm{as}} \mathrm{CF} 2$ absorbance height after exposure to these environments (Figure 20).

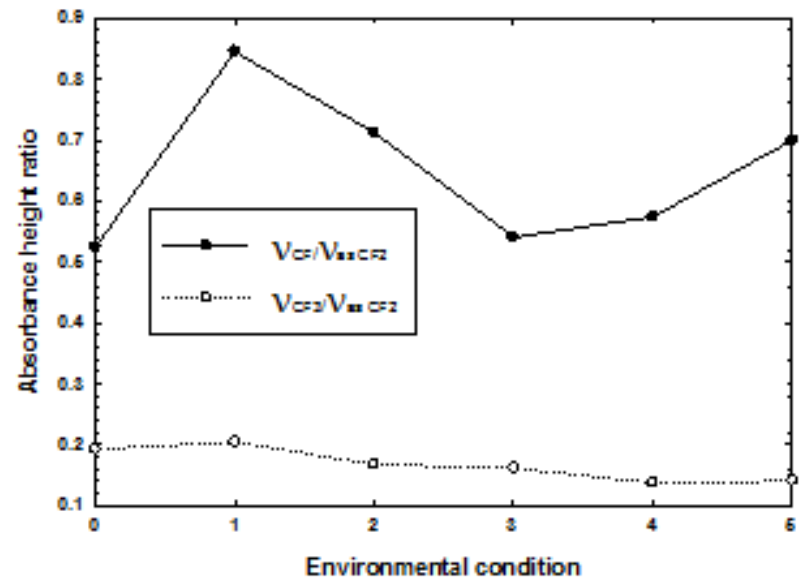

Figure 20. The $V_{\mathrm{CF}} /$ and $V_{\mathrm{CF} 3} / V_{\text {as }} \mathrm{CF} 2$ absorbance height ratios for FFKM after exposure in different environments; (0) control, (1) 5-cycle non-aerated- and (2) aerated- steam-cooling, (3) drilling fluid, (4) geo-brine fluid, and, (5) 5-cycle thermal shock. 


\subsubsection{FSR}

Figure 21 shows the ATR-FTIR spectra and the appearance for FSR O-rings after exposure to the No. 1 environment. The spectrum of the control FSR copolymer, poly(PS-co-TFPPS), encompassed eleven major bands: $V_{\mathrm{as} \mathrm{CH}}$ and $V_{\mathrm{sC}-\mathrm{H}}$ at 2968 and $2918 \mathrm{~cm}^{-1}, \delta_{\mathrm{CH} 2}$ at $1447 \mathrm{~cm}^{-1}, \delta$ $\mathrm{CH}_{3}$ at $1370 \mathrm{~cm}^{-1}$, Si-C bending vibration $\left(\delta_{\text {Si-C }}\right)$ at 1262 and $894 \mathrm{~cm}^{-1}$, Si-C stretching mode $\left(V_{\mathrm{Si}-}\right.$ C) at 794, 767, and $696 \mathrm{~cm}^{-1}$, and Si-O-Si stretching $\left(V_{\mathrm{Si}-\mathrm{O}-\mathrm{Si}}\right)$ at 1056 and $1006 \mathrm{~cm}^{-1}$ [27-32]. Additionally, it is possible to assume that the $\delta$ s-C band at $894 \mathrm{~cm}^{-1}$ was overlapped by the $V_{\mathrm{CF} 3}$ band. A dramatic change in spectral features was observed from the sample exposed in the No. 1 environment; most of the bands, except for an intensive $V_{\text {Si-O-Si }}$ signal and several $V_{\text {Si-C }}$-related bands, were eliminated, and no oxidation derivatives formed, resulting in severe hydrothermal degradation of FSR. In fact, the O-ring was disintegrated, as can be seen in Figure 21. The same FTIR patterns were obtained from the O-rings exposed in the No. 3, 4, and 5 environments (Figure 22), and, consequently, all of the O-rings completely failed. Several investigators had studied the mechanism of hydrothermal degradation for silicon rubber [33-35]. They reported that three linkages within the FSR structure, $\mathrm{Si}-\mathrm{CH}_{3},-\mathrm{CH}_{2}$, and $-\mathrm{O}$, were vulnerable to rupture in hydrothermal environments. Such bond breakages led to the generation of silanol, $\mathrm{Si}-\mathrm{OH}$, groups at the rupture sites and then condensation reactions between silanols created new oxygenbridged Si-O-Si linkages. Assuming a similar degradation mechanism may occur in FSR, the reason for disappearance of the majority of hydrocarbon-related bands could be the breaking off

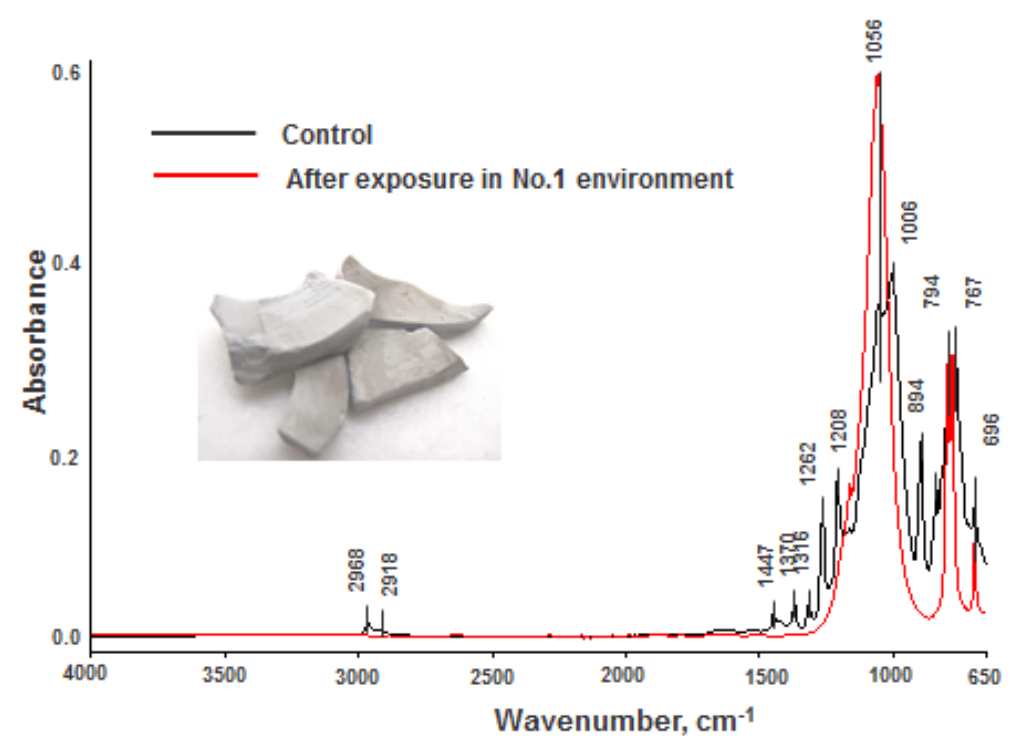

Figure 21. ATR-FTIR absorption spectra and appearance for FSR O-rings before and after exposure in No. 1 non-aerated steam-cooling cycle environment. 


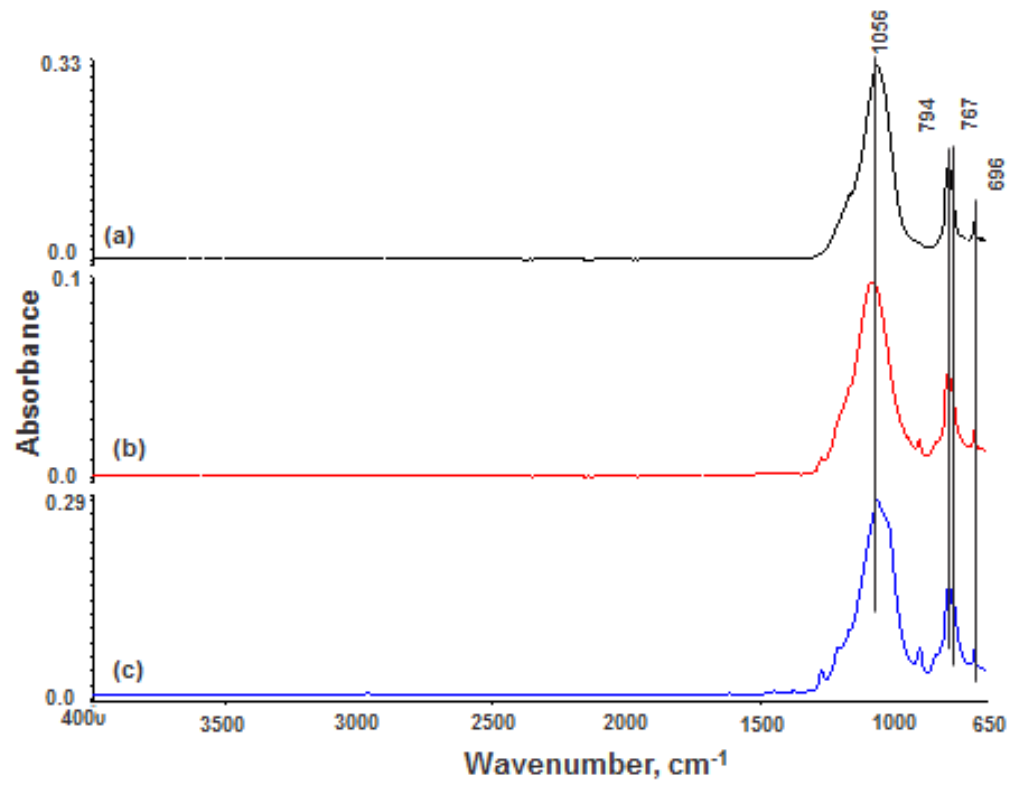

Figure 22. ATR-FTIR absorption spectra for FSR O-rings after exposure in (a) No. 3-, (b) No. 4, and (c) No. 5-environments.

of $-\mathrm{CH}_{3}$ and $-\mathrm{CH}_{2}$ groups. Furthermore, the development of an intensive $\mathrm{Si}-\mathrm{O}-\mathrm{Si}$ linkage signal is likely to be associated with an increased number of new Si-O-Si linkages. These new Si-O-Si linkages formed by condensation reactions may be created during heating the degraded O-rings at $90^{\circ} \mathrm{C}$ before FT-IR analysis. On the other hand, since the $V_{\text {Si-C }}$-related bands were directly related to the $\mathrm{Si}-\mathrm{C}$ bond in $\mathrm{Si}-\mathrm{CH}_{3}$ groups, some $\mathrm{Si}-\mathrm{CH}_{3}$ may be present at the end groups. If this hypothesis is reasonable, the following degradation mechanism of FSR in all hydrothermalassociated geothermal environments at $300^{\circ} \mathrm{C}$ can be postulated (Figure 23). 


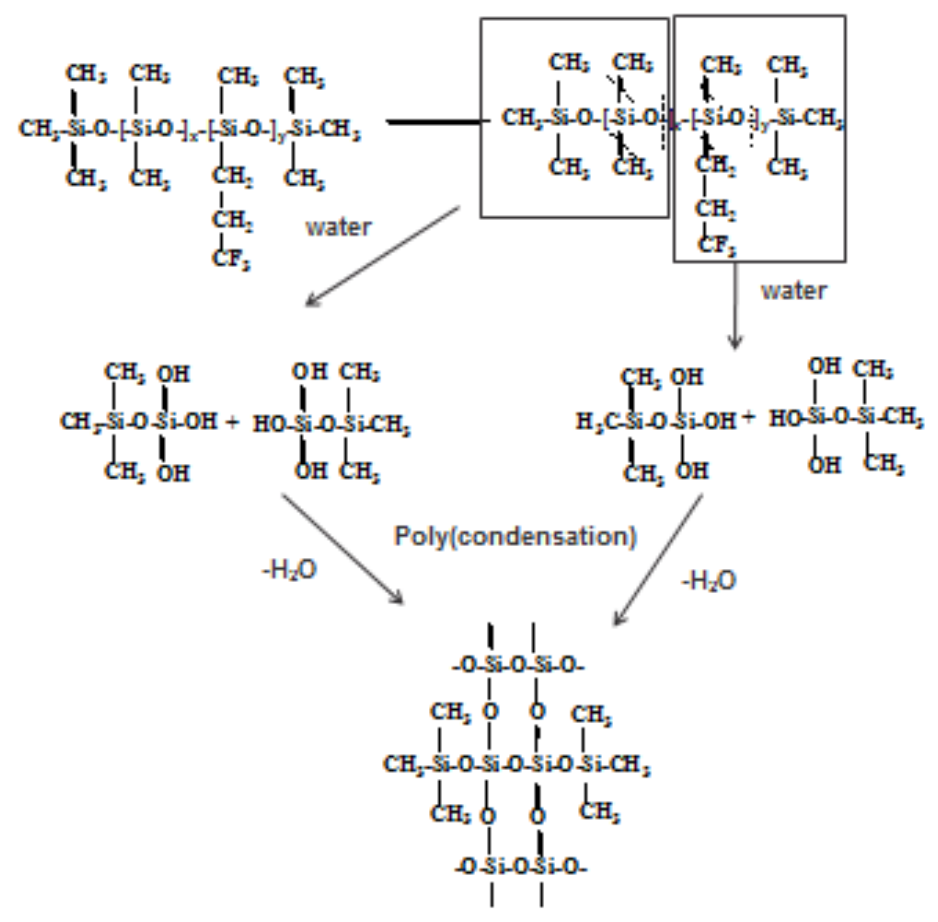

Figure 23. Proposed hydrothermal degradation mechanism of FSR

\subsection{TGA analysis}

To support the above information, thermal degradation of the O-rings and their stability at temperatures of up to $700^{\circ} \mathrm{C}$ were evaluated after exposure to the five environments listed previously. There were three key pieces of data to be collected by the combination of thermogravimetry (TG) and derivative thermogravimetry (DTG): 1) The onset temperature of weight loss, 2) the maximum decomposition rate temperature, and 3) the rate of total mass loss during the entire thermal decomposition.

\subsubsection{EPDM}

Figure 24 gives the TG- and DTG-thermograms for unexposed O-rings and those exposed in the No. 1 and 2 environments. For the control, the TG curve showed that the loss in weight began at a temperature of $118^{\circ} \mathrm{C}$. When O-rings were exposed to No. 1 and 2 environments, the onset temperature $\left(T_{o}\right)$ of weight loss shifted to lower values; the No. 1 environment had a $T_{o}$ of $94^{\circ} \mathrm{C}$ while No. $2 T_{o}$ was $44^{\circ} \mathrm{C}$. These results strongly suggest that EPDM was hydrothermally degraded under those conditions. The magnitude of degradation depended on the environment: No. 2 (aerated steam-cooling) caused a relatively higher degradation than No. 1 (non-aerated) as evidenced by the lower $T_{o}$ of No. 2 versus No. 1. This implies that the extent of oxidation of EPDM played an essential role in the overall degradation state of the material. The comparison 
of the maximum degradation rate temperature, $T_{\max }$, values provides information on the thermal stability of O-rings exposed in these environments. The $T_{\max }$ value of the control was $476^{\circ} \mathrm{C}$, and this value fell to $467^{\circ} \mathrm{C}$ in the No. 1 environment and to $458^{\circ} \mathrm{C}$ in No. 2 , reflecting the decline of the O-ring's thermal stability. Further, this information was supported by the total mass loss rate, $\operatorname{TMLR}\left(\% \cdot \min /{ }^{\circ} \mathrm{C}\right)$, obtained by computing the total area under the curve using the baseline between the onset and the end of the curve. The TMLR value of the control was 2.82, and this value was reduced by $6 \%$ to 2.65 after exposure in the No. 1 environment. Such a reduction was associated with the formation of oxidation derivatives along with the scission of hydrocarbon backbone chains within EPDM resulting from the oxidative degradation (Figure 6). According to the literature [10], these derivatives convert into carbonaceous by-products that slow down the rate of thermal decomposition loss of the O-ring. Thus, the rapid conversion of oxidation derivatives to carbonaceous by-products was pivotal to reducing the TMLR value. If this interpretation is valid, the TMLR value of 2.45 for the No. 2 (aerated) condition, which is 0.2 lower than that of the No. 1 (non-aerated) condition, implies that the aerated environment created more oxidation derivatives, which lead to a further reduction of the rate of decomposition loss.

The TG and DTG thermograms for O-rings before and after exposure in No. 3, 4, and 5 environments are shown in Figure 25. On the TG curves, of particular interest was the comparison of features in the temperature range of $400-550^{\circ} \mathrm{C}$. Exposure to No. 3 (drilling fluid) resulted in a notable shift of the curve to higher temperatures, reflecting an improvement of EPDM's thermal stability. In contrast, the curve from the No. 4-exposed O-ring closely resembled that of the control, which indicated that the sensitivity of EPDM to the geo-brine fluid was minor. 

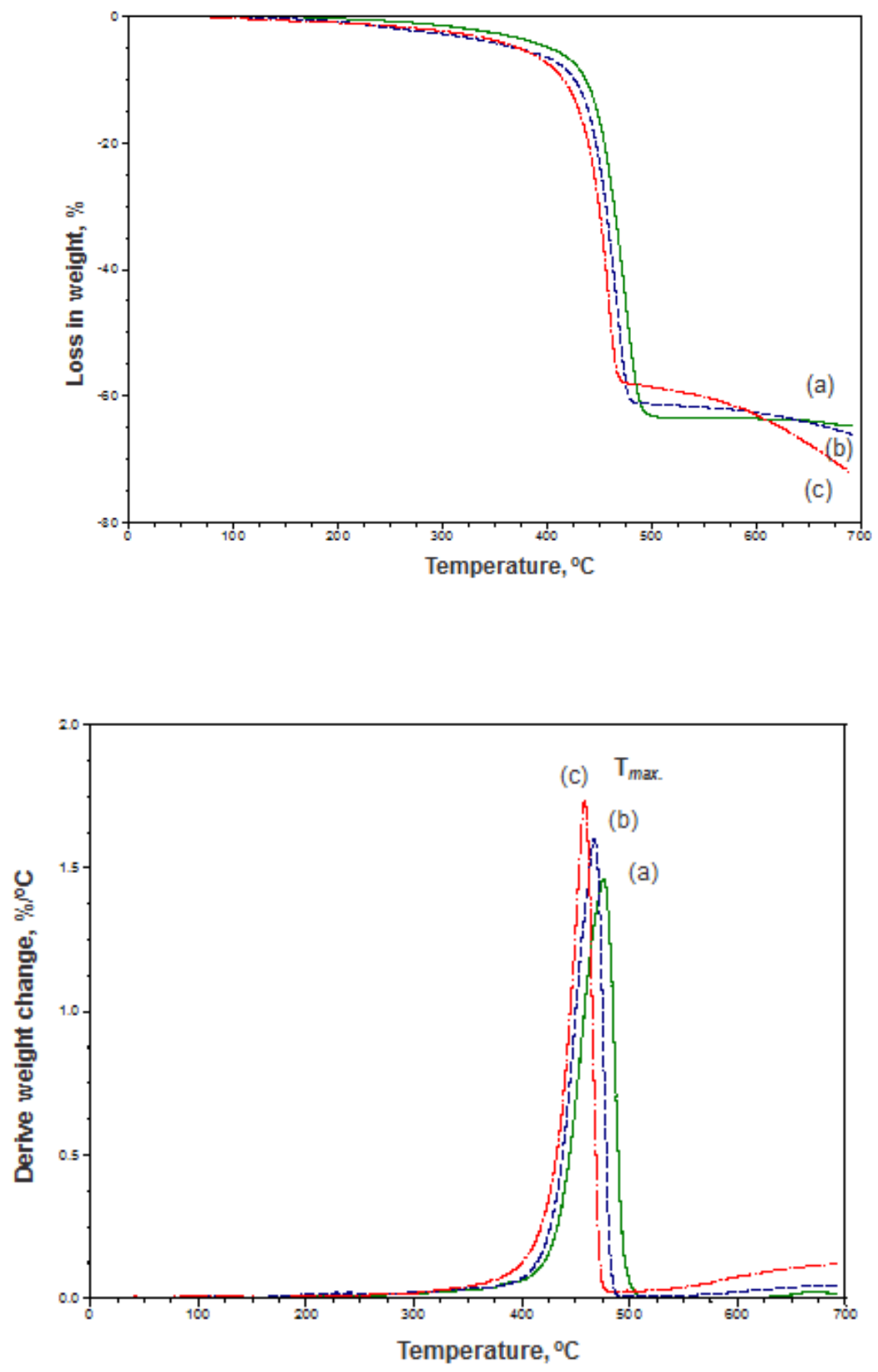

Figure 24. TG (top) and DTG (bottom) thermograms for EPDM before (a), and after exposure in (b) No. 1 environment, and (c) No. 2 environment.

Since the No. 5 (thermal shock) environment undermined the integrity of O-ring by severe oxidation-induced degradation, the features of the curve revealed a typical decomposition pattern of carbonaceous by-product-rich compounds along with minimum decomposable organic compounds. In addition, there were no significant changes in the $T_{o}$ value for Nos. 3 and 4 when compared to the control, whereas No. 5 showed a decrease of $29^{\circ} \mathrm{C}$. Thus, it can be concluded 
that EPDM O-rings displayed good resistance to these environments, with the exception of No. 5 (thermal shock).
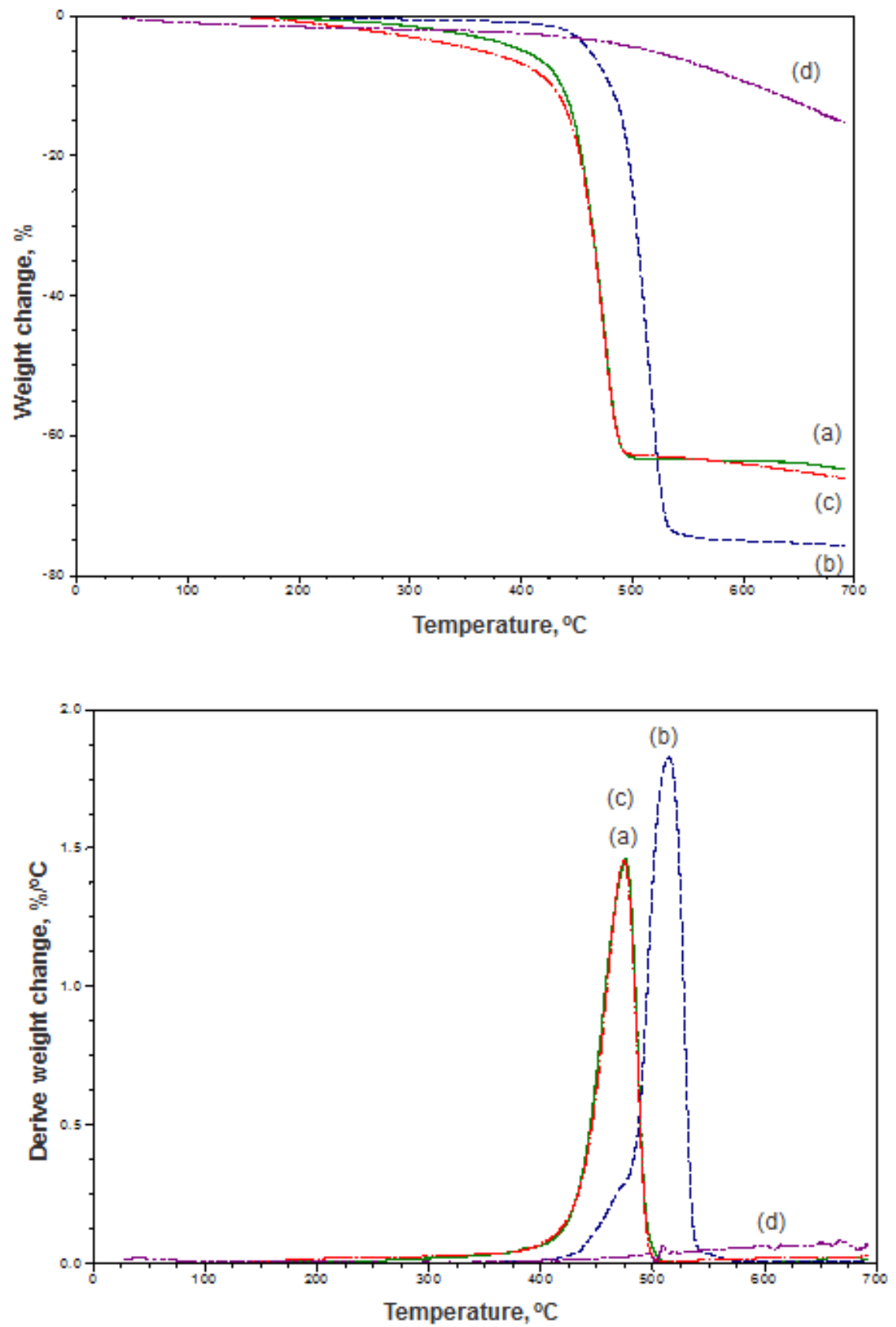

Figure 25. TG- (top) and DTG-(bottom) thermo-grams for EPDM before (a), and after exposure in (b) No. 3, (c) No. 4, and (d) No. 5 environments. 
The DTG curve concomitant with TG (Figure 25, bottom) showed that the $T_{\max }$ value of the EPDM was increased by $38^{\circ} \mathrm{C}$ after exposure in the No. 3 environment, reflecting an improvement of thermal stability; this increase may be due to the formation of interaction products between the EPDM and drilling fluid. However, no further experimental work was undertaken to identity any reaction products. The $T_{\max }$ of the No. 4-exposed O-ring was almost equal to that of the control. No peak was detected from O-ring exposed in the No. 5 environment because most of thermally decomposable organic compounds in EPDM were eliminated during thermal-shock testing. Interestingly, the TMLR value for No. 3 was 3.62, which was $27 \%$ higher than that of the control; this increase may be due to interaction products of the EPDM reacting with the drilling fluid. In other words, such interaction products not only enhanced the loss rate from thermal decomposition, but also were responsible for minimizing the formation of oxidation derivatives. The TMLR value for No. 4 was almost the same as that of the control, supporting the fact that the sensitivity of EPDM to geo-brine fluid was negligible with the formation of a minimum number of oxidation derivatives.

Table 3 summarizes all of the data described above. Based upon two factors, 1) thermal degradation and stability measurement associated with $T_{o}$ and $T_{\max }$, and 2) the quantity of oxidation derivatives as speculated from comparing the TMLR values, the stability of the EPDM O-rings can be ordered as follows: No. 3 drilling fluid > No. 4 geo-brine fluid > No. 1 nonaerated steam-cooling > No. 2 aerated steam-cooling >> No. 5 thermal shock.

Table 3. $T_{o}, T_{\max }$, and TMLR values of EPDM O-ring before and after exposure in different environments.

\begin{tabular}{llll}
\hline $\begin{array}{l}\text { Testing } \\
\text { environment }\end{array}$ & $\boldsymbol{T}_{\boldsymbol{o}},{ }^{\circ} \boldsymbol{C}$ & $\boldsymbol{T}_{\boldsymbol{m a x},}{ }^{\circ} \mathbf{C}$ & $\begin{array}{l}\boldsymbol{T M L R}^{*}{ }^{*} \\
\boldsymbol{\%} . \boldsymbol{m i n} /{ }^{\circ} \mathbf{C}\end{array}$ \\
\hline Control & 118 & 476 & 2.86 \\
No. 1 & 94 & 467 & 2.65 \\
No. 2 & 44 & 458 & 2.45 \\
No. 3 & 95 & 514 & 3.62 \\
No. 4 & 117 & 474 & 2.72 \\
No. 5 & 29 & $-* *$ & - \\
\hline
\end{tabular}

*Total mass loss rate, **not applicable

\subsubsection{Type I FKM}

Figure 26 depicts the TG- and DTG-thermograms for the O-rings before and after exposure in No. 1 and 2 environments. The TG curve for the control revealed a single decomposition pattern that began around $300^{\circ} \mathrm{C}$ and ended around $503^{\circ} \mathrm{C}$. The features of the $\mathrm{TG}$ curve from the O-ring exposed in No. 1 differed in two ways from that of the control. First, there was a two-step decomposition process consisting of the first, major decomposition beginning at $74^{\circ}$ and ending around $500^{\circ} \mathrm{C}$, and the secondary, minor stage occurring in the temperature range of $500-600^{\circ} \mathrm{C}$. 
Second, the $T_{o}$ value shifted considerably lower from $300^{\circ} \mathrm{C}$ to $74^{\circ} \mathrm{C}$. The secondary decomposition stage may be related to the formation of hydration reaction products while the major reduction in $T_{o}$ clearly indicated the degradation of O-ring during the non-aerated steamcooling cycles.
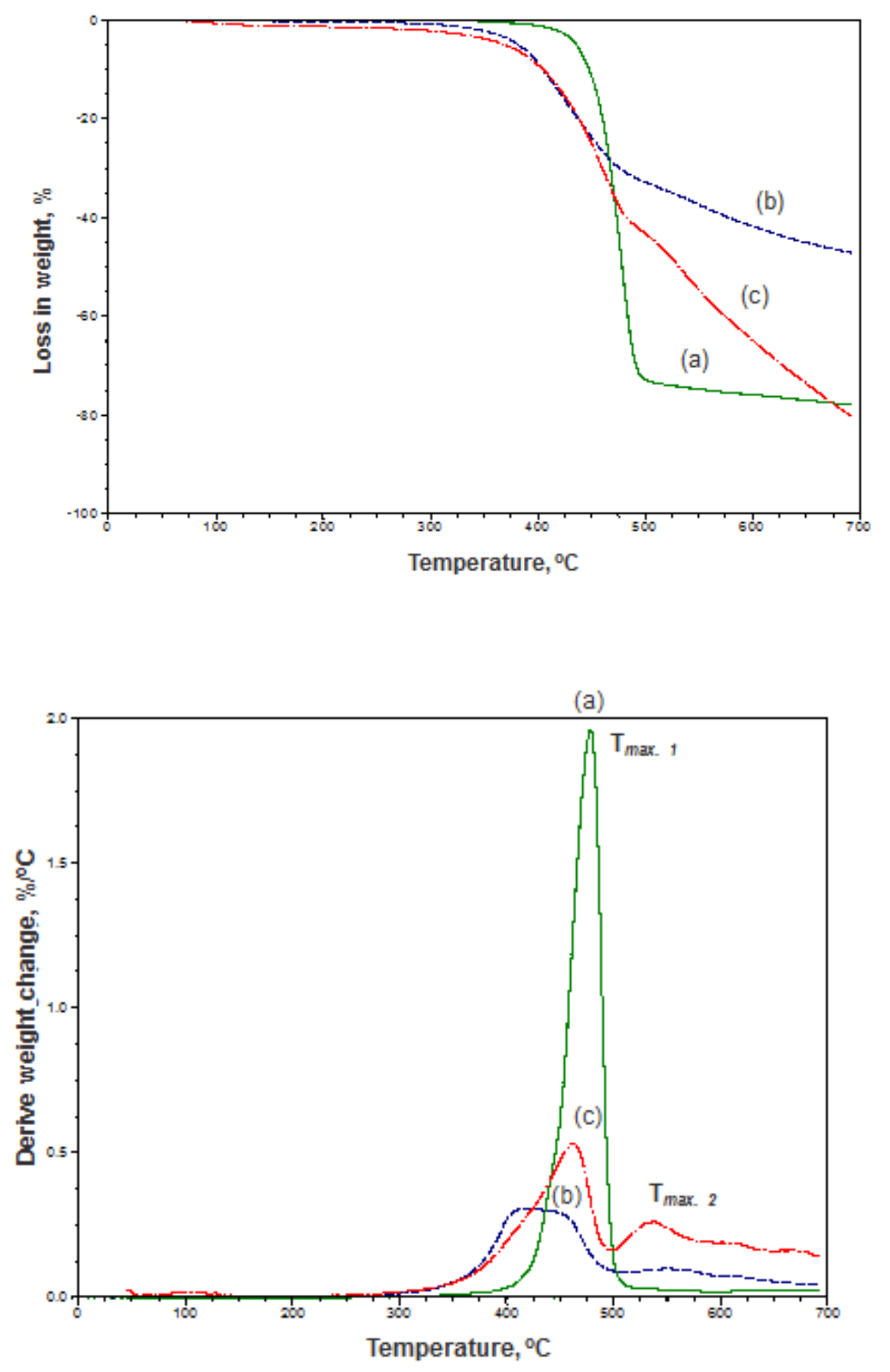

Figure 26. TG (top) and DTG (bottom) thermograms for type I FKM before (a) and after exposure in (b) No. 1 and (c) No. 2 environments. 
Similar to the TG curve of the O-ring in the No. 1 environment, the No. 2-exposed O-ring also had a two-step decomposition pattern with the secondary decomposition stage likely due to the formation of hydration reaction products. In addition, an even more pronounced shift in $T_{o}$ to $50^{\circ} \mathrm{C}$ was detected from the O-ring exposed in the No. 2 environment; this result strongly demonstrates that, like EPDM, the susceptibility of type I FKM to degradation by aerated steamcooling was higher than that caused by non-aerated steam-cooling, leading to the subsequent lowering of $T_{o}$ and decline in thermal stability.

Correspondingly, the DTG data for environments No. 1 and 2 showed two maximum degradation temperatures: One was $T_{\max .1}$ as the major peak, the other was $T_{\max .2}$ as the minor one. For No. 1, the $T_{\max .1}$ and $T_{\max .2}$ were $425^{\circ} \mathrm{C}$ and $533^{\circ} \mathrm{C}$, respectively. The individual mass loss rate $\left(M L R, \% \cdot \mathrm{min} /{ }^{\circ} \mathrm{C}\right)$ was 1.10 for the major peak and 0.04 for the minor one; consequently, the total mass loss rate (TMLR) was 1.14. This TMLR value was 3.1-fold lower than that of the control, meaning that the existence of a substantial amount of carbonaceous byproducts delayed the decomposition loss rate of type I FKM. A similar TMLR value was obtained from No. 2. Hence, the resistance of type I FKM to either aerated or non-aerated steam-cooling cycle-caused oxidation was poor.

Figure 27 presents the TG- and DTG-thermograms for the O-rings before and after exposure in the No. 3, 4, and 5 environments. On the TG curves, the O-ring exposed in environment No. 3 had a $T_{o}$ value of $197^{\circ} \mathrm{C}$, corresponding to a $103^{\circ} \mathrm{C}$ reduction. The No. 4 environment engendered an even larger shift to $68^{\circ} \mathrm{C}$. Additionally, this curve revealed a two-step decomposition pattern: the first, minor decomposition occurred between $68^{\circ}$ and $\sim 200^{\circ} \mathrm{C}$ and the second, major decomposition occurred between approximately 337 to $517^{\circ} \mathrm{C}$. Thus, the type I FKM was much more vulnerable to the No. 4 geo-brine fluid compared to the No. 3 drilling fluid. In contrast, its vulnerability to thermal shock was conspicuously minor; in fact, the curve exhibited a high $T_{o}$ of $286^{\circ} \mathrm{C}$. For the $T_{\max }$ and $T M L R$ values, there were no significant differences between Nos. 3 and 4 - the former ranged from $455-469^{\circ} \mathrm{C}$ and the latter was in the range of $1.83-1.85 \% \cdot \mathrm{min} /{ }^{\circ} \mathrm{C}$. 

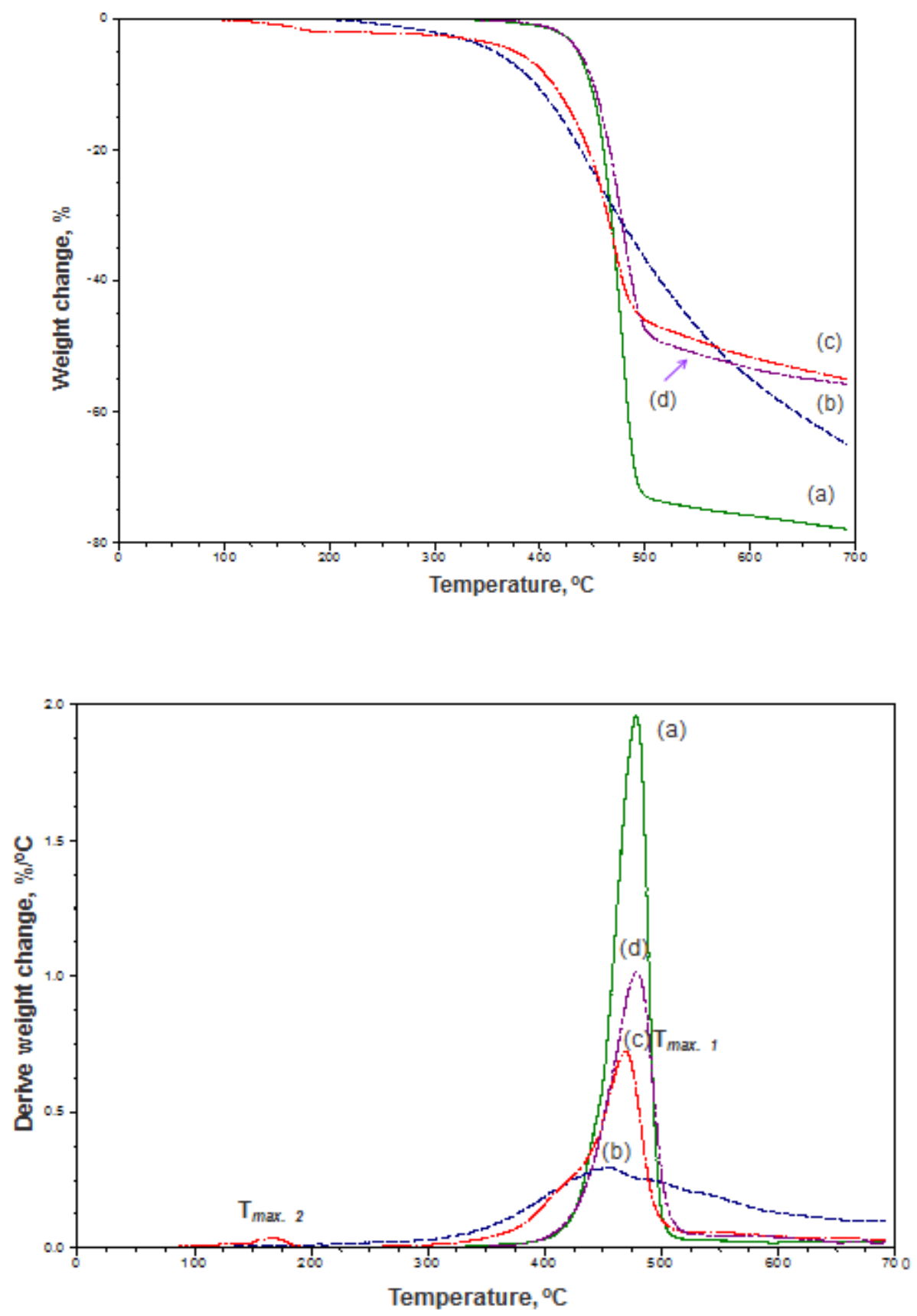

Figure 27. TG- (top) and DTG- (bottom) thermograms for type I FKM before (a) and after exposure in (b) No. 3, (c) No. 4, and (d) No. 5 environments.

Table 4 summarizes the overall data described above. From this information, it was very difficult to clearly rank these environments for susceptibility to oxidation, except for the thermal shock environment. This environment was identified as having the mildest impact on oxidation, compared with all other environments. 
Table 4. Summarized data from TG-DTG analyses for type I FKM

\begin{tabular}{|c|c|c|c|c|c|c|}
\hline $\begin{array}{l}\text { Testing } \\
\text { environment }\end{array}$ & $T_{o},{ }^{\circ} \mathrm{C}$ & $\begin{array}{l}T_{\text {max. } 1,}, \\
{ }^{\circ} \mathrm{C}\end{array}$ & $\begin{array}{l}M L R^{*}, \\
\% . \min /{ }^{\circ} \mathrm{C}\end{array}$ & $\begin{array}{l}T_{\max .2,}, \\
{ }^{\circ} \mathrm{C}\end{array}$ & $\begin{array}{l}\text { MLR, } \\
\% . \min /{ }^{\circ} \mathrm{C}\end{array}$ & $\begin{array}{l}\operatorname{TMLR}^{* *}, \\
\% . \min /{ }^{\circ} \mathrm{C}\end{array}$ \\
\hline Control & 300 & 478 & 3.52 & - & - & 3.52 \\
\hline No. 1 & 74 & 425 & 1.10 & 533 & 0.04 & 1.14 \\
\hline No. 2 & 50 & 462 & 1.13 & 539 & 0.28 & 1.42 \\
\hline No. 3 & 197 & 455 & 1.83 & - & - & 1.83 \\
\hline No. 4 & 68 & 469 & 1.82 & 169 & 0.03 & 1.85 \\
\hline No. 5 & 286 & 479 & 2.21 & - & - & 2.21 \\
\hline
\end{tabular}

*Mass loss rate, $* *$ Total mass loss rate

\subsubsection{Type II FKM}

Figure 28 depicts the TG- and DTG-thermograms for the O-rings before and after exposure to the No. 1 and 2 environments. Compared to the TG curve of type I FKM, type II FKM was characterized by a single-step decomposition pattern. A similar shifting of $T_{o}$ values to lower temperatures from the $228^{\circ} \mathrm{C}$ control was observed for exposed O-rings, with $T_{o}=$ at $65^{\circ} \mathrm{C}$ for No. 1 , and $53^{\circ} \mathrm{C}$ for No. 2.

For the control, the DTG curves exhibited a $T_{\max }$ of $497^{\circ} \mathrm{C}$ and a $T M L R$ of $3.39 \% . \mathrm{min} /{ }^{\circ} \mathrm{C}$. This $T_{\max }$ value dropped $2.6 \%$ to $484^{\circ} \mathrm{C}$ after exposure in both the Nos. 1 and 2 environments, demonstrating a slight decline in thermal stability. The TMLR for No. 1 and 2 was 2.27 and 1.85 $\% . \min /{ }^{\circ} \mathrm{C}$, respectively, corresponding to 33 and $45 \%$ reduction over that of the control. However, these reductions were much smaller than those of type I FKM. Thus, type II FKM contained a lower amount of oxidation derivatives responsible for reducing the conversion rate of carbonaceous by-products in a short period of thermal decomposition. Hence, type II displayed a better hydrothermal stability both in aerated- and non-aerated-steam-cooling environments than did that of type I. 

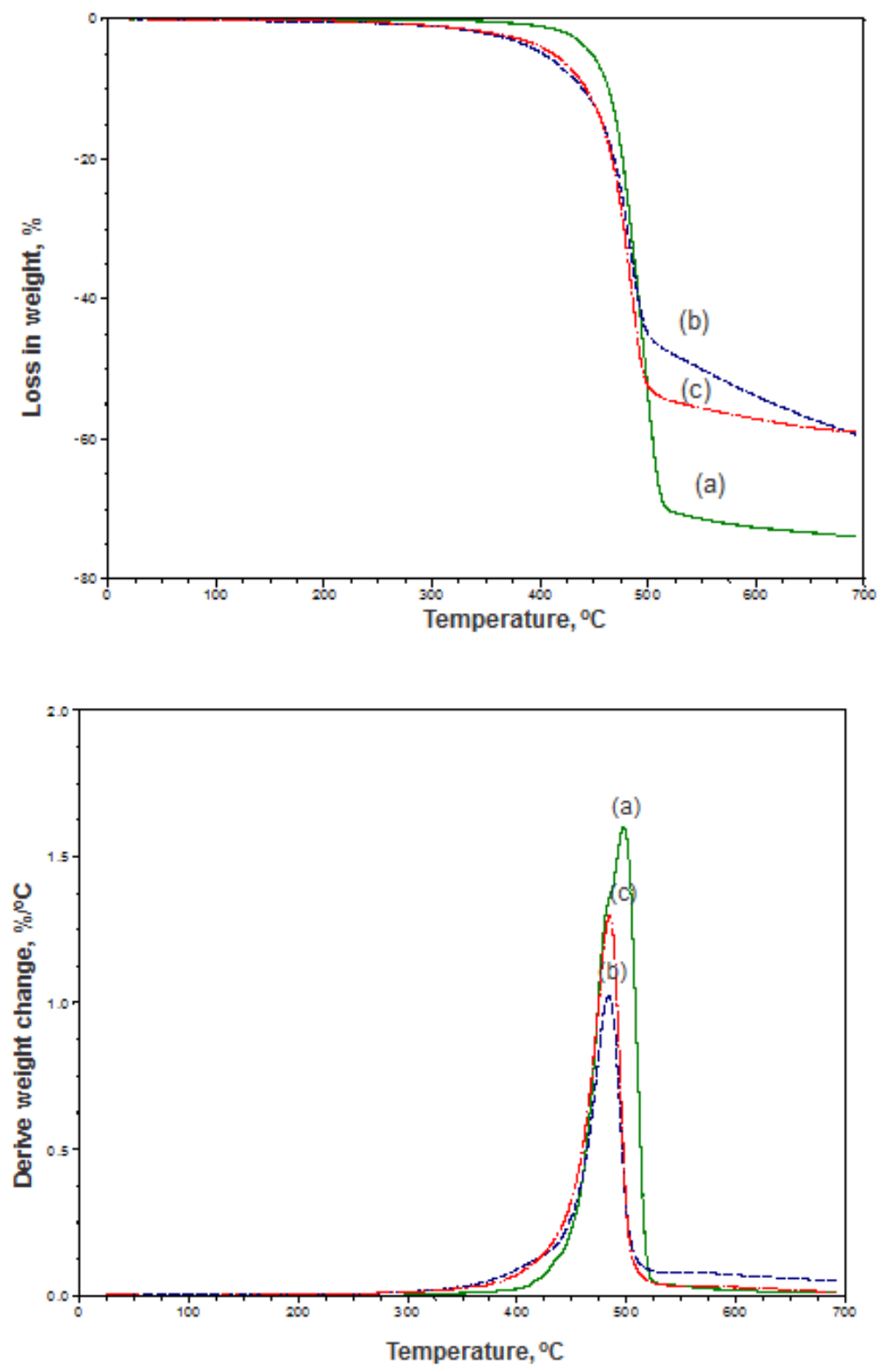

Figure 28. TG (top) and DTG (bottom) thermograms for type II FKM before (a) and after exposure in (b) the No. 1 and (c) No. 2 environments.

In the No. 4, 5, and 6 environments, the TG- and DTG-thermograms (Figure 29) were similar to those of type I; namely, the oxidation of type II was affected by No. 3 drilling fluid and No. 4 geo-brine fluid, but not by thermal shock. 

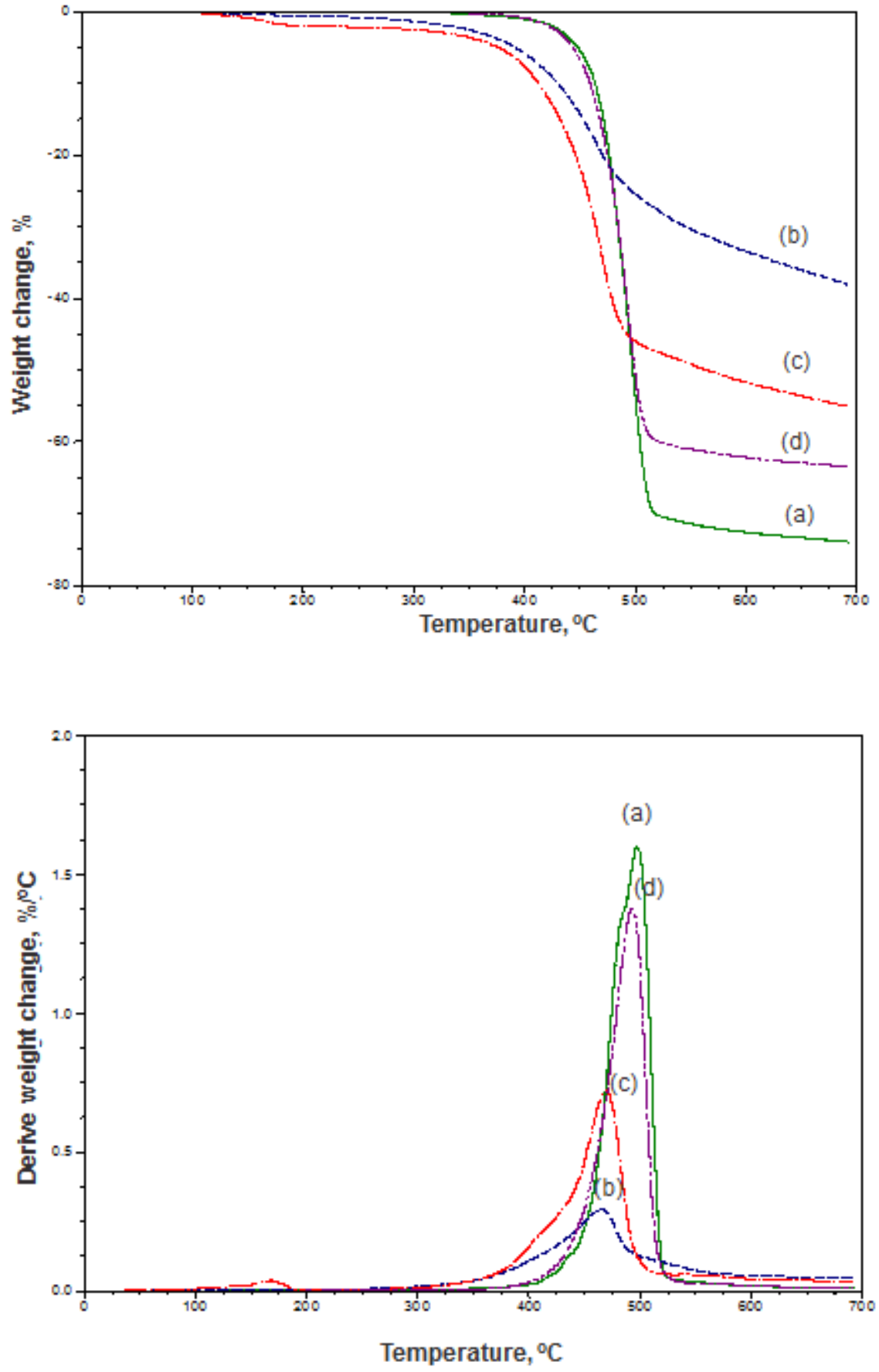

Figure 29. TG- (top) and DTG-(bottom) thermograms for type II FKM before (a), and after exposure in (b) No. 3, (c) No. 4, and (d) No. 5 environments.

Table 5 lists all these data, including the $T_{o}, T_{\max }$, and $T M L R$ values. Relating these data to those of type I, type II was less susceptible to both aerated and non-aerated steam-cooling conditions. Based upon the overall results, the extent of the impact on the degradation of type II FKM O-ring 
was ordered as follows from the lowest to the highest: No. 5 thermal shock $>$ No. 1 non-aerated steam-cooling $>$ No. 2 aerated steam-cooling > No. 4 geo-brine fluid > No. 3 drilling fluid.

Table 5. Summarized data of TG-DTG results for type II FKM

\begin{tabular}{llll}
\hline $\begin{array}{l}\text { Testing } \\
\text { environment }\end{array}$ & $\boldsymbol{T}_{\boldsymbol{o}},{ }^{\circ} \boldsymbol{C}$ & $\boldsymbol{T}_{\boldsymbol{m a x},}{ }^{\circ} \boldsymbol{C}$ & $\begin{array}{l}\boldsymbol{T M L R}^{*} \\
\boldsymbol{\%} . \boldsymbol{m i n} /{ }^{\circ} \boldsymbol{C}\end{array}$ \\
\hline Control & 228 & 497 & 3.39 \\
No. 1 & 65 & 484 & 2.27 \\
No. 2 & 53 & 484 & 1.85 \\
No. 3 & 54 & 465 & 1.09 \\
No. 4 & 107 & 469 & 1.85 \\
No. 5 & 241 & 492 & 2.93 \\
\hline
\end{tabular}

*Total mass loss ratio

\subsubsection{FEPM}

Figure 30 depicts the TG- and DTG-thermograms for the FEPM O-rings before and after exposure in No. 1 and 2 environments. The TG curves showed a single decomposition mode, and from these data it is evident that the FEPM O-rings were sensitive to both the aerated- and nonaerated- steam-cooling. In fact, after the No. 1 and 2 exposures, the $T_{o}\left(152^{\circ} \mathrm{C}\right)$ of the control shifted to $54^{\circ}$ and $47^{\circ} \mathrm{C}$, respectively. Correspondingly, the $T_{\max }\left(514^{\circ} \mathrm{C}\right)$ of the control fell to $506^{\circ}$ and $502^{\circ} \mathrm{C}$ for No. 1 and 2 . Meanwhile, their respective TMLR values also were reduced from $3.64 \% \cdot \mathrm{min} /{ }^{\circ} \mathrm{C}$ (control) to 3.35 and $3.25 \% \cdot \mathrm{min} /{ }^{\circ} \mathrm{C}$ after No. 1 and 2 exposures. Hence, aerated steam-cooling had caused the incorporation of more oxidation derivatives into FEPM compared with that of non-aerated steam-cooling.

Figure 31 shows the TG and DTG thermograms for Nos. 3-, 4-, and 5-aged O-rings. As is clear from the TG curve, like EPDM, FEPM was very vulnerable to No. 5 (thermal shock); in fact, the $152^{\circ} \mathrm{C} T_{o}$ value of the control fell to $27^{\circ} \mathrm{C}$. By contrast, the impact of No. 3 and No. 4 was minimal; the No. 3 and 4 data showed the $T_{o}$ values of $114^{\circ} \mathrm{C}$ and $95^{\circ} \mathrm{C}$, respectively, corresponding to $38^{\circ}$ and $57^{\circ} \mathrm{C}$ lower than that of control. The DTG findings showed that the values of $T_{\max }$ and $T M L R$ of the control fell by $\sim 7$ and $\sim 22 \%$, respectively, to $480^{\circ} \mathrm{C}$ and $2.83 \% \cdot \mathrm{min} /{ }^{\circ} \mathrm{C}$ after exposure in No. 3, while there were no significant changes in these values after exposure in the No. 4 environment. Thus, the FEPM was susceptible to oxidation reactions with drilling fluid, lowering the thermal stability of the O-ring and promoting the incorporation of more oxidation derivatives into the material, whereas, the No. 4 (geo-brine fluid) exposure did not show any significant aging and degradation vulnerability.

Table 6 summarizes all of the data obtained from the thermograms. Interestingly, in the case of FEPM, all the data, except for No. 5, revealed a correlation between $T_{\max }$ and TMLR; namely, the $T M L R$ value tended to decline with decreasing $T_{\max }$. From this correlation, the impact on the 
degradation of the FEPM O-ring was ordered from lowest to the highest as follows: No. 4 geobrine fluid > No. 1 non-aerated steam-cooling > No. 2 aerated steam-cooling > No. 3 drilling fluid $\gg$ No. 5 thermal shock.
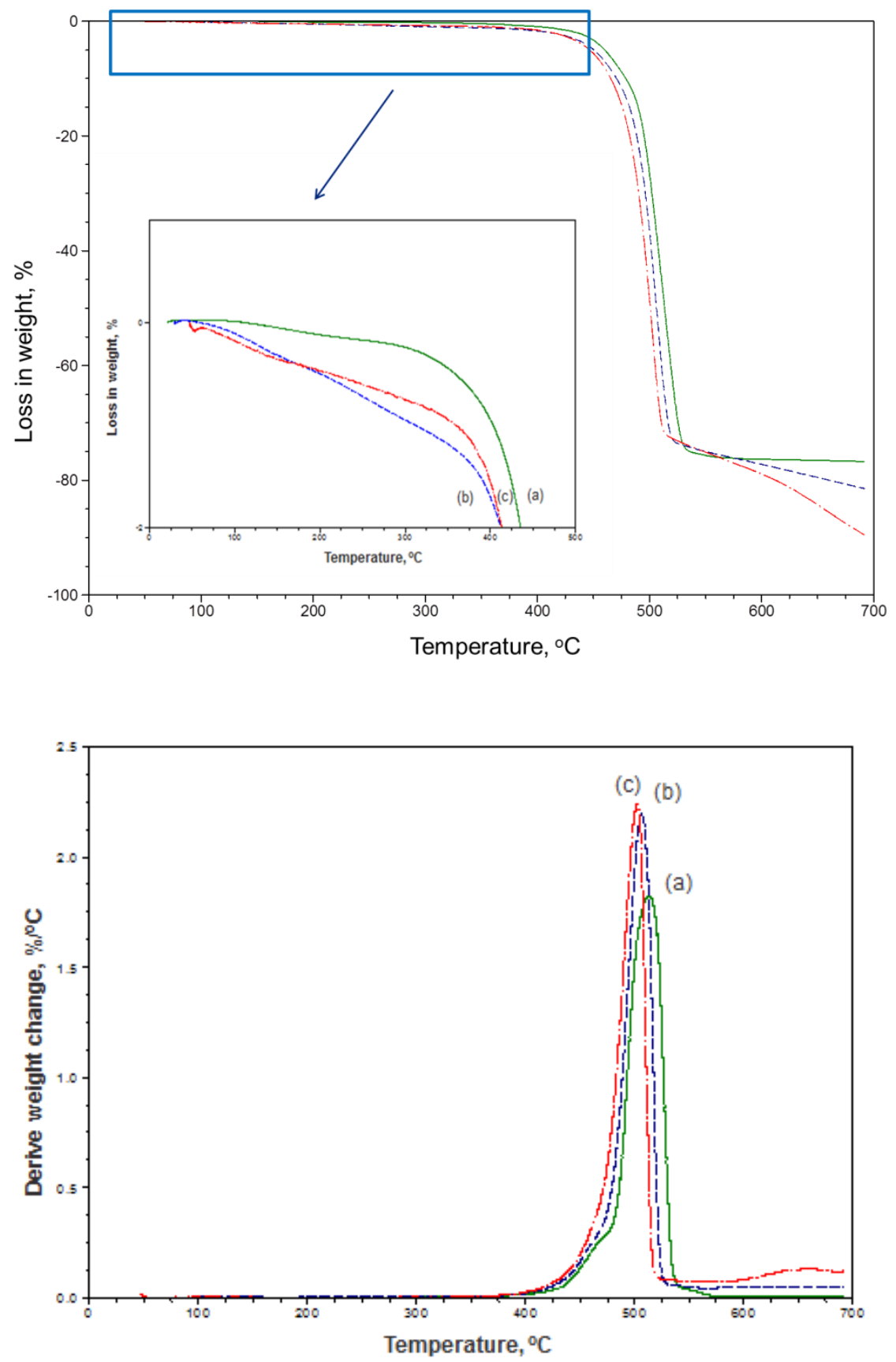

Figure 30. TG (top) and DTG (bottom) thermograms for FEPM before (a) and after exposure in (b) No. 1 and (c) No. 2 environments. 

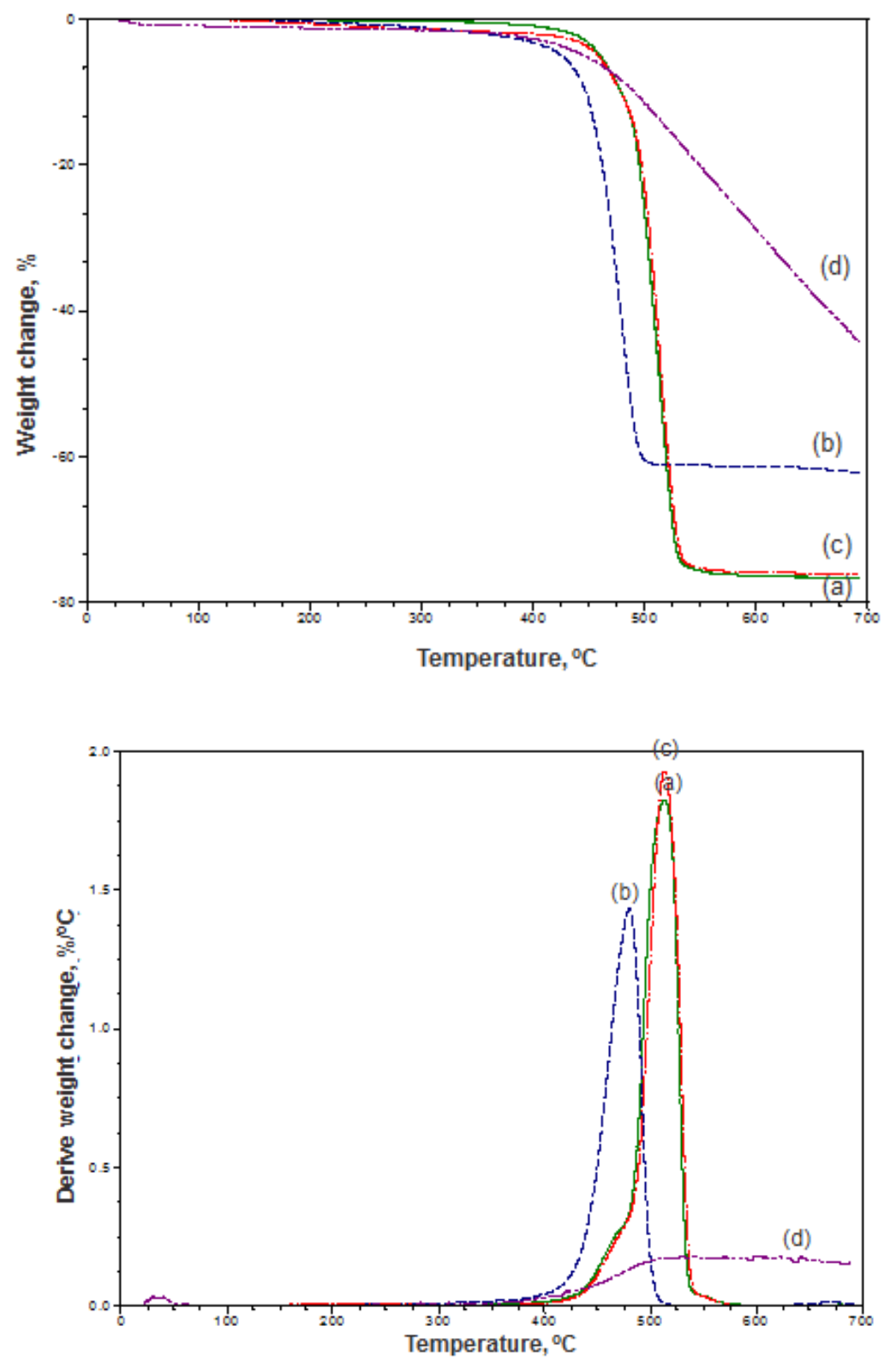

Figure 31. TG (top) and DTG (bottom) thermograms for FEPM before (a) and after exposure in (b) No. 3, (c) No. 4, and (d) No. 5 environments. 
Table 6. Summarized data of TG-DTG results for FEPM

\begin{tabular}{llll}
\hline $\begin{array}{l}\text { Testing } \\
\text { environment }\end{array}$ & $\boldsymbol{T}_{\boldsymbol{o}},{ }^{\circ} \boldsymbol{C}$ & $\boldsymbol{T}_{\boldsymbol{m a x},}{ }^{\circ} \mathbf{C}$ & $\begin{array}{l}\boldsymbol{T M L R}^{*}, \\
\boldsymbol{\%} . \boldsymbol{m i n} /{ }^{\circ} \mathbf{C}\end{array}$ \\
\hline Control & 152 & 514 & 3.64 \\
No. $\mathbf{1}$ & 54 & 506 & 3.35 \\
No. 2 & 47 & 502 & 3.25 \\
No. 3 & 114 & 480 & 2.83 \\
No. 4 & 95 & 513 & 3.66 \\
No. 5 & 27 & 507 & 0.65 \\
\hline
\end{tabular}

*Total mass loss ratio

\subsubsection{FFKM}

Figure 32 illustrates the TG- and DTG-thermograms for FFKM O-rings before and after exposure in the No. 1 and 2 environments. Viewing the TG curves, those of No. 1 and 2 were located in a site of somewhat lower temperature compared with that of the control, reflecting some sensitivity of FFKM to aerated- and non-aerated-steam-cooling. In fact, the $T_{o}\left(354^{\circ} \mathrm{C}\right)$ of the control shifted to $273^{\circ}$ and $162^{\circ} \mathrm{C}$, respectively for No. 1 and 2. On the other hand, the DTG results did not show any changes in $T_{\max }$ and $T M L R$ values over that of the control, highlighting a good hydrothermal stability and anti-oxidation behavior of the O-ring. Similarly, in the No. 3, 4, and 5 environments (Figure 33), although the $T_{o}$ shifted to $229^{\circ}$ and $141^{\circ} \mathrm{C}$ for No. 3 and 4 , no significant changes in $T_{\max }$ and $T M L R$ values were recorded under all these testing conditions. Of a particular attention here was No. 5, namely, FFKM displayed superior resistance to thermal shock. All of the data detailed above were summarized in Table 7. As evident from these results, the FFKM O-ring sustained its integrity in all of the environments. 

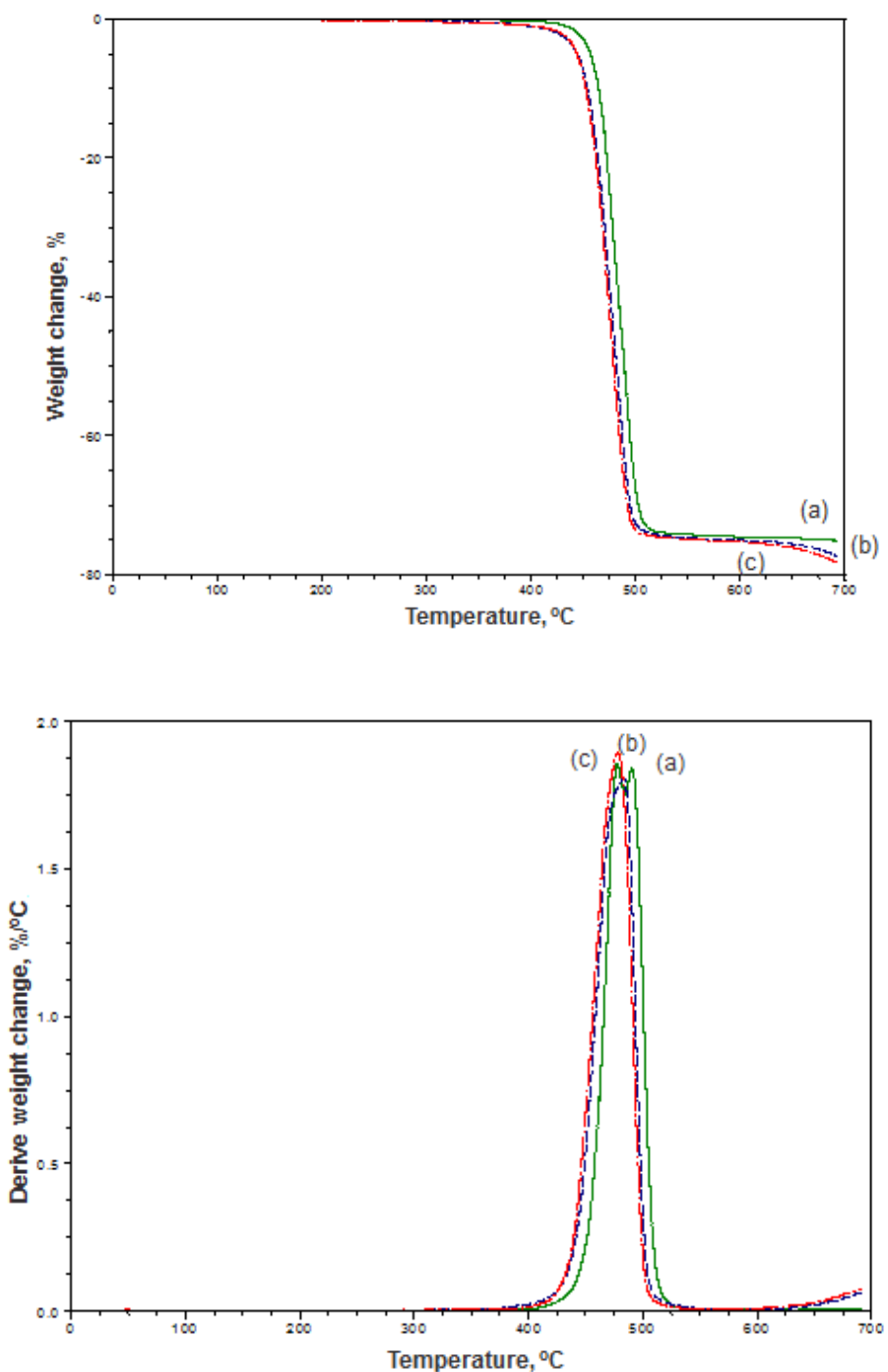

Figure 32. TG- (top) and DTG-(bottom) thermograms for FFKM before (a) and after exposure in (b) No. 1 and (c) No. 2 environments. 

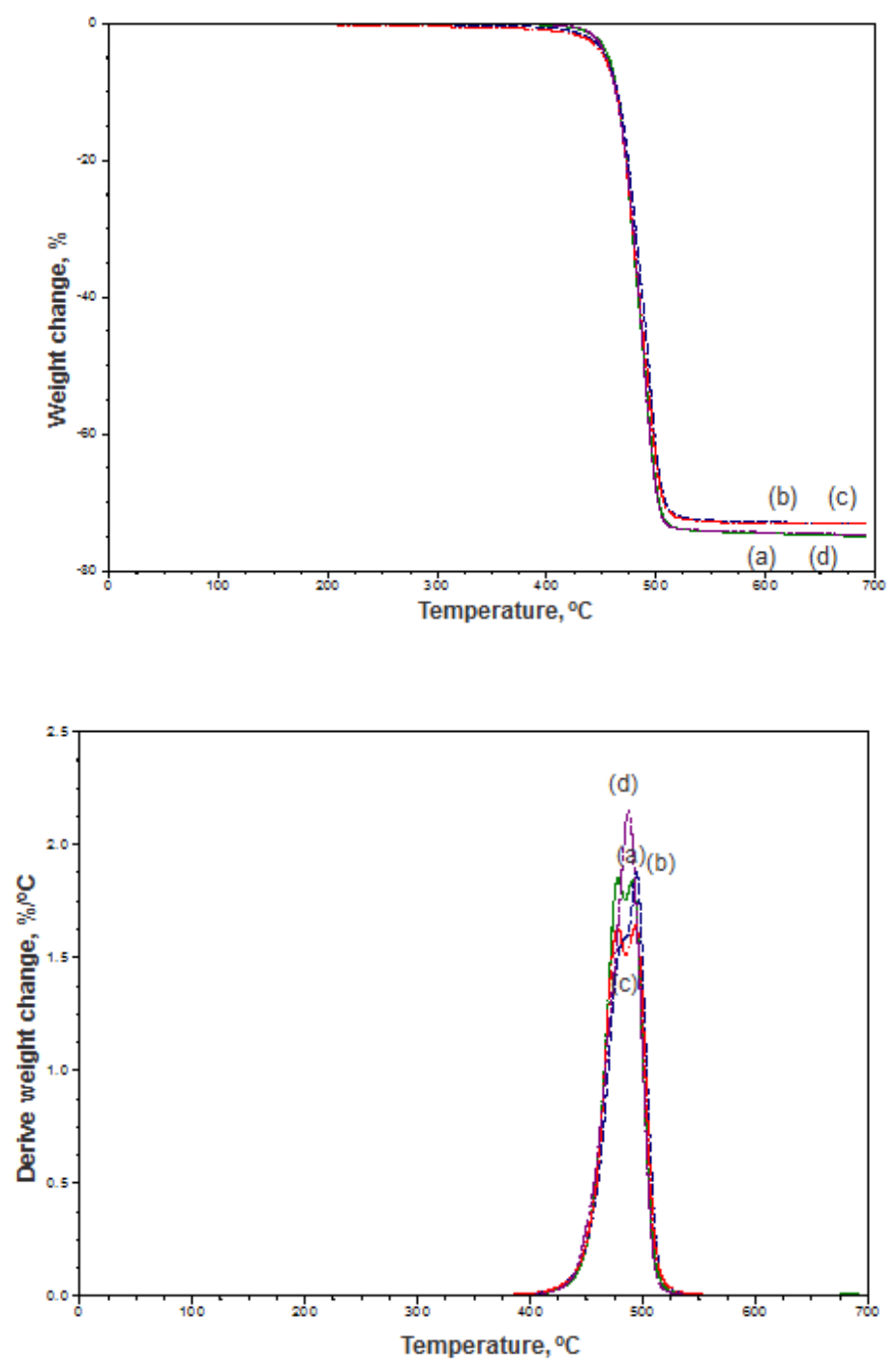

Figure 33. TG (top) and DTG (bottom) thermograms for FFKM before (a) and after exposure in environments (b) No. 3, (c) No. 4, and, (d) No. 5.

Table 7. Summarized data of TG-DTG results for FFKM

\begin{tabular}{llll}
\hline $\begin{array}{l}\text { Testing } \\
\text { environment }\end{array}$ & $\boldsymbol{T}_{\boldsymbol{o}},{ }^{\circ} \boldsymbol{C}$ & $\boldsymbol{T}_{\boldsymbol{m a x},}{ }^{\circ} \mathbf{C}$ & $\begin{array}{l}\boldsymbol{T M L R}^{*}, \\
\boldsymbol{\%} \cdot \boldsymbol{m i n} /{ }^{\circ} \mathbf{C}\end{array}$ \\
\hline Control & 354 & 478 & 3.58 \\
No. $\mathbf{1}$ & 273 & 483 & 3.58 \\
No. 2 & 162 & 478 & 3.59 \\
No. 3 & 229 & 494 & 3.53 \\
No. 4 & 141 & 478 & 3.52 \\
No. 5 & 372 & 487 & 3.66 \\
\hline
\end{tabular}

*Total mass loss ratio 


\subsubsection{FSR}

As described earlier in ATR-FTIR study, all the environments severely degraded the FSR-made O-ring. Figure 34 shows the TG- and DTG-curves of the O-rings before and after they were exposed in the No. 3, 4, and 5 environments. These results are summarized in

Table 8. Among all the employed elastomeric polymers, the "as-received" FSR was identified as O-ring possessing the highest $T_{\max }$ value of $522^{\circ} \mathrm{C}$. However, this undesirable vulnerability to all hydrothermal environments suggested that it would be very difficult to apply in geothermal fields. Thus, no further study was made for FSR.
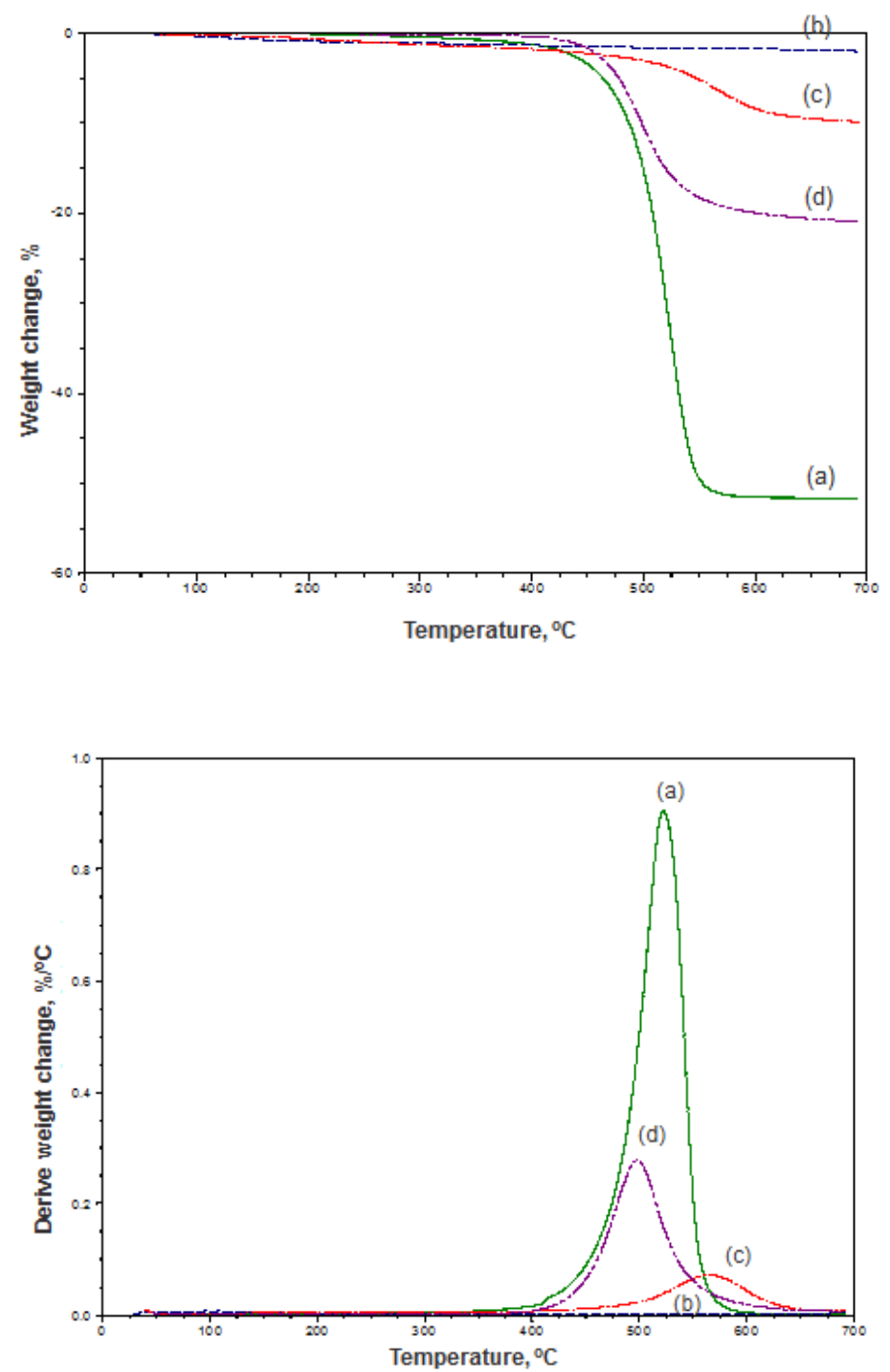

Figure 34. TG- (top) and DTG-(bottom) thermograms for FFKM before exposure (a), and after exposure in (b) No. 3, (c) No. 4, and, (d) No. 5 environments. 
Table 8. Summarized data from TG-DTG results for FSR

\begin{tabular}{llll}
\hline $\begin{array}{l}\text { Testing } \\
\text { environment }\end{array}$ & $\boldsymbol{T}_{\boldsymbol{o}},{ }^{\circ} \boldsymbol{C}$ & $\boldsymbol{T}_{\boldsymbol{m a x},}{ }^{\circ} \mathbf{C}$ & $\begin{array}{l}\boldsymbol{T M L R}^{*}, \\
\boldsymbol{\%} . \boldsymbol{m i n} /{ }^{\circ} \mathbf{C}\end{array}$ \\
\hline Control & 168 & 522 & 2.43 \\
No. 1 & 51 & - & - \\
No. 2 & $-* *$ & - & - \\
No. 3 & 40 & 422 & 0.009 \\
No. 4 & 41 & 563 & 0.30 \\
No. 5 & 49 & 498 & 0.91 \\
\hline
\end{tabular}

*Total mass loss ratio, $* *$ Untested.

\section{3. $\mu E D X$ imaging and Ca mapping analyses}

As previously identified in the ATR-FTIR analysis, the carboxylate, $-\mathrm{COO}^{-}$, group was among the several oxidation derivatives formed by the oxidation of the elastomeric polymers. It is possible for the $-\mathrm{COO}^{-}$group to react with $\mathrm{Na}, \mathrm{K}, \mathrm{Mg}$, and $\mathrm{Ca}$ counter mono- and di-valent cations present in No. 3 and No. 4 environments. This reaction would engender the formation of $\mathrm{a}-\mathrm{COO}^{-}{ }^{+} \mathrm{M}(\mathrm{M}=$ metallic elements $)$ linkage structure. Thus, the trace of these metallic cations pervading the oxidized O-ring will provide information on how deeply oxidation-induced degradation occurred during exposure. To obtain this information, we employed the Ca element from among the other metallic elements to act as a tracing and labeling moiety. This oxidationdepth profiling study by the permeation of $\mathrm{Ca}$ ion through the degraded O-rings was carried out by $\mu$ EDX elemental mapping analysis coupled with micro-image exploration. The $\mu$ EDX analyses were mapped on an area of $2.0 \times 1.5 \mathrm{~mm}\left(3 \mathrm{~mm}^{2}\right)$.

\subsubsection{EPDM}

Figure 35 shows the $\mu \mathrm{EDX}$ maps of $\mathrm{Ca}$ for the cross-sectional area marked with a red rectangle from the edge to the core of EPDM O-rings before and after exposure in the No. 3 environment. During mapping, the X-ray intensity count in the total detected area, particularly for $3.7 \mathrm{keV}$ spectral resolution at $\mathrm{Ca} K \alpha$ energy line, was recorded and used to determine the relative amount of the element and its distribution and to create a color-coded concentration map. The maximum amount of elemental distribution is given in the color barcode. Further, the concentration of these elements was ranked by the difference in colors; namely, the areas in white and red symbolized the highest relative concentrations of this element. By contrast, blue color was assigned to the Ca-free area.

There were no notable defects in the microstructure of the oxidized EPDM terpolymer O-rings after No. 3 and 4 exposures. In fact, the Ca mapping image of the control closely resembled that 
of the No. 3-exposed O-rings. A similar mapping image was observed from No. 4-exposed materials (not shown), strongly verifying that although EPDM underwent some degree of the oxidation in these environments, the integrity of O-ring remained intact, reflected by the lack of permeation of the $\mathrm{Ca}$ ion through it.
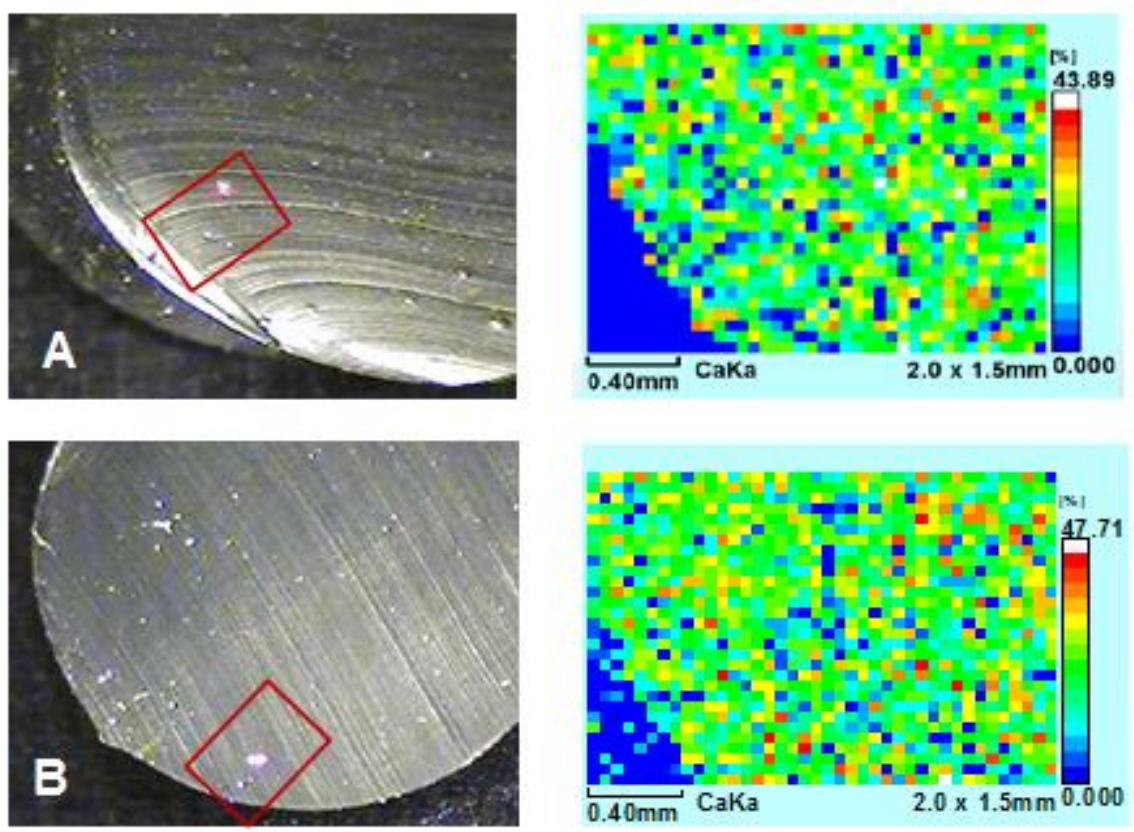

Figure 35. EDX mapping of Ca coupled with micro-structural images of the cross-sectional area of EPDM before (a), and after exposure in (b) No. 3 (drilling fluid).

\subsubsection{Type I FKM}

Figure 36 represents the alteration in morphologies and the $\mu$ EDX maps of the Ca for the crosssectional area marked with a red rectangle from the edge to the core of type I FKM O-rings before and after exposure in the No. 3 and No. 4 environments. For the control, all of the mapped area was occupied by dark- and light-blue colors, suggesting that the content of $\mathrm{Ca}$ in the "asreceived" type I FKM-made O-ring was very low, if at all present. Compared with the morphological image of the type II control (Figure 37), O-rings exposed to No. 3 and 4 had significant degradation. This degradation can be explained by the fact that a high amount of $\mathrm{Ca}$ (represented by the white- and red-colors) was detected throughout the entire $3.0 \mathrm{~mm}^{2}$ area of the No. 3-exposed O-ring. It appeared that a substantial amount of $\mathrm{Ca}$ ion had permeated deeply through the failed O-ring during exposure in the No. 3 drilling fluid. A deep permeation of $\mathrm{Ca}$ also was detected from the No. 4-exposed O-ring. However, the quantity of permeated Ca was less than that of No. 3, which can be ascertained from the green and yellow colors in No. 4 versus red and white for No. 3 . 

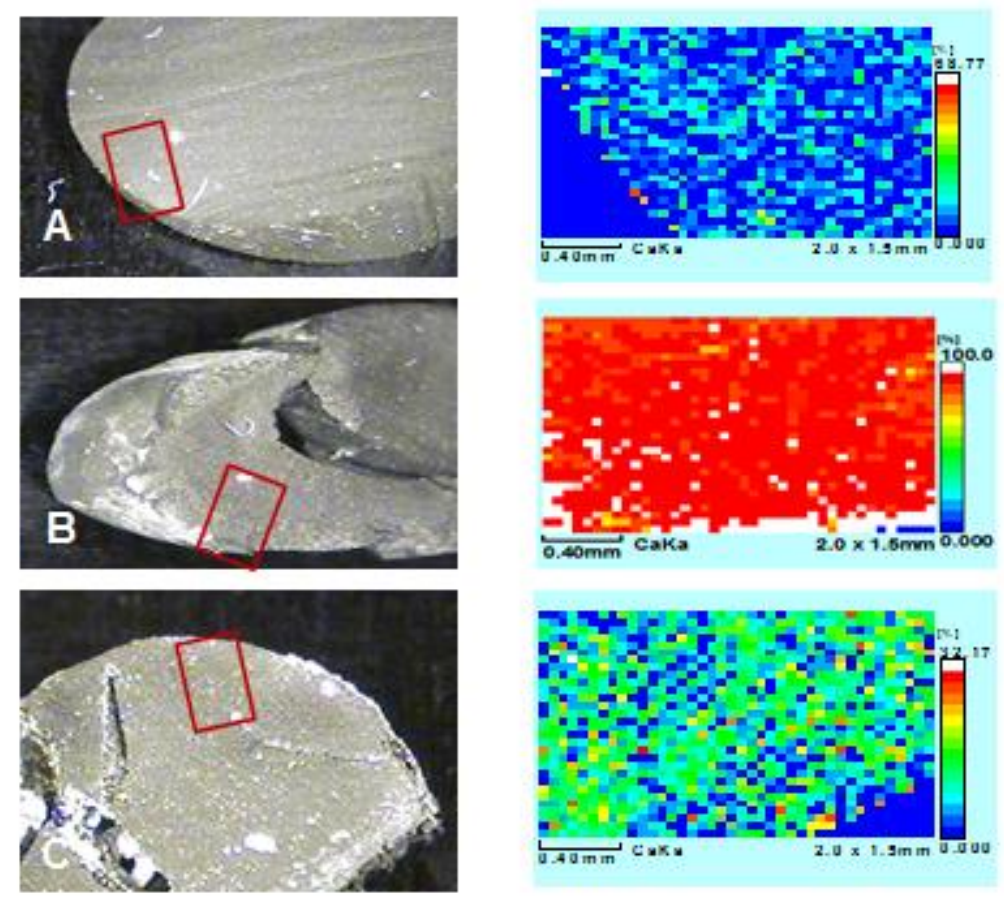

Figure 36. EDX mapping of Ca coupled with micro-structure images for cross-sectional area of type I FKM before (a) and after exposure in (b)No. 3 (drilling fluid), and (c) No. 4 (geo-brine fluid).

\subsubsection{Type II FKM}

Figure 37 shows the $\mu \mathrm{EDX}$ maps of $\mathrm{Ca}$ for the cross-sectional area marked with a red rectangle from the edge to the core of type II FKM O-rings before and after exposure in the No. 3 and No. 4 environments. The Ca mapping image of the "as-received" (control) O-ring showed that the material already contained some Ca elements, as indicated by the uniform distribution of whiteand red-color codes throughout the cross-sectional area. In contrast, for the O-ring exposed in the No. 3 environment, the morphological image revealed the creation of a rim-like layer structure in subsurface areas. Additionally, the micro-defects in the O-ring were observed in interfacial critical regions between the rim layer and the rest of O-ring body, demonstrating that the formation of this rim layer promoted structural damage in the O-ring. The Ca mapping image of this defect-laden area revealed relatively high concentration of $\mathrm{Ca}$, represented by the dense redcolor in the defective areas down to a depth of at least $0.4 \mathrm{~mm}$ from the top surfaces. The O-ring exposed in the No. 4 environment also created a rim layer in subsurface. However, this layer was thinner than that of No. 3, and no micro-defects were observed. Correspondingly, the distribution image of dense red-color is evident in a superficial layer of around $0.2 \mathrm{~mm}$ thick. Thus, the extent of type II FKM oxidation in No. 3 (drilling fluid) appeared to be much higher than that in No. 4 (geo-brine fluid). A higher oxidation rate can account for the deeper pervasion $(>0.4 \mathrm{~mm})$ 

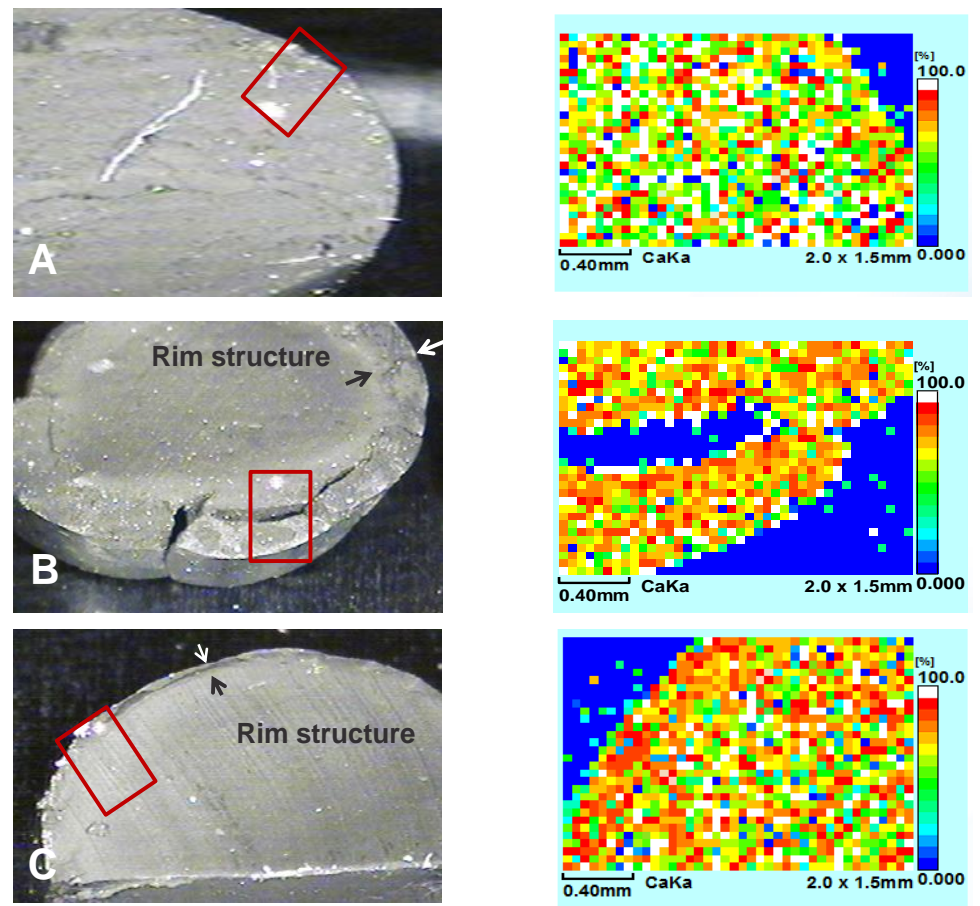

Figure 37. EDX mapping analysis of Ca coupled with images for cross-sectional area of type II FKM before (a), after exposed in (b)No. 3 (drilling fluid), and (c) No. 4 (geo-brine fluid).

of the $\mathrm{Ca}$ ion; namely, between a depth of $0.4 \mathrm{~mm}$ from the top surfaces to the top surface of $\mathrm{O}$ ring was oxidized. By contrast, the oxidation depth of the No .4-exposed O-ring was only in $\sim 0.2$ $\mathrm{mm}$. This evidence strongly supported the results from the FT-IR and TGA analyses. The creation of the oxidized outer layer of the materials is likely the result of diffusion limited oxidation (DLO). DLO occurs when the diffusion rate of oxygen into the material is slower than the oxidation reactions, thus limiting those reactions to the surface of the material. Determination of oxidation and permeation rates for these systems could be carried out to verify this phenomenon and also to predict material lifetimes, if there is interest.

\subsubsection{FEPM}

The same interpretations as those made for EPDM are applicable to the FEPM O-rings exposed in No. 3 and 4 environments. Namely, no micro-defects were observed from microstructure image analysis, nor had Ca ions permeated through the oxidized O-ring for No. 3 (Figure 38) and No. 4 (not shown) exposures, validating their excellent integrity under those conditions. 

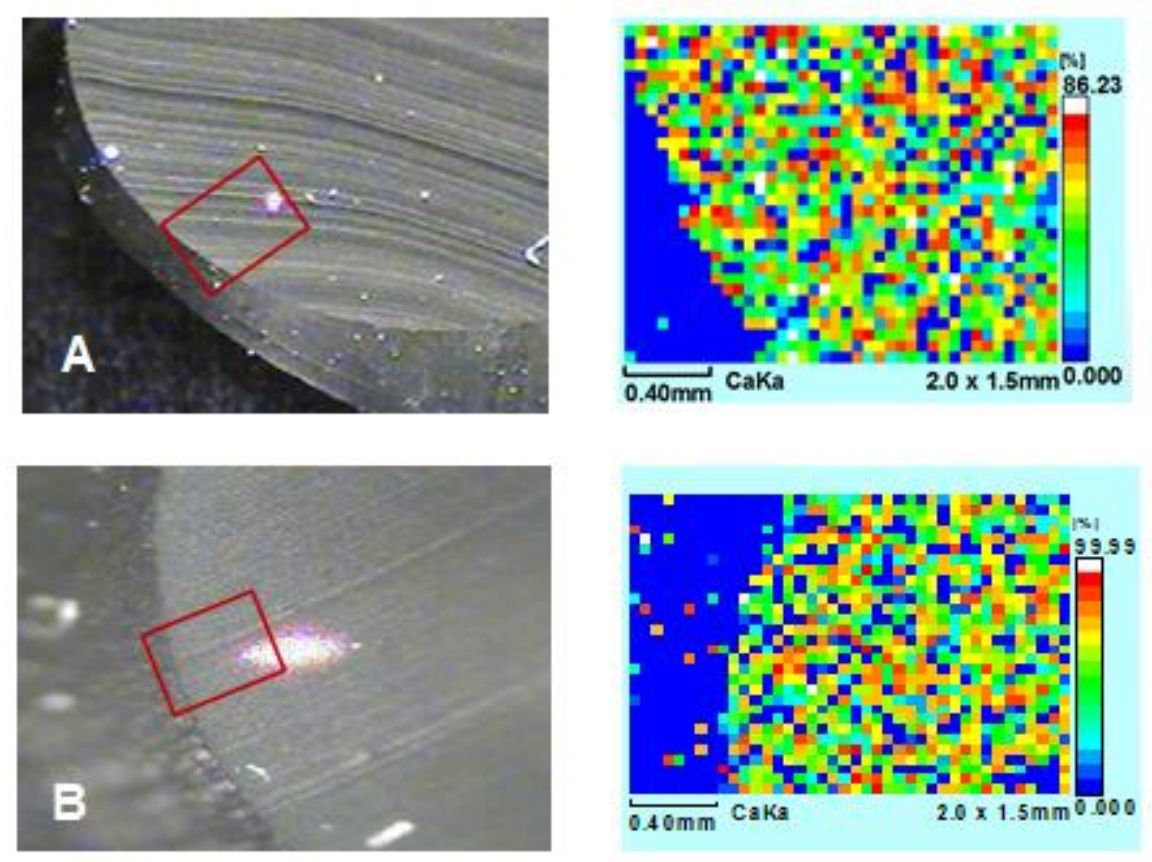

Figure 38. EDX mapping of Ca coupled with micro-structural images of the cross-sectional area of FEPM before (a) and after exposure in (b) No. 3 (drilling fluid).

\subsubsection{FFKM}

The Ca mapping image of the "as-received" FFKM O-ring revealed a Ca-free pattern. A similar chemical make-up was obtained from the No. 3 (not shown) and the No. 4 (Figure 39)-exposed O-rings, highlighting that $\mathrm{Ca}$ ions had not permeated the material. As expected, there were no micro-defects in these exposed O-rings. One interesting observation was the deposition of some Ca-based scales on the surface of the O-ring exposed to No. 4 (geo-brine fluid), suggesting that the outermost surface site of the FFKM copolymer might have undergone a physicochemical modification during the exposure in a hot geo-fluid. This fact strongly supported the results from our earlier ATR-FTIR study. This modified surface may have an affinity for the deposition of Ca scales, although there was no scientific evidence for this. If this assumption reasonable, then such scale deposition should be addressed as a potential drawback of FFKM, despite possessing an outstanding stability in all environments, because of the possibility of an accumulation of scales as a function of exposure time. 

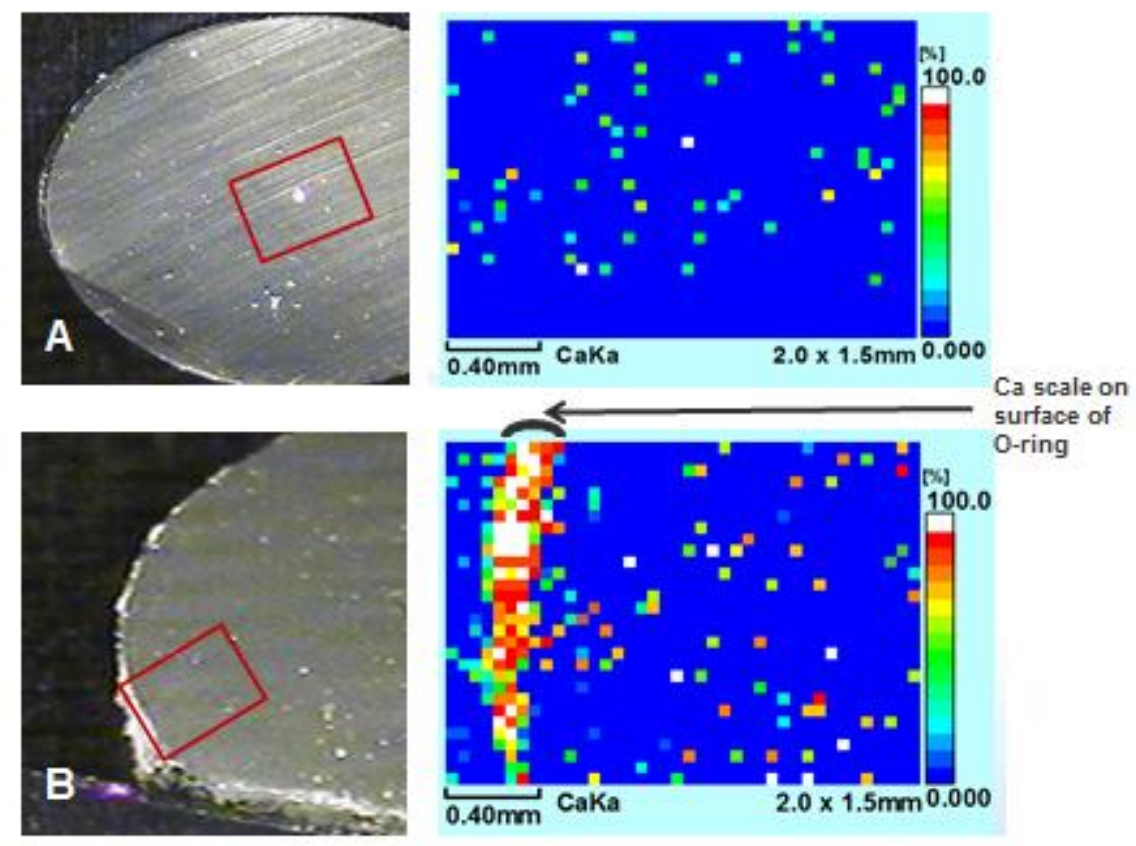

Figure 39. EDX mapping of Ca coupled with micro-structure images for a cross-sectional area of FFKM before (a) and after exposure in (b) No. 4 (geo-brine fluid).

\subsection{Modulus Profiling Analysis}

Modulus profiling was performed over O-ring cross-sections to look at changes in the inverse tensile compliance (i.e. elastic modulus) of materials after exposure to different environments. Of particular interest in any O-ring application are changes in elasticity, which could negatively impact sealing force (e.g. edge hardening and/or overall hardening or softening). In addition, modulus profiling can assist in elucidating mechanical property changes associated with DLO and correlating it to any chemical changes uncovered using $\mu$ EDX and FTIR.

\subsubsection{EPDM}

The average modulus of the unaged EPDM o-ring was determined to be 2.8 MPa (Figure 40). The steam tests (No. 1, non-aerated and 2, aerated) are shown in Figure 41 and Figure 42, respectively. In both cases, there was an overall slight decline in modulus throughout the O-ring, except at the outermost edge. This result indicates that the steam tests had a similar, small impact on the EPDM material. 


\section{Modulus Profile of O-ring Cross Section - Unaged}

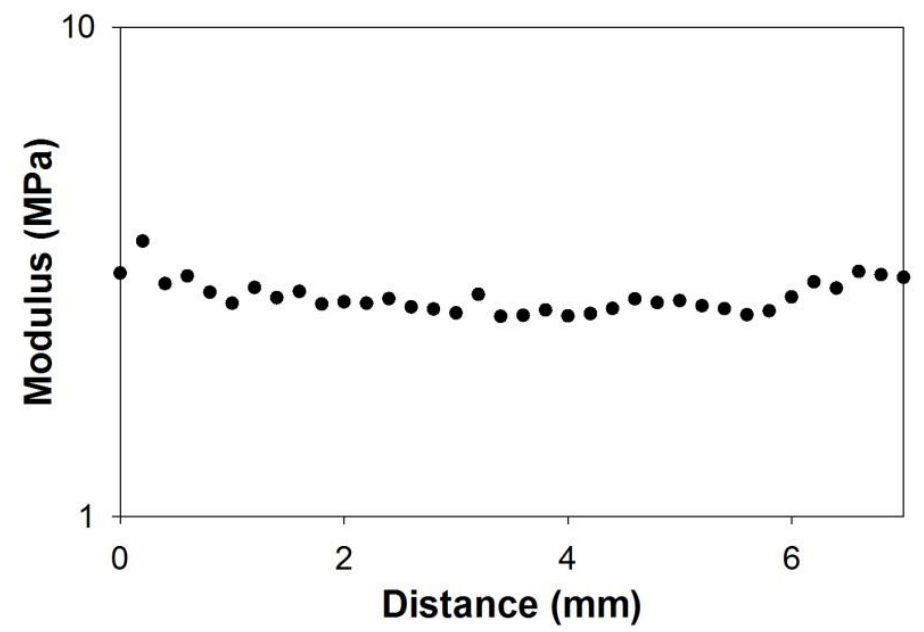

Figure 40. Modulus versus distance of an unaged EPDM O-ring cross section.

\section{Modulus Profile of O-ring Cross Section - Steam $/ \mathrm{N}_{2}$}

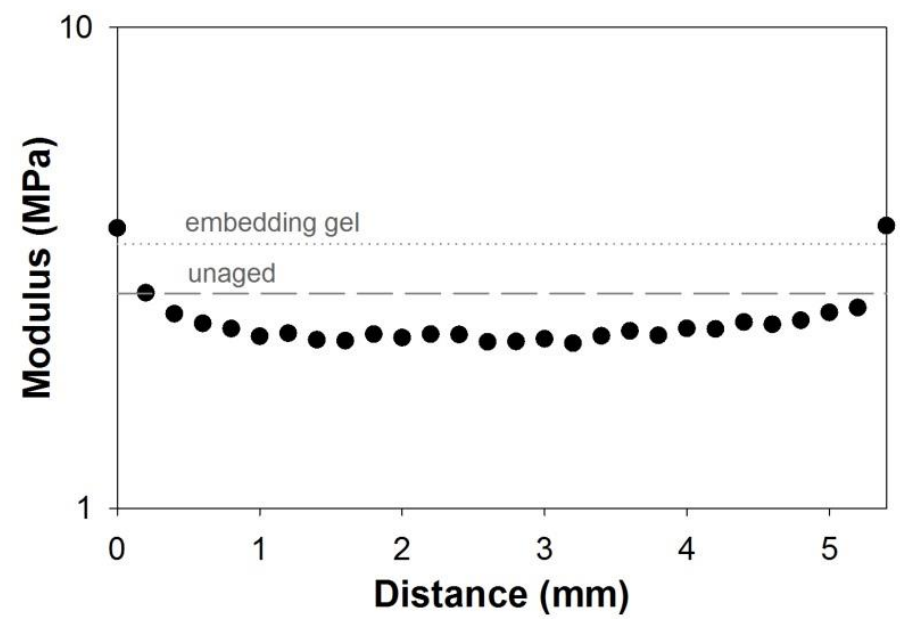

Figure 41. Modulus versus distance of an EPDM O-ring aged in the No. 1 environment. The dotted line indicates the modulus of the embedding material, while the modulus of the unaged (control) material is shown using a dashed line. 


\section{Modulus Profile of O-ring Cross Section - Steam/Air}

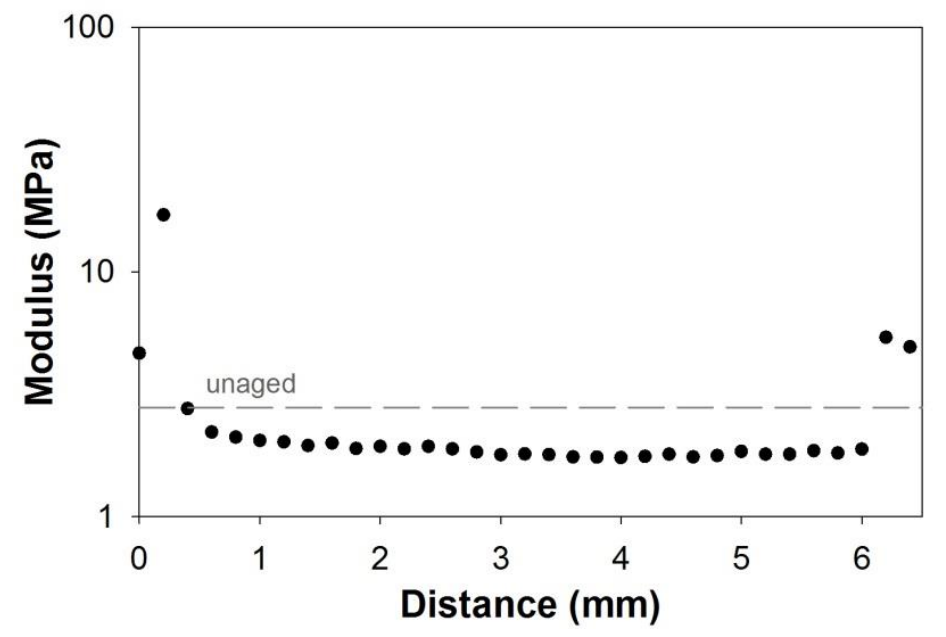

Figure 42. Modulus versus distance of an EPDM O-ring aged in the No. 2 environment. The dashed line shows the modulus of the unaged (control) material.

After aging in the drilling fluid (No. 3), the O-ring appeared to have little change in surface appearance (Figure 43). However, the O-ring did exhibit a slight drop in modulus over the majority of the cross section ( 2.2 MPa). Figure 44 shows the modulus profile of the EPDM Oring cross section after aging under the No. 4 (brine solution) conditions. While the overall modulus of the material increased to $7-9 \mathrm{MPa}$, the inset in Figure 44 shows little change on the surface of the EPDM after the aging experiment. These results indicate that EPDM is relatively stable in the No. 3 environment, but has a susceptibility to No. 4, substantiating the findings reported earlier. A profile of the No. 5 (thermal shock) environment was not conducted as the material was essentially disintegrated following that test. 


\section{Modulus Profile of O-ring Cross Section in Drilling Fluid}

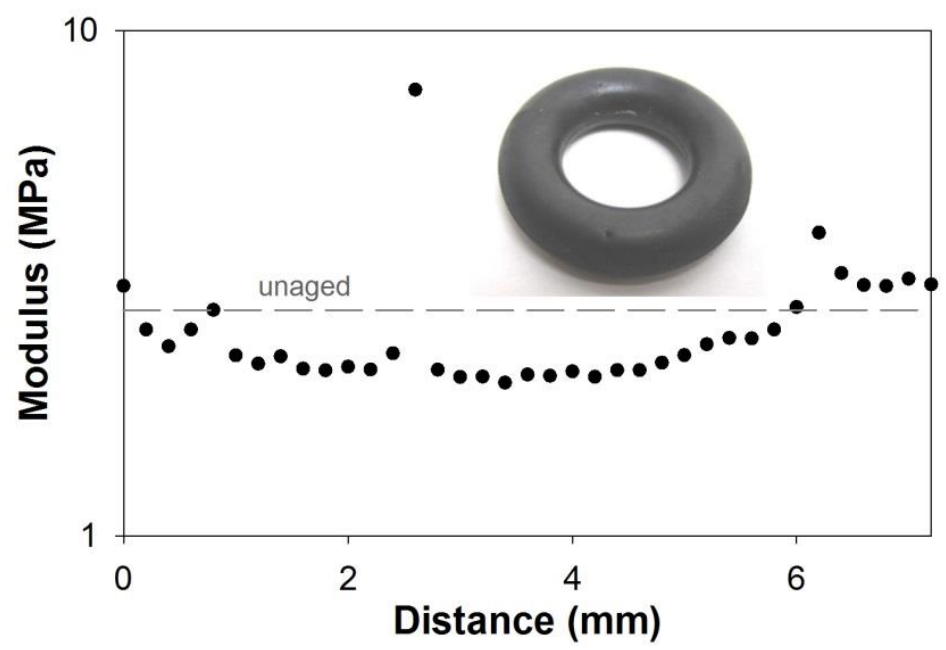

Figure 43. Modulus versus distance of an EPDM O-ring aged in drilling fluid. The inset picture shows the O-ring after aging.

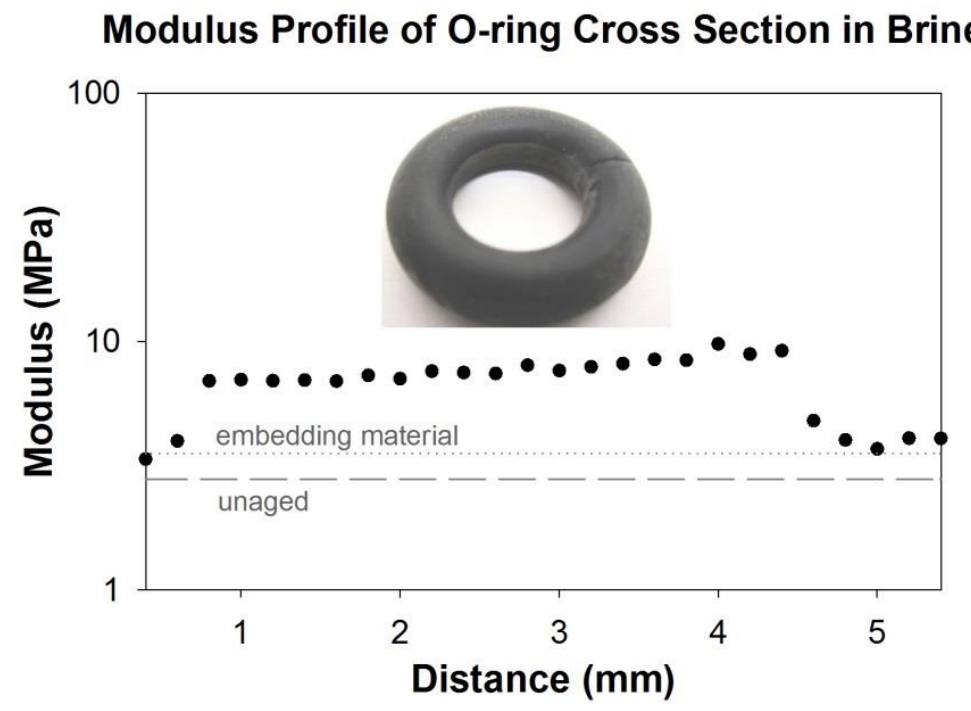

Figure 44. Modulus versus distance of an EPDM O-ring aged in brine. The inset picture shows the O-ring after aging. Modulus of the embedding material is depicted using a dotted line, while the modulus of the unaged (control) material is shown using a dashed line.

\subsubsection{Type I FKM}

Type I FKM had an average modulus of 1.7 MPa across the profile of the material (Figure 45). No. 1 and 2 environments (Figure 46 and Figure 47, respectively) both resulted in significant edge hardening of the material, along with a slight softening of the interior. These data support 
the TG and DTG analyses that also indicated type I FKM had poor resistance to both the aerated and non-aerated steam-cooling cycles.

Modulus Profile of O-ring Cross Section - Unaged

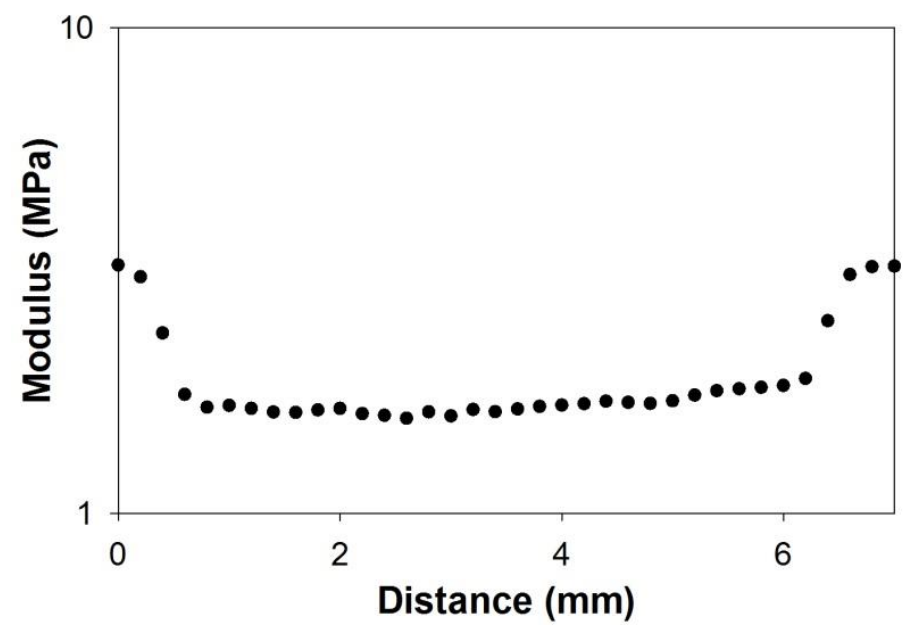

Figure 45. Modulus versus distance of an unaged Type I FKMO-ring cross section.

\section{Modulus Profile of O-ring Cross Section - Steam $/ \mathrm{N}_{2}$}

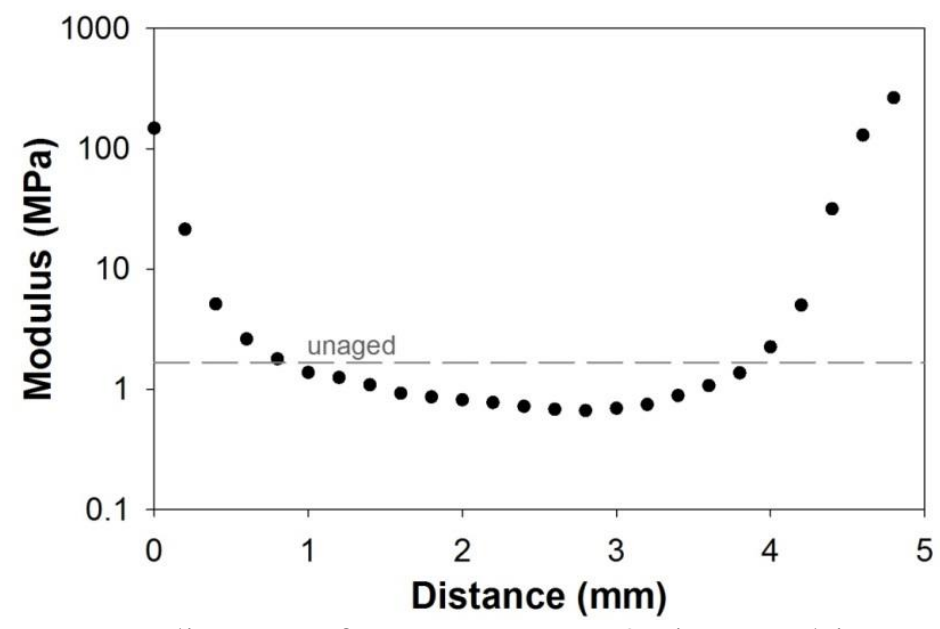

Figure 46. Modulus versus distance of a type I FKM O-ring aged in No. 1 (non-aerated, filled circles) along with average unaged modulus (dashed line). 


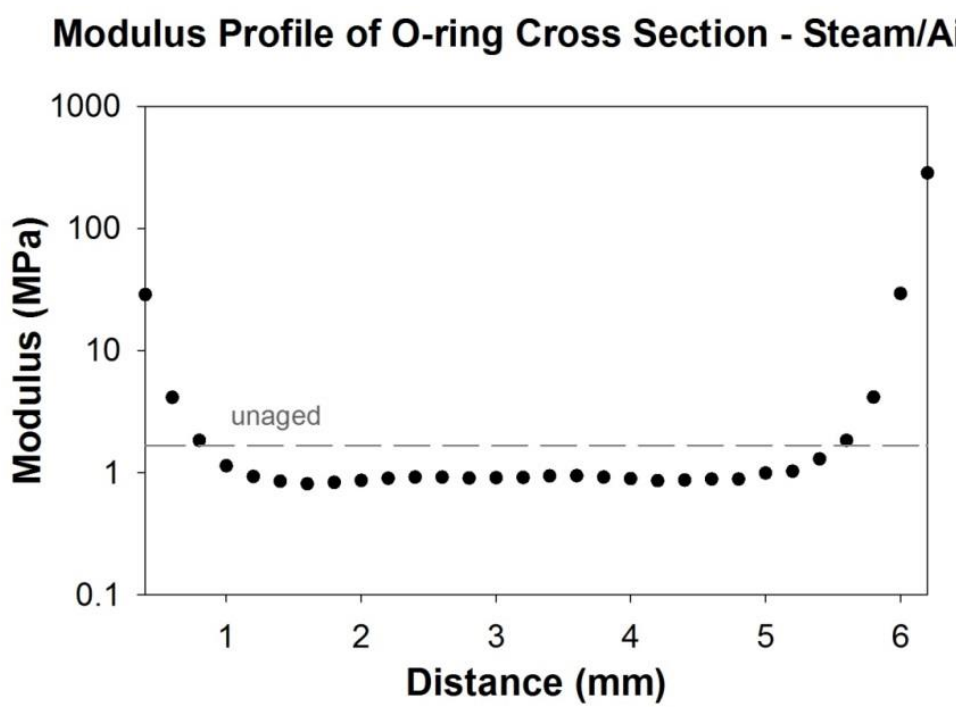

Figure 47. Modulus versus distance of a type I FKM O-ring aged in No. 2 (aerated, filled circles) along with average unaged modulus (dashed line).

Figure 48 shows the modulus profile of the O-ring cross section of type I FKM after aging in the drilling fluid (No. 3). From this graph, it is clear that a slight increase in the overall modulus from 1.6 to $2.8 \mathrm{MPa}$; also apparent is significant edge hardening (over $100 \mathrm{MPa}$ ). The inset picture of the O-ring shows that the material broke apart after aging and also that flaking of the material from the surface occurred. Thus, under these conditions, type I FKM would not be a suitable O-ring material. However, in cases where the surface integrity is not important (i.e. where bulk properties are more relevant) or at lower temperatures, this material may be useful. Note that FKM materials are not typically recommended for applications exceeding $\sim 200^{\circ} \mathrm{C}$.

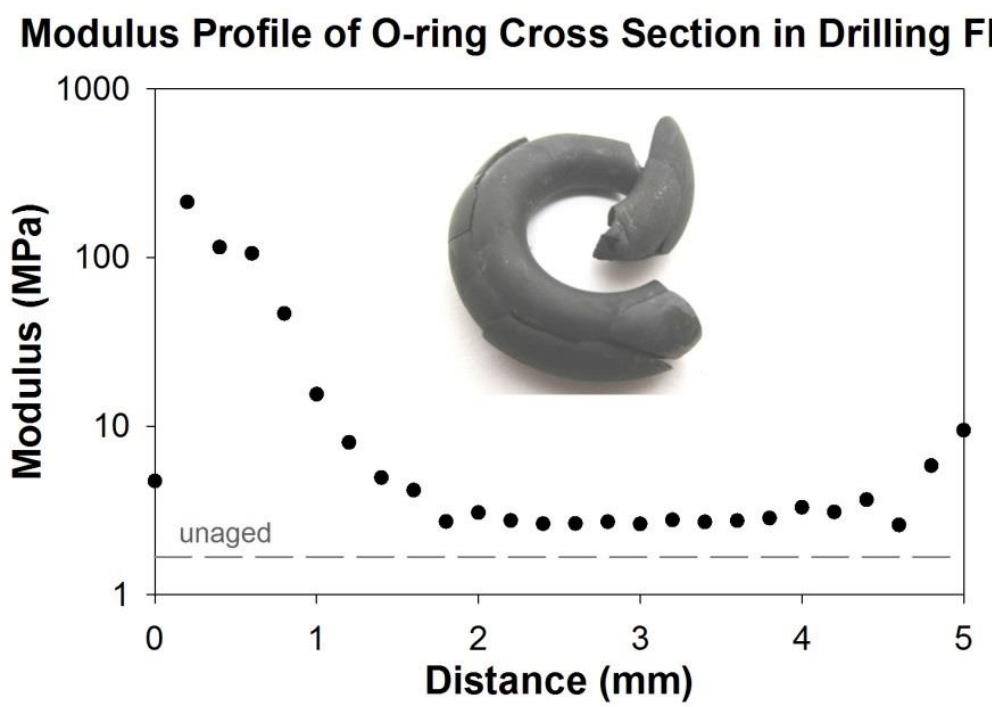

Figure 48. Modulus versus distance of a type I FKM O-ring aged in drilling fluid (filled circles) along with average unaged modulus (dashed line). The inset picture shows the O-ring after aging. 
Aging type I FKM at elevated temperatures and pressures in the brine solution (No. 4) caused flaking and scale deposition on the O-ring surface (Figure 49). Figure 49 additionally illustrates an overall increase in modulus of the material, with edge hardening effects. This edge hardening is likely what is causing the outer surface material to flake off and is similar to what was observed with the drilling fluid solution.

Thermal cycle aging of type I FKM resulted in an overall decrease in the modulus (c.a. 0.3 MPa) of the inner portion of the O-ring along with edge hardening (Figure 50). Furthermore, discoloration on the surface of the O-ring was noted (Figure 50) but no flaking was evident.

\section{Modulus Profile of O-ring Cross Section in Brine}

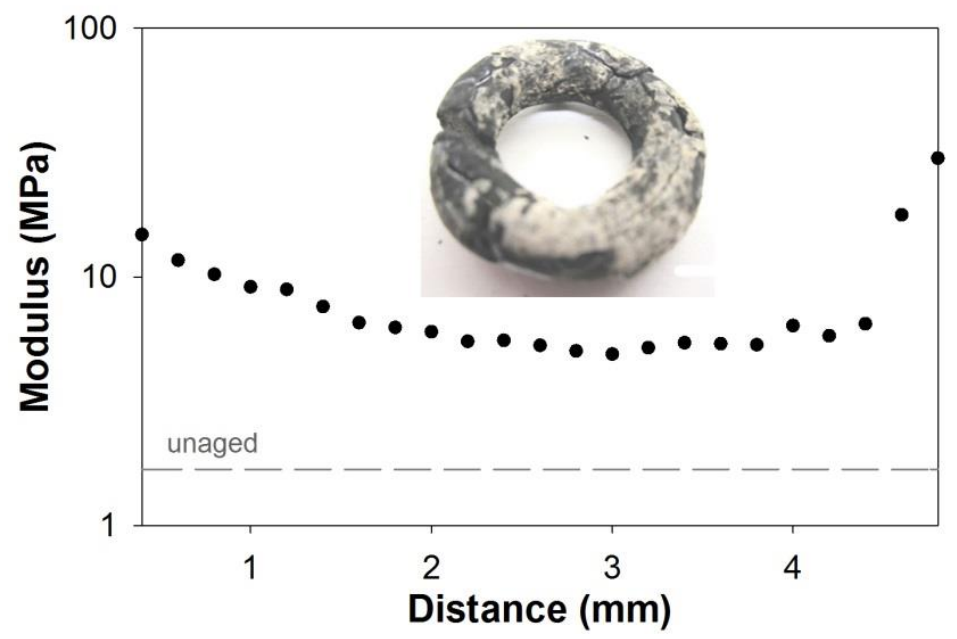

Figure 49. Modulus versus distance of a type I FKM O-ring aged in brine (filled circles) along with average unaged modulus (dashed line). The inset picture shows the O-ring after aging.

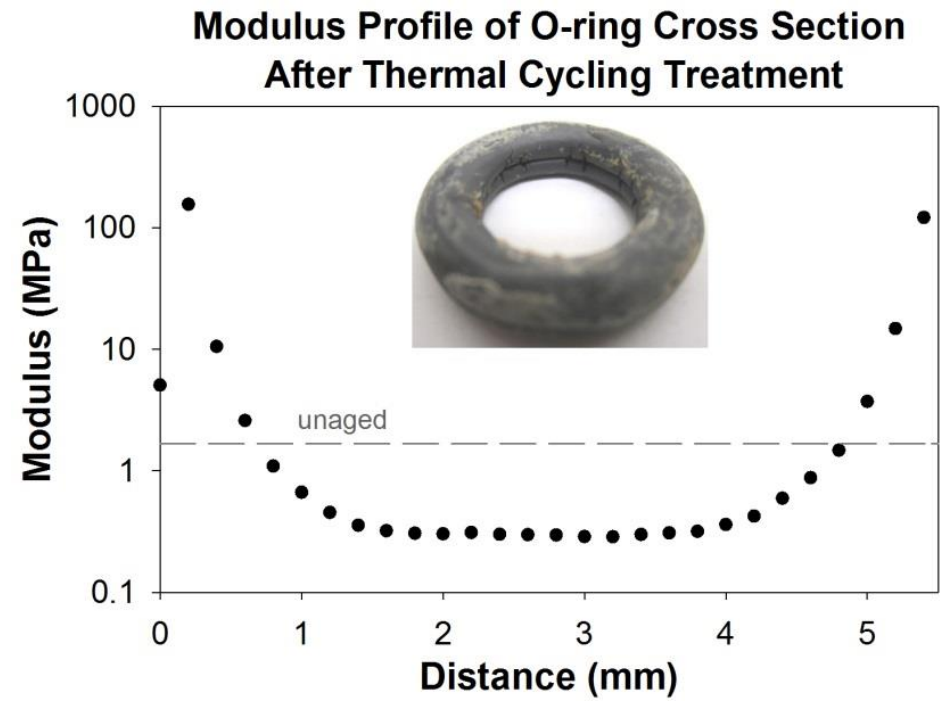

Figure 50. Modulus versus distance of a type I FKM O-ring aged using the thermal cycle test (filled circles) along with average unaged modulus (dashed line). The inset picture shows the Oring after aging. 


\subsubsection{Type II FKM}

The modulus of the unaged type II FKM sample was approximately 3.0 MPa (Figure 51). After exposure to the No. 1 environment, the material behaved similarly to type I FKM, in that edge hardening with internal softening was evident. No. 2 aging had a rather unique profile resembling a "W". The edges of the material showed slight hardening, followed by a large dip in modulus to the lowest overall value of approximately $0.8 \mathrm{MPa}$. As the probe moved closer to the interior, the modulus increased to about $2 \mathrm{MPa}$ before again declining to an average of $\sim 1.5 \mathrm{MPa}$ in the interior; this preceded another increase to c.a. $2 \mathrm{MPa}$, another decrease to $0.8 \mathrm{MPa}$ and final increase as the other edge of the O-ring was reached. As with type I FKM, type II was also susceptible to Nos. 1 and 2 aging conditions; however, which material fared better is difficult to ascertain from these plots alone.

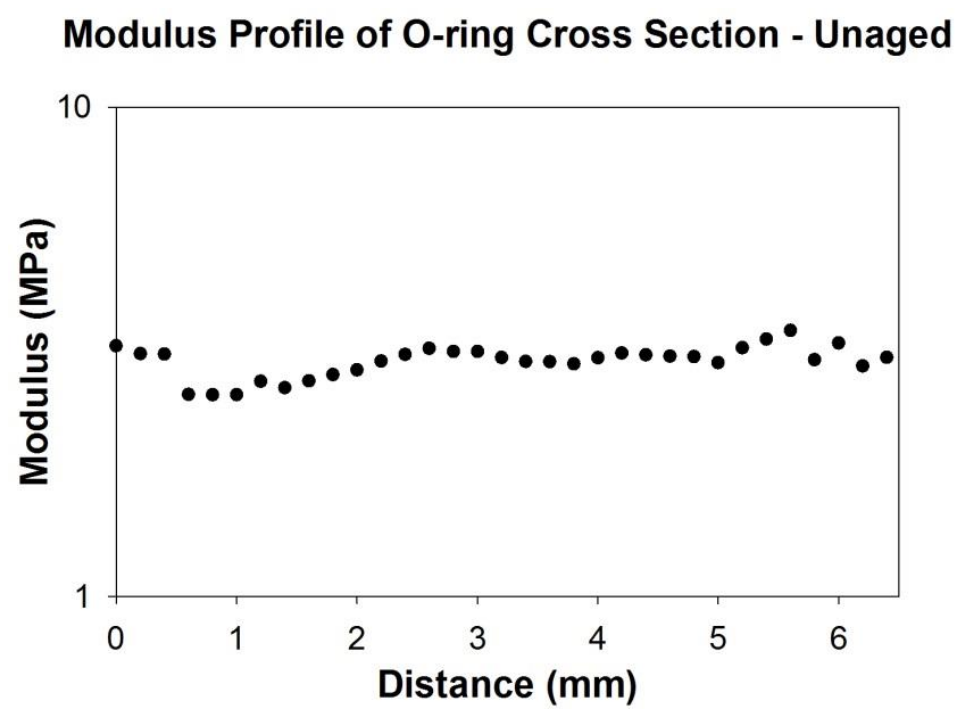

Figure 51. Modulus versus distance of an unaged type II FKM O-ring cross section. 

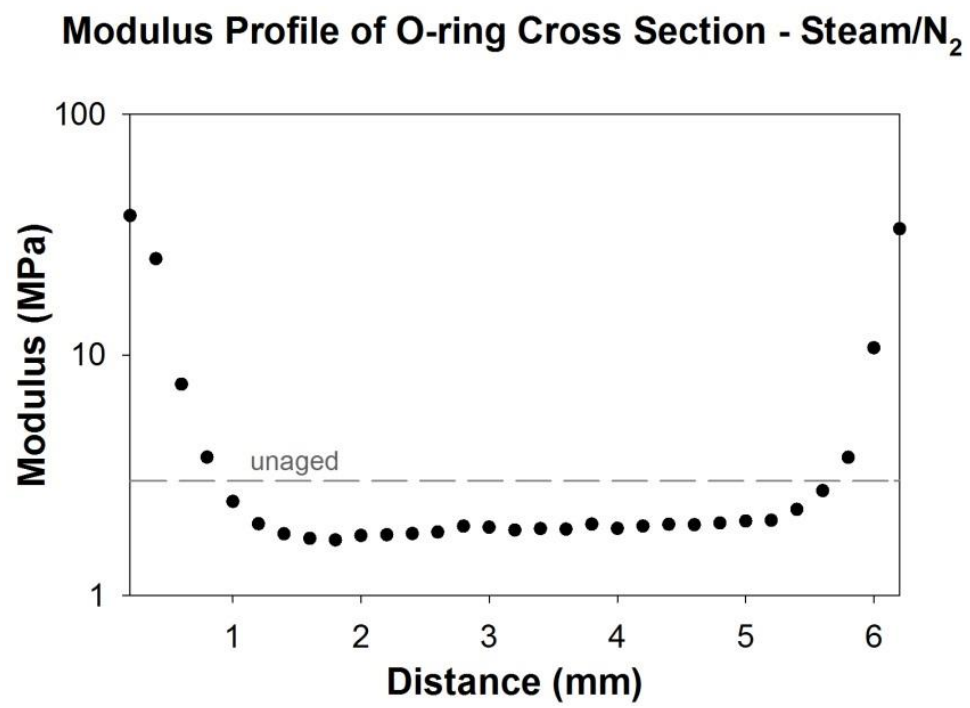

Figure 52. Modulus versus distance of a type II FKM O-ring aged in No. 1 (non-aerated, filled circles) along with average unaged modulus (dashed line).

\section{Modulus Profile of O-ring Cross Section - Steam/Air}

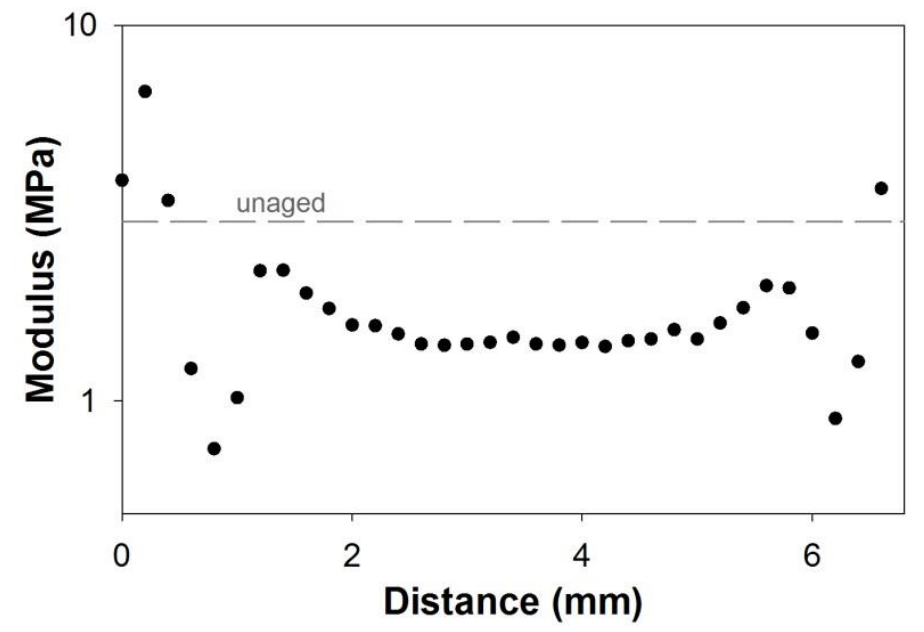

Figure 53. Modulus versus distance of a type II FKM O-ring aged in No. 2 (aerated, filled circles) along with average unaged modulus (dashed line).

Submergence in No. 3, drilling fluid, at elevated temperature and pressure caused an overall decrease in the interior modulus of the O-ring - down to roughly $1 \mathrm{MPa}$; edge hardening with subsequent flaking of the material surface is also apparent (Figure 54). As with aging in drilling fluid, exposing type II FKM to brine caused a decrease of the overall modulus of the material (c.a. $2 \mathrm{MPa}$ ) at the interior of the O-ring while the exterior exhibited edge hardening effects (Figure 55); material flaking off of the outer surface of the O-ring was less prominent in brine (No. 4) than drilling fluid (No. 3). 


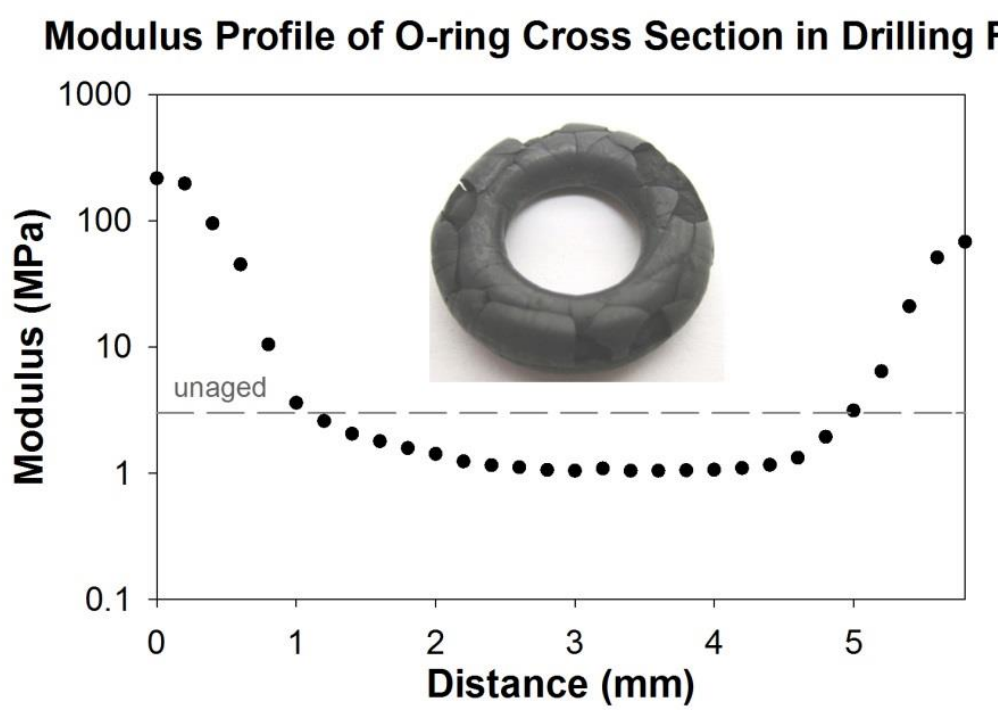

Figure 54. Modulus versus distance of a type II FKM O-ring aged in No. 3, drilling fluid (filled circles) along with average unaged modulus (dashed line). The inset picture shows the O-ring after aging.

\section{Modulus Profile of O-ring Cross Section in Brine}

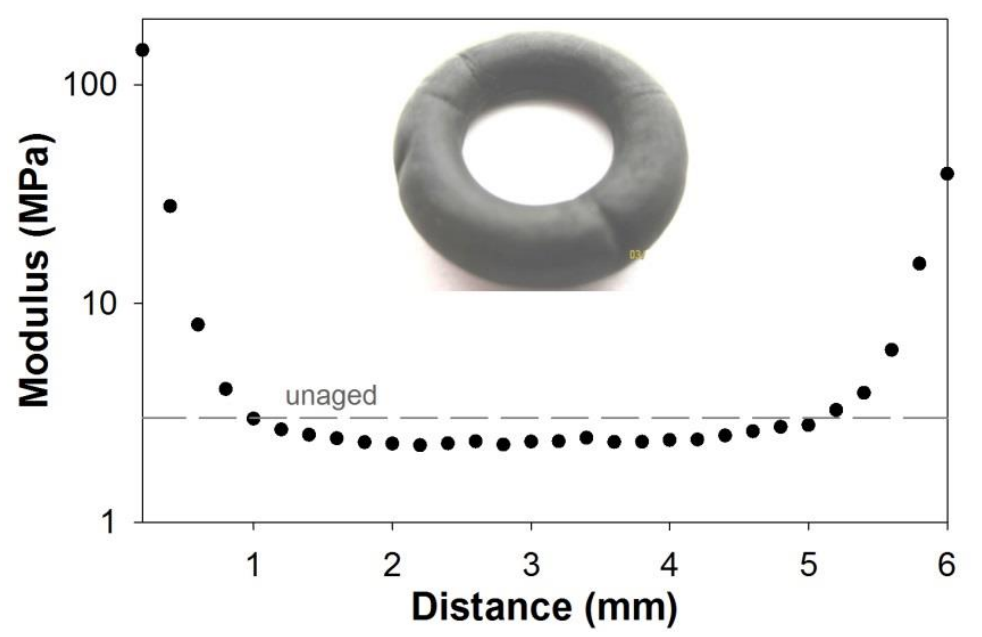

Figure 55. Modulus versus distance of a Type II FKM O-ring aged in No. 4, brine (filled circles) along with average unaged modulus (dashed line). The inset picture shows the O-ring after aging.

Thermal cycle aging of the type II FKM O-ring saw the largest decrease in overall internal modulus of the material, with measurements as low as $0.5 \mathrm{MPa}$ (Figure 56) while the modulus of the outer edges of the O-ring remained at about 3.0 MPa, which is consistent with unaged material. This material also had an unusual "W" type feature, where the modulus decreased to a minimum before increasing to a secondary maximum ( 0.7 MPa), then decreasing to the minimum before again increasing to a value near the unaged material. The Figure 56 inset shows 
some discoloration of the O-ring following the thermal cycling. As with type I FKM, this material should be considered unsuitable, under the aging conditions studied herein, for applications where surface properties and modulus must be maintained.

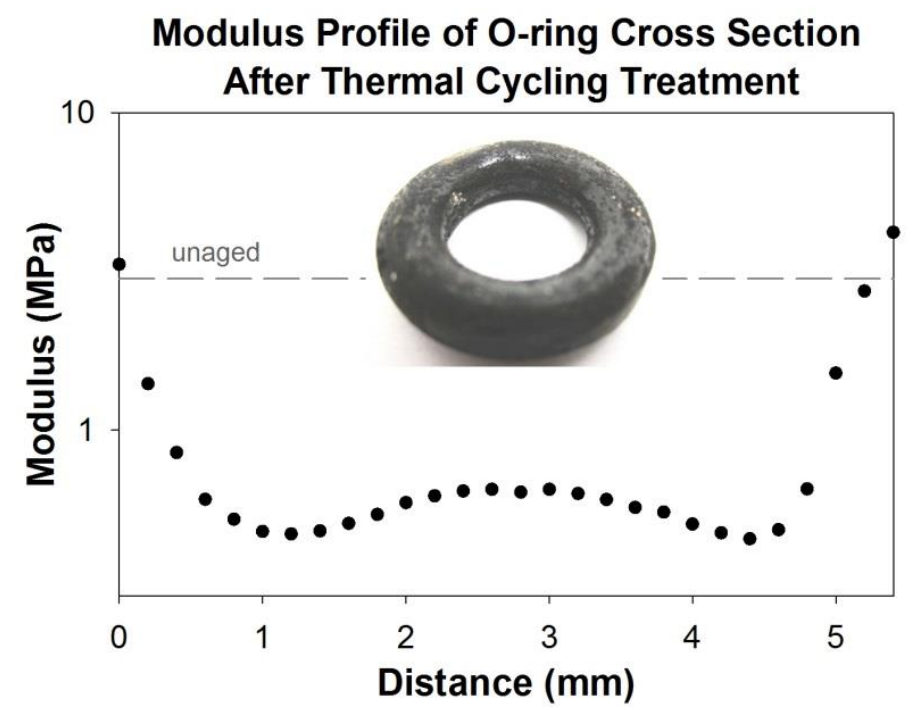

Figure 56. Modulus versus distance of a type II FKM O-ring aged using the thermal cycle test (filled circles) along with average unaged modulus (dashed line). The inset picture shows the Oring after aging.

\subsubsection{FEPM}

FEPM was determined to have an average modulus of $13.5 \mathrm{MPa}$ (Figure 57). This is the highest modulus of all of the unaged materials tested. After exposure to Nos. 1 and 2 environments the O-ring experienced no change in the modulus profile (Figure 58 and Figure 59, respectively). The slight decrease around $2.5 \mathrm{~mm}$ in Figure 59 was attributed to a slight tear that was created during sample preparation. 


\section{Modulus Profile of O-ring Cross Section - Unaged}

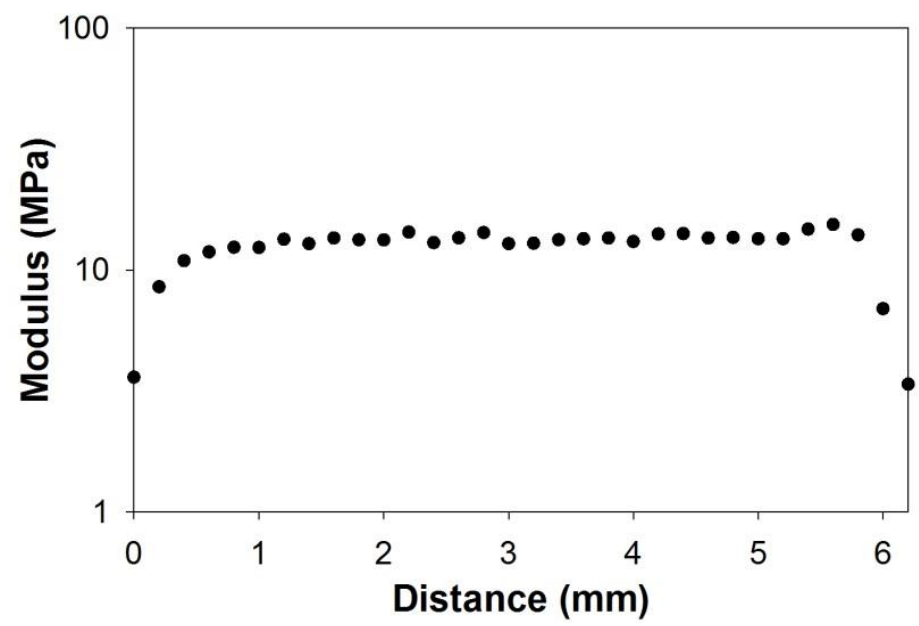

Figure 57. Modulus versus distance of an unaged FEPM O-ring cross section.

Modulus Profile of O-ring Cross Section - Steam $/ \mathrm{N}_{2}$

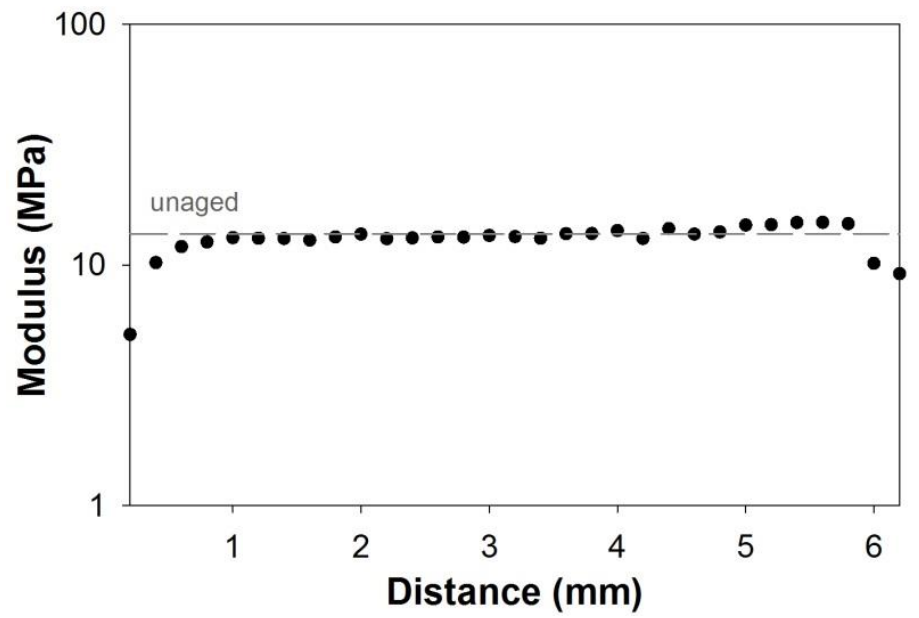

Figure 58. Modulus versus distance of an FEPM O-ring aged in No. 1 (non-aerated, filled circles) along with average unaged modulus (dashed line). 


\section{Modulus Profile of O-ring Cross Section - Steam/Air}

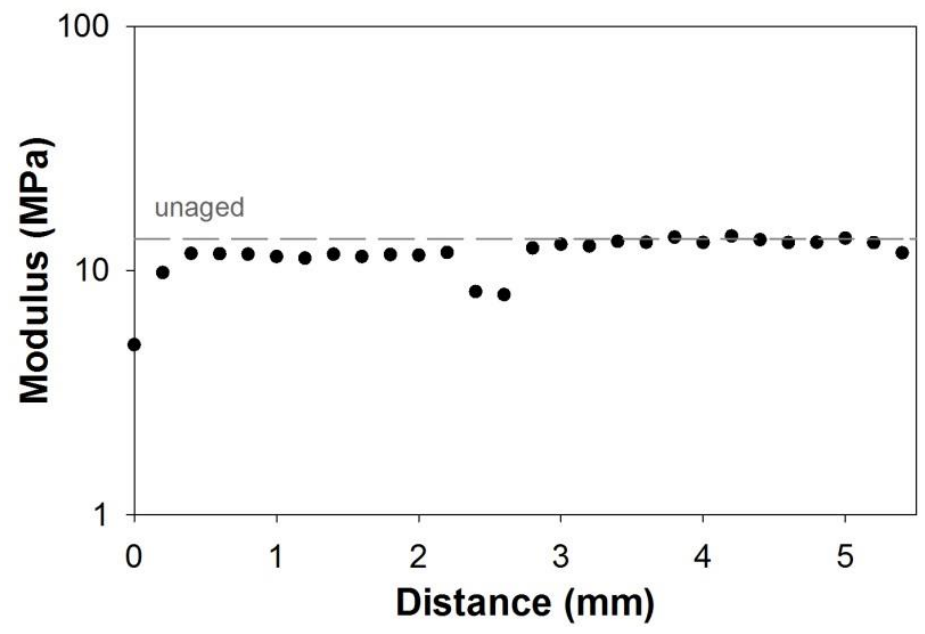

Figure 59. Modulus versus distance of an FEPM O-ring aged in No. 2 (aerated, filled circles) along with average unaged modulus (dashed line). The dip around $2.5 \mathrm{~mm}$ is due to a tear that occurred during sample preparation.

Aging in No. 3 drilling fluid (Figure 60) and No. 4 brine (Figure 61) also saw little to no change in the modulus of the O-rings with only slight surface discoloration (Figure 60 and Figure 61, insets). The thermal shock test created significant edge hardening in the O-ring, with material flaking off of the surface (Figure 62). In all cases, a slight edge softening may have occurred. However, this could also be an artifact of the interface between the FEPM and embedding material.

\section{Modulus Profile of O-ring Cross Section in Drilling Fluid}

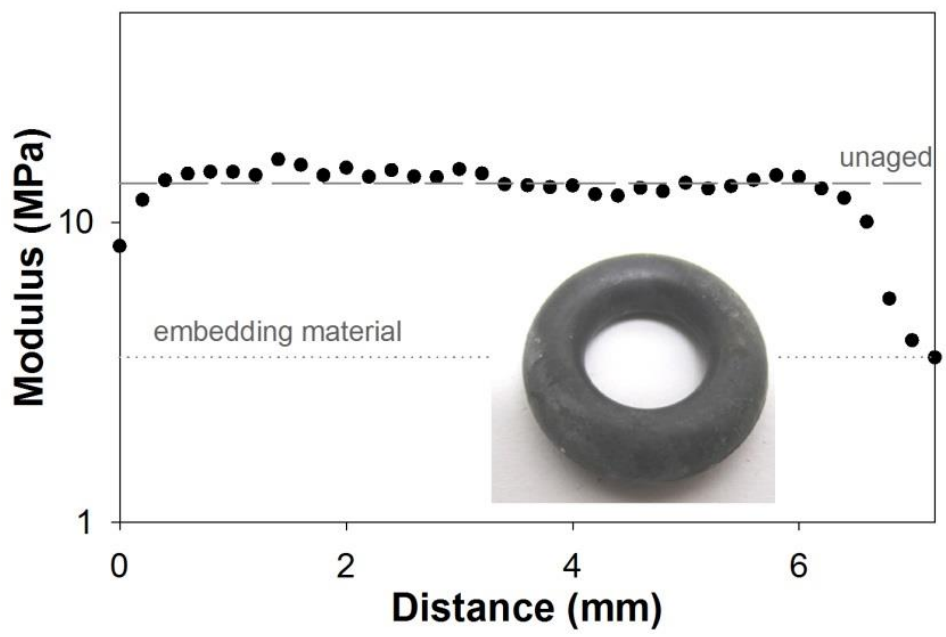

Figure 60. Modulus versus distance of an FEPM O-ring aged in drilling fluid (filled circles) along with average unaged modulus (dashed line) and the modulus of the embedding material (dotted line). The inset picture shows the O-ring after aging. 
FEPM is the second most expensive material in this study, at nearly six times the price of EPDM. However, this material fared very well under the brine and drilling fluid aging conditions. FEPM is a good alternative to EPDM for high temperature applications in which the environments are similar to that of the brine and drilling fluid tests. However, the material did show susceptibility to thermal shock and is not recommended for those types of uses.

Modulus Profile of O-ring Cross Section in Brine

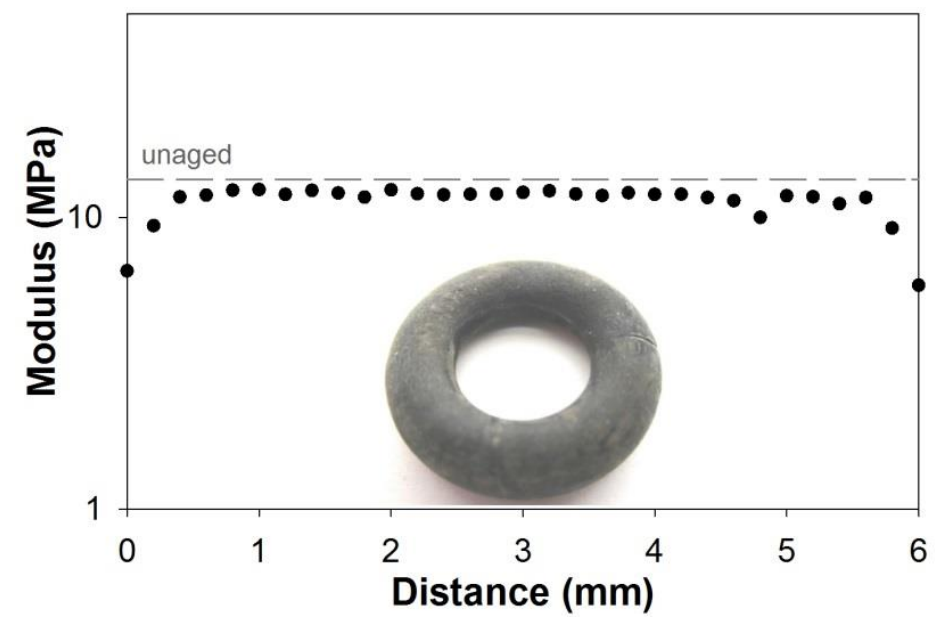

Figure 61. Modulus versus distance of an FEPM O-ring aged in brine (filled circles) along with average unaged modulus (dashed line). The inset picture shows the O-ring after aging.

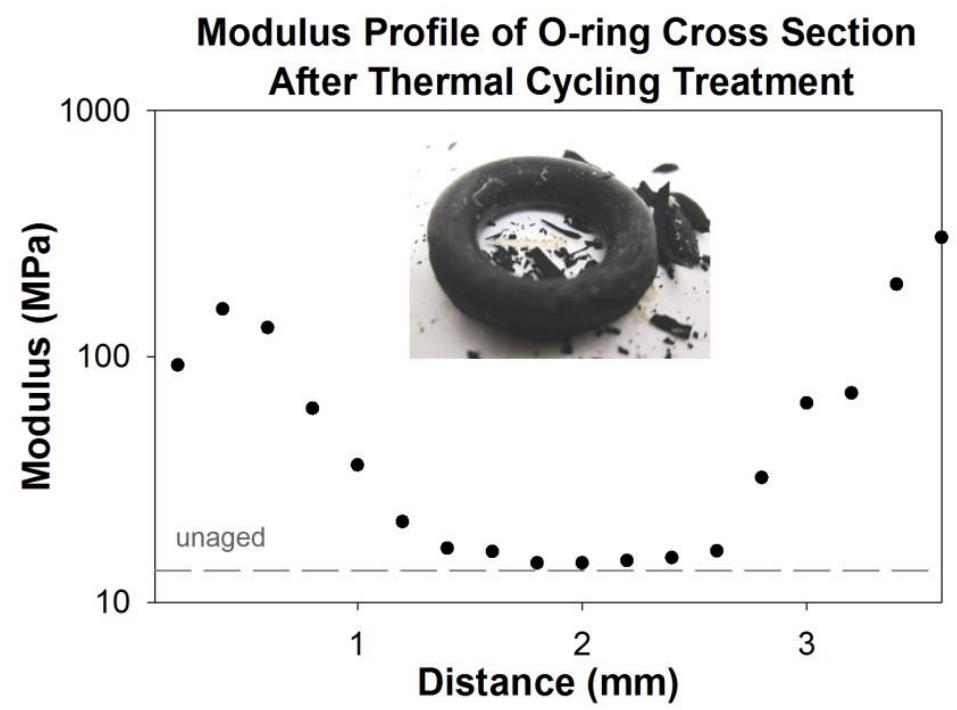

Figure 62. Modulus versus distance of an FEPM O-ring aged using the thermal cycle test (filled circles) along with average unaged modulus (dashed line). The inset picture shows the O-ring after aging. 


\subsubsection{FFKM}

Figure 63 shows the modulus profile of an unaged FFKM O-ring, which has an average modulus across the thickness of 5.1 MPa (Figure 63). Both non-aerated (No. 1, Figure 64) and aerated (No. 2, Figure 65) steam-cooling tests showed a slight decline in the overall modulus of the FFKM material. Note that the sample from No. 1 exposure (Figure 64) tore during sample preparation, which is seen in the figure as the dip in modulus around $3 \mathrm{~mm}$; this feature is indicated on the figure.

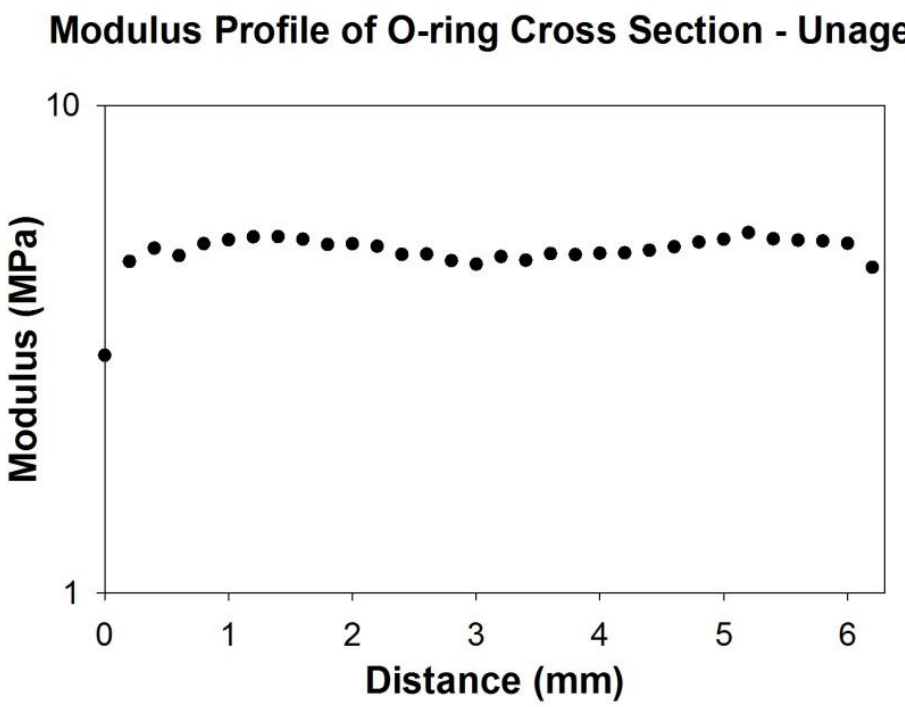

Figure 63. Modulus versus distance of an unaged FFKM O-ring cross section.

Modulus Profile of O-ring Cross Section - Steam $/ \mathrm{N}_{2}$

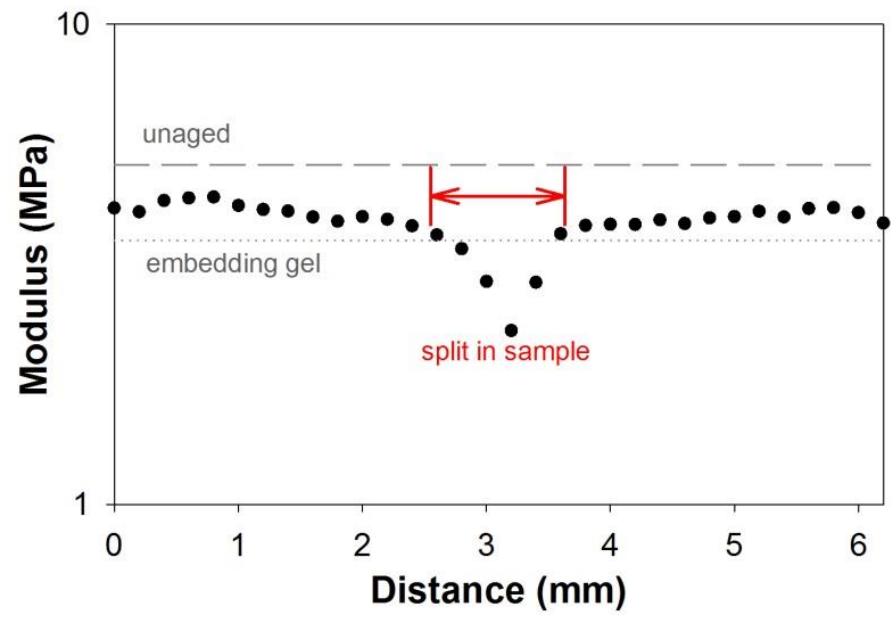

Figure 64. Modulus versus distance of an FFKM O-ring aged in No. 1 (non-aerated, filled circles) along with average unaged modulus (dashed line) and embedding gel modulus (dotted line). 


\section{Modulus Profile of O-ring Cross Section - Steam/Air}

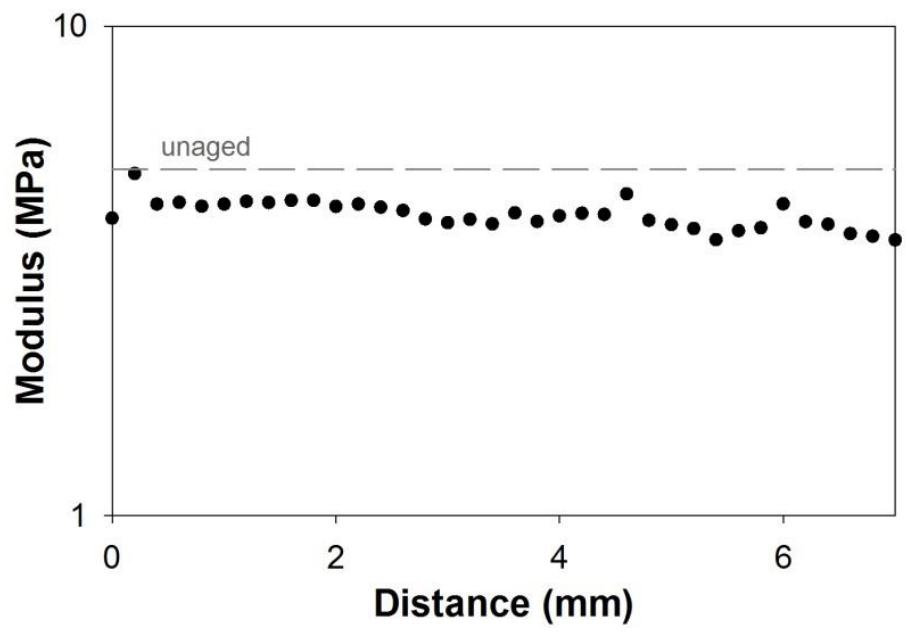

Figure 65. Modulus versus distance of an FFKM O-ring aged in No. 2 (aerated, filled circles) along with average unaged modulus (dashed line).

A slight softening at the interior of the O-ring was observed after aging in brine (Figure 66) and no scaling or change in appearance to the outer surface of the material was found (Figure 66, inset picture). Contrarily, a slight increase in modulus was observed across the entire O-ring after brine aging (Figure 67), and yellowish deposits/discoloration appeared on the outer surface. The thermal cycle test saw very little change in the overall modulus, with some very slight softening at the edges (Figure 68). White deposits were also found on the O-ring surface after this test was complete (Figure 68, inset).

Modulus Profile of O-ring Cross Section in Drilling Fluid

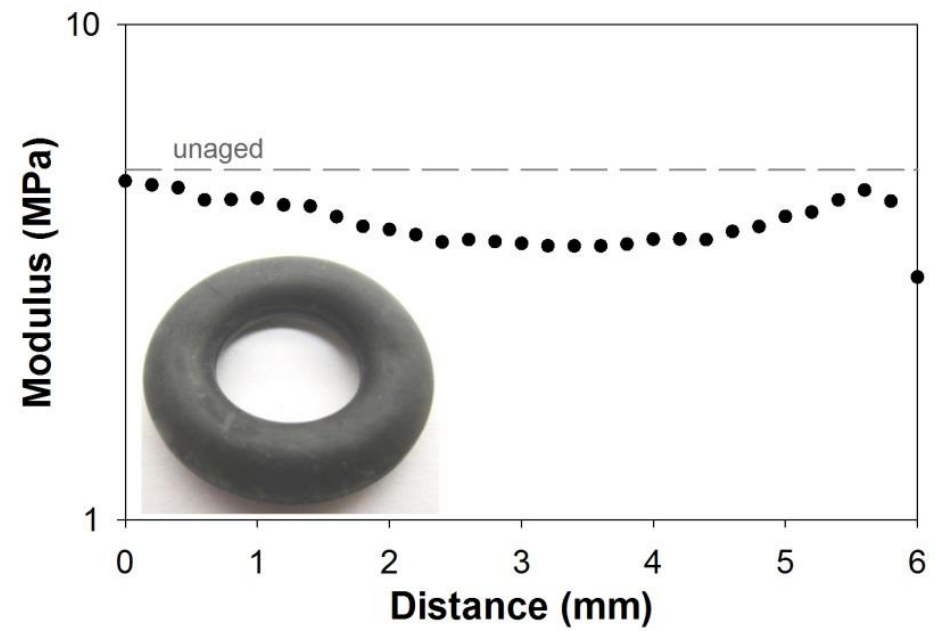

Figure 66. Modulus versus distance of an FFKM O-ring aged in drilling fluid (filled circles) along with average unaged modulus (dashed line). The inset picture shows the O-ring after aging. 
While FFKM is the most expensive of the materials investigated in this study, at nearly 14 times the cost of EPDM, it also was able to survive all five test conditions with little to no change in modulus. Thus, FFKM would be the best choice for geothermal applications out of all of the materials studied if the cost is not prohibitive.

Modulus Profile of O-ring Cross Section in Brine

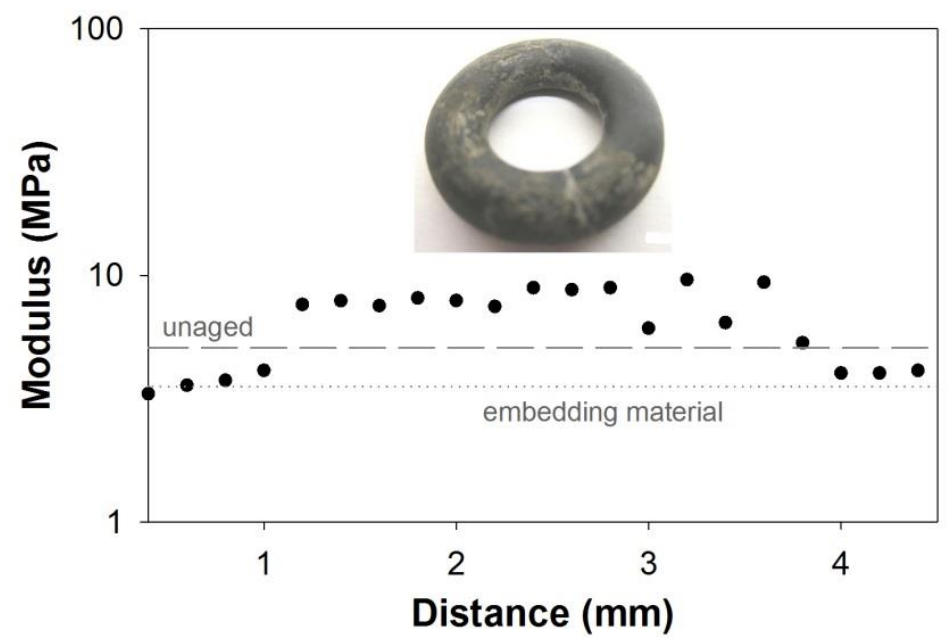

Figure 67. Modulus versus distance of an FFKM O-ring aged in brine (filled circles) along with average unaged modulus (dashed line) and the modulus of the embedding material (dotted line). The inset picture shows the O-ring after aging.

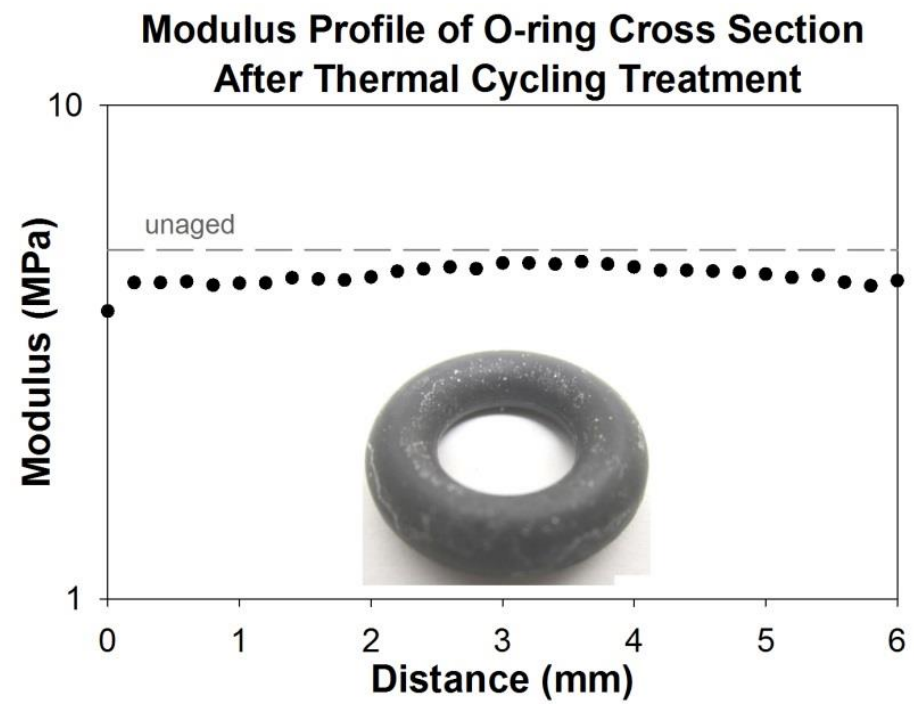

Figure 68. Modulus versus distance of an FFKM O-ring aged using the thermal cycle test (filled circles) along with average unaged modulus (dashed line). The inset picture shows the O-ring after aging. 


\section{Conclusions}

O-rings made with six different elastomeric polymers (EPDM, type I- and II-FKM, FEPM, FFKM, and FSR, were exposed in five different environments at $300^{\circ} \mathrm{C}$ : 1) Non-aerated steamcooling cycles, 2) aerated steam-cooling cycles, 3) drilling fluid with $\mathrm{pH} 9-10,4) \mathrm{CO}_{2}$-rich geo-

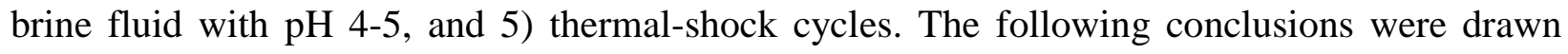
from the post-test analyses for each O-ring material:

\subsection{EPDM}

This material was susceptible to oxidation reactions under all the employed testing conditions, leading to the incorporation of oxidation derivatives containing carboxylate $\left(-\mathrm{COO}^{-}\right)$and alkene $(\mathrm{C}=\mathrm{C})$ groups into the molecular structures. The magnitude of such susceptibility depended on the environment; in particular, the impact of the thermal shock was considerably higher than that of the other environments, causing the rupture of the backbone hydrocarbon chains and undermining the integrity of O-ring. The extent of oxidation estimated from the total mass loss revealed that the aerated steam-cooling environment was the second harshest condition for the material survival. In contrast, the drilling fluid afforded a special environment that alleviated oxidation. Such an anti-oxidation effect of the drilling fluid may be due to the formation of reaction products between the chemical ingredients present in the drilling fluid and EPDM. Also, the thermal stability was correlated with the oxidation rate of exposed O-ring; namely, the increased oxidation rate resulted in a declined thermal stability. The ranking of these environments from lowest susceptibility to oxidation was in the following order: drilling fluid > geo-brine fluid > non-aerated steam-cooling > aerated steam-cooling > thermal shock. Furthermore, EPDM conferred great integrity on the O-ring held in drilling fluid and geo-brine fluid; in fact, no micro-defects were detected, nor did it allow the ionic species in these fluids to permeate through O-ring. However, there was the deposition of silicate-related scale on the Oring's surface. In addition, only slight reductions in modulus were noted for EPDM in Nos. 1, 2, and 3 environments, whereas an increase was observed in No. 4.

\subsection{Type I FKM}

For all environments, the poly[vinylidene fluoride (VDF)] in the copolymer structure of FKM was preferentially oxidized over poly[hexafluoropropylene (HFP)], reflecting the incorporation of oxidation derivatives, along with the $\mathrm{C}=\mathrm{O}, \mathrm{C}=\mathrm{C}, \mathrm{COO}^{-}$, and $\mathrm{COOH}$ groups, into poly-VDF. Although the integrity of O-rings exposed in the non-aerated and aerated steam-cooling environments remained intact, their oxidation rates were higher than in drilling fluid or geobrine fluid. However, the integrity of the O-rings exposed to drilling and geo-brine fluids was undermined severely, suggesting that such disintegration was caused by a combination of hydrothermal- and chemical-oxidations. Correspondingly, the oxidation depth, estimated by permeation of $\mathrm{Ca}$ ion through O-ring, was more than $1.5 \mathrm{~mm}$ for both environments. Modulus profile analysis agreed with these findings, showing roughly $1 \mathrm{~mm}$ of hardening of the O-ring edges. While some environments showed a softening in the center (e.g. Nos. 1, 2 and 5) others 
showed middle hardening (Nos. 3 and 4). Unlike the EPDM O-ring, this O-ring displayed a better performance in a thermal shock environment, indicating a lower oxidation rate compared with the other testing environments.

\subsection{Type II FKM}

Compared with polymeric structure of type I FKM, one important character of type II FKM terpolymer, consisting of VDF, HFP, and tetrafluoroethylene (TFE), was a low content of VDF, which was most susceptible to oxidation. Thus, the resistance to oxidation of O-rings in these environments was greater than that of type I, as reflected in the maintenance of the thermal stability of the exposed O-rings. However, one critical concern was the development of a dense oxidation layer as a rim-like structure below the top surface of the O-rings. Its formation undesirably created micro-defects in critical interfacial boundary regions between the rim and core. In drilling fluid, the thickness of the rim layer developed was nearly $0.4 \mathrm{~mm}$, causing the disintegration and failure of the O-ring. Further, this layer absorbed $\mathrm{Ca}$ ions present in drilling fluid. Likewise, the rim structure was observed from the O-ring exposed in geo-brine fluid, but its thickness was only $0.2 \mathrm{~mm}$, demonstrating that the impact of geo-brine fluid in creating dense oxidation was milder than that of drilling fluid. Also, this O-ring displayed a good resistance to thermal shock. The ranking of these environments from least to most susceptibility to oxidation was in the following order: thermal shock > non-aerated steam-cooling > aerated steam-cooling $>$ geo-brine fluid > drilling fluid. Modulus profiling revealed that the type II FKM material showed higher moduli at the edges with interior softening. The addition of the higher $\mathrm{Ca}$ concentration into the edges of the O-ring observed with EDX may explain the edge hardening effect. The aerated (No. 2) and thermal shock and thermal cycle tests had similar "W" profiles which were not observed in any other system.

\subsection{FEPM}

As described above, the presence of hydrocarbon groups in the main backbone chains of polymeric structures inevitably resulted in their preferential oxidation over the fluorocarbon groups in all of the environments. Accordingly, the poly(propylene) in the FEKM copolymer with poly-TFE was preferentially oxidized. Although the same oxidation derivatives were incorporated in this copolymer structure as that of EPDM, and type I- and II-FKM, the extent of oxidation in the copolymer was markedly lower than those other polymers for all environments, except for thermal shock. The enhanced oxidation resistance to these environments was verified by: no observed micro-defects, no permeation of $\mathrm{Ca}$ ions during exposure to drilling and geobrine fluids, no-deposition of silicate scales, and sustainment of thermal stability. However, like EPDM, this copolymer was vulnerable to the thermal shock environment, owing to thermal- and hydrothermal-combined oxidations which undermined the integrity of O-ring. Consequently, our ranking of these environments from least susceptibility to oxidation was in the following order: Geo-brine fluid > non-aerated steam-cooling > aerated steam-cooling > drilling fluid >> thermal shock. Modulus profile analysis found that there was little to no change in modulus after 
exposure to Nos. 1-4 conditions. However, edge hardening was observed with the thermal shock test (No. 5).

\subsection{FFKM}

The FFKM copolymer, poly-TFE and poly(perfluoromethylvinylether), exhibited the best performance in impeding oxidation of the O-ring from all the environments employed due to the absence of a hydrocarbon-based backbone chain. One consideration of this copolymer was the deposition of silica-related scale on the O-ring surface during exposure in geo-brine fluid. Conceivably, in geo-brine fluid a surface may undergo physicochemical alterations that promote such scale deposition.

\subsection{FSR}

Among these "as-received" O-rings, the FSR material had the highest maximum degradation temperature of $522^{\circ} \mathrm{C}$. Despite such great thermal stability, the FSR copolymer, composed of poly(siloxane) and poly(trifluoropropylpolysiloxane), was very vulnerable to all the hydrothermal environments utilized in this study, which resulted in severe disintegration. In the thermal shock (No. 5) environment, decomposition was observed shortly after immersion in water during the first quenching event. Thus, FSR-based elastomeric materials are not very applicable for use in geothermal fields.

\subsection{Overall Summary}

Based upon the integrated information from this study, the ranking of stability of various elastomeric polymer O-rings for each different environment was determined (Table 9). Also, to assess the relation between cost-effectiveness and performance of these O-rings, the raw material costs were compared to that of the most economical, EPDM (Table 9). As is evident, the relative strengths and weaknesses of these O-rings, as well as their chemical compatibility, depended on the environments. For instance, the inexpensive EPDM had acceptable performance for use as a hydrothermal and chemical-compatible O-ring end product, but was deemed unsuitable for a heat-quenching environment. On the other hand, the FEPM O-ring, which costs nearly six times EPDM, displayed similar strengths and weaknesses to that of EPDM in terms of environmental stability. Interestingly, FEPM performed better than EPDM during aerated steam-cooling, alleviating the deposition of silicate scales, but not in drilling fluid. FEPM also maintained modulus better than EPDM after exposure to environment Nos. 1-4. There was no doubt that among these tested O-rings, the FFKM O-ring performed far better than the others, however, its cost was approximately 14 times higher than EPDM.

One important consideration is the economic impact of elastomeric materials on the end-used products. Therefore, if a cost-effective material possesses a long life-cycle in $300^{\circ} \mathrm{C}$ hydrothermal and other high temperature environments containing oxidation-promoting chemical ingredients, the products made with this material will substantially reduce its total downtime 
costs, including: strip-down, repair time, material replacement, and installation in the field, consequently reducing the expense of operating and maintaining wells and power plants. Under these considerations, the ideal cost-effective and high-performance elastomeric materials of the future will be required to possess properties bridging the gap between the expensive FFKM, and FEPM or EPDM.

Table 9. Ranking of stability, with one being the best, of different polymerO-rings for each environment and comparison of their raw material costs based upon EPDM as the benchmark.

\begin{tabular}{lccccc}
\hline $\begin{array}{l}\text { Elastomeric } \\
\text { polymer (raw } \\
\text { material cost } \\
\text { factor based } \\
\text { on EPDM) }\end{array}$ & $\begin{array}{l}\text { Non-aerated } \\
\text { steam- } \\
\text { cooling }\end{array}$ & $\begin{array}{l}\text { Aerated } \\
\text { steam- } \\
\text { cooling }\end{array}$ & $\begin{array}{l}\text { Drilling } \\
\text { fluid }\end{array}$ & $\begin{array}{l}\mathbf{C O}_{2} \text {-rich geo- } \\
\text { brine fluid }\end{array}$ & $\begin{array}{l}\text { Heat-quenching } \\
\text { thermal shock }\end{array}$ \\
\hline EPDM (1) & 2 & 3 & 2 & 3 & 4 \\
$\begin{array}{l}\text { Type I FKM } \\
(1 \times 2.5)\end{array}$ & 4 & 5 & 5 & 5 & 3 \\
$\begin{array}{l}\text { Type II FKM } \\
(1 x 2.6)\end{array}$ & 3 & 4 & 4 & 4 & 2 \\
FEPM $(1 \times 5.6)$ & 2 & 2 & 3 & 2 & 4 \\
\hline $\begin{array}{l}\text { FFKM } \\
(1 x 13.8)\end{array}$ & 1 & 1 & 1 & 1 & 1 \\
FSR $(1 x 6.3)$ & 5 & 6 & 6 & 6 & 5 \\
\hline
\end{tabular}




\section{References}

1. T. Sugama, Surface analyses of fluoroelastomer bearings exposed to geothermal environments, Material Letters 50 (2001) 66-72.

2. T. Sugama and B. Sullivan, Hydrothermal oxidation of fluoroelastomer bearings after a yearlong exposure to geothermal environments, Journal of Materials Science Letters 20 (2001) 17371740.

3. R. Fuller, Advanced polymer architecture sealing solutions for oil and gas applications, Sealing Technology, September 2006, 6-11.

4. W. Stahl, Choosing the right elastomers for the right application, World Pumps, October 2006, 30-33.

5. FFKM seals are resistant to chemicals and high temperatures, Sealing Technology, February 2014, 2-3, Parker Hannifin Corp.

6. P. Sui and S. Anderle, Elastomers in drilling fields, Wear 271 (2011) 2466-2470.

7. J. Walters, S. Thorhallsson, and E. Wood, International partnership for geothermal technology zonal isolation for geothermal wells, Working Group Documents, August, 2012.

8. K.T. Gillen, R.L. Clough, C.A. Quintana, Modulus Profiling of Polymers, Polymer Degradation and Stability 17 (1987) 31-47.

9. Q. Zhao, X. Li, and J. Gao, Surface degradation of ethylene-propylene-diene monomer (EPDM) containing 5-ethylidene-2-norbornene (ENB) as diene in artificial weathering environment, Polymer Degradation and Stability 93 (2008) 692-699.

10. G. Tang, Y. Hu, and L. Song, Study on the flammability and thermal degradation of a novel intumescent flame retardant EPDM composite, Procedia Engineering 62 (2013) 371-376.

11. Y. Bao, J. Ma, and Li Na, Synthesis and swelling behaviors of sodium carboxymethyl cellulose-g-poly(AA-co-AM-co-AMPS)/MMT superabsorbent hydrogel, Carbohydrate Polymers 84 (2011) 76-82.

12. S. Mishar, GU. Rani, and G. Sen, Microwave initiated synthesis and application of polyacrylic acid grafted carboxymethyl cellulose, Carbohydrate Polymers 87 (2012) 2255-2262.

13. T. Sugama, T. Pyatina, and A. Muraca, Role of PVA flakes in promoting self-degradation of sodium metasilicate-activated cement under a hydrothermal environment at $\geq 150^{\circ} \mathrm{C}$, J. Technology Innovations in Renewable Energy 2 (2013) 352-365. 
14. T. Nakamura, O. Chaikumpollert, Y. Yamamoto, Y. Ohtake, and S. Kawahara, Degradation of EPDM seal used for water supplying system, Polymer Degradation and Stability 96 (2011) 1236-1241.

15. A. Demirbas, A. Sari, and O. Isildak, Adsorption thermodynamics of stearic acid onto bentonite, Journal of Hazardous Materials B135 (2006) 226-231.

16. L. Zhirong, M.A. Uddin, and S. Zhanxue, FT-IR and XRD analysis of natural Na-bentonite and $\mathrm{Cu}$ (II)-loaded Na-bentonite, Spectrochmica Acta Part A 79 (2011) 1013-1016.

17. S.J. Lim, K.K. Gleason, D.J. Edell, and E.F. Gleason, Flexible fluorocarbon wire coatings by pulsed plasma enhanced chemical vapor deposition, Journal Vacuum Science Technology A 15 (1997) 1814-1818.

18. S. Mitra, A. Ghanbari-Siahkalia, P. Kingshotta, K. Almdala, H.K. Rehmeierb, and A. G. Christensenc, Chemical degradation of fluoroelastomer in an alkaline environment, Polymer Degradation and Stability 83 (2004) 195-206.

19. C. Biloiu, I. A. Biloiu, Y. Sakai, Y. Suda, and A. Ohta, Amorphous fluorocarbon polymer (aC:F) films obtained by plasma enhanced chemical vapor deposition from perfluoro-octane $\left(\mathrm{C}_{8} \mathrm{~F}_{18}\right)$ vapor I: Deposition, morphology, structure and chemical properties, Journal Vacuum Science Technology A 22 (2004) 13-19.

20. A.N. Theodore, M. Zinbo, and R.O. Carter III, Characterization of fluoroelastomer networks: II. SEC, FTIR, and ODR analysis, Journal of Applied Polymer Science 61 (1996) 2065-2073.

21. I. Banik, A. K. Bhowmick, S.V. Raghavan, A.B. Majali, and V.K. Tikku, Thermal degradation studies of electron beam cured terpolymeric fluorocarbon rubber, Polymer Degradation and Stability 63 (1999) 413-421.

22. G.J. Knight and W.W. Wright, The thermal degradation of some fluorine-containing elastomers, Thermochimica Acta 60 (1983) 187-194.

23. G.J. Ross, J.F. Watts, M.P. Hill, and P. Morrissey, Surface modification of poly(vinylidene fluoride) by alkaline treatment 1 . The degradation mechanism, Polymer 41 (2000) 1685-1696.

24. M. Celina and G.A. George, A heterogeneous model for the thermal oxidation of solid polypropylene from chemiluminescence analysis, Polymer Degradation and Stability 40 (1993) 323-335.

25. S. Morlat, B. Mailhot, D. Gonzalez, and J.L. Gardette, Photo-oxidation of polypropylene/montomorillonite nanocomposites. 1. Influence of naoclay and compatibilizing agent, Chemistry of Materials 16 (2004) 377-383. 
26. P. Concepcion, P. Botella, and J.M. Lopez Nieto, Catalytic and FT-IR study on the reaction pathway for oxidation of propane and propylene on V-or Mo-V-based catalysts, Applied Catalysis: A General 278 (2004) 45-56.

27. M. Ouyang, R.J. Muisener, A. Boulares, and J.T. Koberstein, UV-ozone induced growth of a $\mathrm{SiO}_{2}$ surface layer on a cross-linked polysiloxane film: characterization and gas separation properties, Journal of Membrane Science 177 (2000) 177-187.

28. M. Zou, S. Wand, Z. Zhang, and X. Ge, Preparation and characterization of polysiloxanepoly(butylacrylate-styrene) composite lattices and their film properties, European Polymer Journal 41 (2005) 2602-2613.

29. L. Su, S. Pei, L.L. Hong Li, Y. Zhang, W. Yu, and C. Zhou, Preparation of polysiloxane/perfluorosulfonic acid nanocomposite membranes in supercritical carbon dioxide system for direct methanol fuel cell, International Journal of Hydrogen Energy 34 (2009) 68926901.

30. D. Chen, J. Nie, S. Yi, W. Wu, Y. Zhong, J. Liao, and C. Huang, Thermal behavior and mechanical properties of novel RTV silicon rubbers using divinyl-hexa(trimethoxysily)ethyl]POSS as cross-linker, Polymer Degradation and Stability 95 (2010) 618-626.

31. S. Radi, S. Tighadouini, Y. Toubi, and M. Bacquet, Polysiloxane surface modified with bipyrazolic tripodal receptor for quantitative lead adsorption, Journal of Hazardous Materials 185 (2011) 494-501.

32. A. Durdureanu-Angheluta, M. E. Ignat, S.S. Maier, L. Pricop, A. Coroaba, A. Fifere, M. Pinteala, and A. Chiriac, Lipolytic biocatalyst based on recyclable magnetite-polysiloxane nanoparticles, Applied Surface Science 292 (2014) 898-905.

33. B. Pilch-Pitera, Polyurethane powder coatings containing polysiloxane, Progress in Organic Coatings 77 (2014) 1653-1662.

34. A. Ghanbari-Siahkali, S. Mitra, P. Kingshott, K. Almdal, C. Bloch, and H.K. Rehmeier, Investigation of the hydrothermal stability of cross-linked liquid silicone rubber (LSR), Polymer Degradation and Stability 90 (2005) 471-480.

35. T. Cui, Y.J. Chal, X.M. Chen, and J.W. Van Zee, Effect of water on life prediction of liquid silicone rubber seals in polymer electrolyte membrane fuel cell, Journal of Power Sources 196 (2011) 9536-9543.

36. J. Feng, Q. Zhang, Z. Tu, W. Tu, Z. Wan, M. Pan, and H. Zhang, Degradation of silicone rubbers with different hardness in various aqueous solutions, Polymer Degradation and Stability 109 (2014) 122-128. 